Chemical Technology

Division

Chemical Technology

Duvision

Chemical Technology

Division

Chemical Technology

Division

Chemical Technology

Division

Chemical Technology

Division

Chemical Technology

Division

Chemical Technology

ovision

Chemical Technology

Division

Chemical Technology

Division

Chemical Technology

Dyvision

Chemical Technology

Division

Chemical Technology

onvislon

Chemical Technology

OMision

Chemical Technology

Division

Chemical Technology

Division

RECEIVED

SEP 231997

OSTI

\section{Laboratory Testing of Glasses for Lockheed Idaho Technology Company: Final Report}

\author{
by A. J. G. Ellison, E. C. Buck,
} N. L. Dietz, W. L. Ebert, J. S. Luo, S. F. Wolf, and J. K. Bates

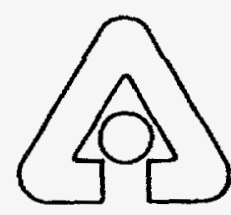

Argonne National Laboratory, Argonne, Illinois 60439

operated by The University of Chicago

for the United States Department of Energy under Contract W-31-109-Eng-38

Chemical Technology

Duvision

Chemical Technology

Division

Chemical Technology

Division

Chemical Technology

Division 
Argonne National Laboratory, with facilities in the states of Illinois and Idaho, is owned by the United States government, and operated by The University of Chicago under the provisions of a contract with the Department of Energy.

\section{DISCLAIMER}

This report was prepared as an account of work sponsored by an agency of the Lnited States Government. Neither the United States Government nor any agency thereof, nor any of their employees, makes any warranty, express or implied, or assumes any legal liability or responsibility for the accuracy, completeness, or usefulness of any information, apparatus, product, or process disclosed, or represents that its use would not irffringe privately owned rights. Reference herein to any specific commercial product, process, or service by trade name, trademark, manufacturer, or otherwise, does not necessarily constitute or imply its endorsement, recommendation, or favoring by the United States Government or any agency thereof. The views and opinions of authors expressed herein do not necessarily state or reflect those of the United States Government or any agency thereof.

Reproduced from the best available copy.

A vailable to DOE and DOE contractors from the

Office of Scientific and Technical Information

P.O. Box 62

Oak Ridge, TN 37831

Prices available from (423) 576-8401

Available to the public from the

National Technical Information Service

U.S. Department of Commerce

5285 Port Royal Road

Springfield, VA 22161 
Distribution Category:

Nuclear Waste Management

(UC-510)

ANL-97/12

\author{
ARGONNE NATIONAL LABORATORY \\ 9700 South Cass Avenue \\ Argonne, Illinois 60439
}

\title{
LABORATORY TESTING OF GLASSES FOR \\ LOCKHEED IDAHO TECHNOLOGY COMPANY: \\ FINAL REPORT
}

by

\author{
A. J. G. Ellison, E. C. Buck, N. L. Dietz, W. L. Ebert, \\ J. S. Luo, S. F. Wolf, and J. K. Bates
}

Chemical Technology Division

June 1997 


\section{DISCLAMBER}

Portions of this document may be illegible in electronic image products. Images are produced from the best available original document. 


\section{TABLE OF CONTENTS}

Page

ABSTRACT

I INTRODUCTION ..........................................................................................

II. EXPERIMENTAL APPROACH ………………............................................ 5

III. RESULTS: FORMULA 127 GLASS ...............................................................

A. Test Matrix................................................................................................... 7

B. Sample Characteristics...................................................................... 7

C. Test Results.......................................................................................... 9

1. Materials Characterization Center Type-1 Test Results ........................ 9

2. Product Consistency Test Results ........................................................... 10

3. Vapor Hydration Test Results ............................................................. 17

IV. RESULTS: FORMULA 532 GLASS ............................................................. 19

A. Test Matrix........................................................................................ 19

B. Sample Characteristics................................................................................... 19

C. Test Results ............................................................................................ 20

1. Product Consistency Test Results ....................................................... 20

2. Vapor Hydration Test Results............................................................. 22

V. RESULTS: 630 SERIES GLASSES …...................................................... 24

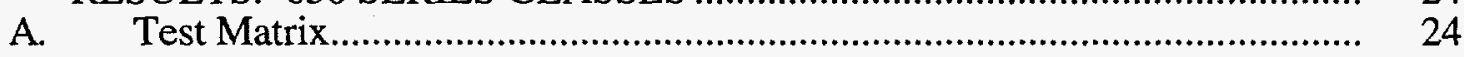

B. Sample Characteristics.................................................................... 24

C. Test Results ................................................................................ 30

1. Product Consistency Test Results ...................................................... $\quad 30$

2. Vapor Hydration Test Results........................................................... 47

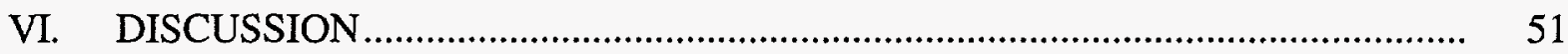

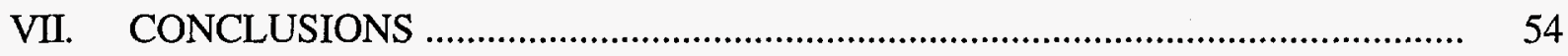

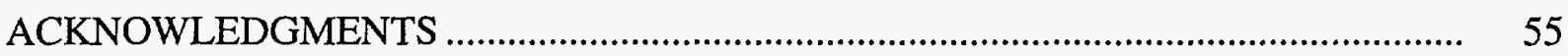

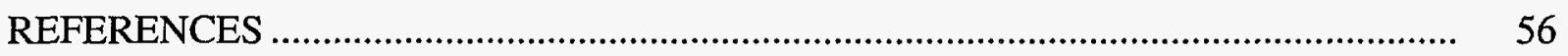




\section{LIST OF FIGURES}

No.

Title

1. Schematic Representation of the Reaction Path of Glass Corrosion

2. Electron Backscatter Image of a Polished Monolith of Formula 127 Glass.

White needles and patches are fluorite quench crystals

3. Normalized Mass Losses in MCC-1 Tests of Formula 127 Glass:

(•) $\mathrm{Al},(\square) \mathrm{B},(\Delta) \mathrm{Ca},(\mathbf{\square}) \mathrm{Li},(\mathrm{O}) \mathrm{Na}$, and (ム) $\mathrm{Si}$

4. Normalized Mass Losses in PCT-Bs of Formula 127 Glass at $\mathrm{S} / \mathrm{V}=2000 \mathrm{~m}^{-1}$ :

(๑) $\mathrm{Al},(\square) \mathrm{B},(\Delta) \mathrm{Ca},(\mathbf{\square}) \mathrm{Li},(\mathrm{O}) \mathrm{Na}$, and $(\mathbf{\Delta}) \mathrm{Si}$

5. Normalized Mass Losses in PCT-Bs of Formula 127 Glass at $\mathrm{S} / \mathrm{V}=20,000 \mathrm{~m}^{-1}$ :

(๑) $\mathrm{Al},(\square) \mathrm{B},(\Delta) \mathrm{Ca},(\mathbf{\square}) \mathrm{Li},(\mathrm{O}) \mathrm{Na}$, and $(\mathbf{\Delta}) \mathrm{Si}$

6. Transmission Electron Micrograph of a Clay Layer Formed where Formula 127 Glass was in Contact with Iron, from the PCT-B W127-11

7. A SEM Image of a Glass Particle Recovered from PCT-B of Formula 127 Glass (test W127-6: $70 \mathrm{~d}, \mathrm{~S} / \mathrm{V}=2000 \mathrm{~m}^{-1}$ ), Showing Dissolution around Fluorite Grain.

8. Transmission Electron Micrograph of a Near-Surface Fluorite Grain Recovered from PCT-B with Formula 127 Glass (test W127-11: $98 \mathrm{~d}$, $\left.\mathrm{S} / \mathrm{V}=20,000 \mathrm{~m}^{-1}\right)$

9. Scanning Electron Micrographs of Alteration Phases Formed as a Result of Reaction of Formula 127 Glass with Water Vapor at $200^{\circ} \mathrm{C}$ : (a) Ca-Si-F-0, with Pillars of $\mathrm{Ca}-\mathrm{Zr}-\mathrm{O}$; (b) $\mathrm{CaCO}_{3}$; and (c) Ca-Si-F-O-Phase on Blades of Ca-Zr-Si-O.

10. Transmission Electron Micrograph of (a) Ti-Cu-O Phase and (b) $\mathrm{TiO}_{2}$, Present in Unreacted Formula 532 Glass.

11. Normalized Mass Losses in PCT-Bs of Formula 532 Glass at $\mathrm{S} / \mathrm{V}=2000 \mathrm{~m}^{-1}$ :

(๑) $\mathrm{Al},(\square) \mathrm{B},(\Delta) \mathrm{Ca},(\mathbf{\square}) \mathrm{Li},(\mathrm{O}) \mathrm{Na}$, and $(\mathbf{\Delta}) \mathrm{Si}$

12. Normalized Mass Losses in PCT-Bs of Formula 532 Glass at $\mathrm{S} / \mathrm{N}=20,000 \mathrm{~m}^{-1}$ :

(๑) $\mathrm{Al},(\square) \mathrm{B},(\Delta) \mathrm{Ca},(\mathbf{\square}) \mathrm{Li},(\mathrm{O}) \mathrm{Na}$, and $(\mathbf{\Delta}) \mathrm{Si}$

13. Electron Photomicrographs of Alteration Phases Formed during VHT of Formula 532 Glass.

14. Comparison of Normalized Mass Losses for 630 Series and Formula 127

Glasses in PCT-Bs at $\mathrm{S} / \mathrm{V}=2000 \mathrm{~m}^{-1}$ : (a) Aluminum, (b) Boron,

(c) Lithium, (d) Sodium, and (e) Silicon 


\section{LIST OF FIGURES (contd)}

No.

Title

Page

15. Comparison of Normalized Mass Losses for 630 Series and Formula 127

Glasses in PCT-Bs at $\mathrm{S} / \mathrm{V}=20,000 \mathrm{~m}^{-1}$ : (a) Aluminum, (b) Boron,

(c) Lithium, (d) Sodium, and (e) Silicon

16. Comparison of Normalized Mass Losses for Original and Revised

630 Series Glasses in PCT-Bs at $S / V=20,000 \mathrm{~m}^{-1}$ : (a) Aluminum,

(b) Boron, (c) Lithium, (d) Sodium, and (e) Silicon

17. Optical Photographs of the Surfaces of Samples of (a) 630.6L, (b) 630.6LM, (c) $631.6 \mathrm{~L}$, and (d) $631.6 \mathrm{LM}$ Recovered from VHTs at $200^{\circ} \mathrm{C}$

18. Scanning Electron Photomicrographs of a Cross-Section through a Sample of 631.6L Glass Recovered from a 56-d VHT.

19. High Magnification Image of Surface Layer.

49

20. High Magnification Image of Interface Between Hydrated Layer and Glass

50 


\section{LIST OF TABLES}

No.

Title

Page

1. Test Matrix for Formula 127 Glass ....................................................................

2. Composition of Formula 127 Glass (from [STAPLES-1983])................................ 8

3. Final $\mathrm{pH}$ and Solution Compositions (mg/L) Obtained from MCC-1 Tests Performed on Formula 127 Glass

4. Normalized Mass Losses $\left(\mathrm{g} / \mathrm{m}^{2}\right)$ Obtained from MCC-1 Tests Performed on Formula 127 Glass

5. Final $\mathrm{pH}$ and Solution Concentrations (mg/L) from PCT-Bs Performed with Formula 127 Glass.

6. Normalized Mass Losses $\left(\mathrm{g} / \mathrm{m}^{2}\right)$ from PCT-Bs Performed with Formula 127 Glass

7. Test Matrix for Formula 532 Glass

8. As-Batched Composition of Formula 532 Glass

9. Final $\mathrm{pH}$ and Solution Compositions (mg/L) Obtained from PCT-Bs Performed with Formula 532 Glass

10. Normalized Mass Losses $\left(\mathrm{g} / \mathrm{m}^{2}\right)$ Obtained from PCT-Bs Performed with Formula 532 Glasses

11. Matrix of PCT-Bs Used to Evaluate the Original 630 Series Glasses ..................... 25

12. Matrix of VHTs Used to Evaluate the Original 630 Series Glasses........................ 26

13. Test Matrix for Revised 630 Series Glasses …….................................................... 26

14. As-Batched and Measured Compositions (Mass \%) of the Original 630 Series Glasses

15. As-Batched and Measured Compositions (Mass \%) of the Revised 630 Series Glasses

16. Final $\mathrm{pH}$ and Solution Compositions (mg/L) from $2000 \mathrm{~m}^{-1}$ PCT-Bs Performed with the Original 630 Series Glasses

17. Normalized Mass Losses $\left(\mathrm{g} / \mathrm{m}^{2}\right)$ from $2000 \mathrm{~m}^{-1}$ PCT-Bs Performed with the Original 630 Series Glasses

18. Final $\mathrm{pH}$ and Solution Compositions ( $\mathrm{mg} / \mathrm{L}$ ) Obtained from $20,000 \mathrm{~m}^{-1}$ PCT-Bs Performed with the Original 630 Series Glasses

19. Normalized Mass Losses $\left(\mathrm{g} / \mathrm{m}^{2}\right)$ Obtained from $20,000 \mathrm{~m}^{-1}$ PCT-Bs Performed with the Original 630 Series Glasses 


\section{LIST OF TABLES (contd)}

No.

Title

Page

20. Final $\mathrm{pH}$ and Solution Compositions (mg/L) Obtained from PCT-Bs

Performed with the Revised 630 Series Glasses.

21. Normalized Mass Losses $\left(\mathrm{g} / \mathrm{m}^{2}\right)$ Obtained from PCT-Bs Performed with the Revised 630 Series Glasses

22. Comparison of Tests Conducted for 28 days at $20,000 \mathrm{~m}^{-1}$ in Teflon and Type 304L Stainless Steel Vessels

23. Results of 7-Day PCTs Conducted at $90^{\circ} \mathrm{C}$ in Deionized Water with Several Reference Glasses

24. Calculated Distribution of $\mathrm{Na}$ and $\mathrm{Li}$ between Non-Bridging Oxygen (NBO) and Charge-Balance (CB) Sites, in \% of Total Na or Li in Glass 


\title{
LABORATORY TESTING OF GLASSES FOR LOCKHEED IDAHO TECHNOLOGY COMPANY: FINAL REPORT
}

\author{
by
}

\author{
A. J. G. Ellison, E. C. Buck, N. L. Dietz, W. L. Ebert, \\ J. S. Luo, S. F. Wolf, and J. K. Bates
}

\begin{abstract}
Tests have been conducted at Argonne National Laboratory (ANL) in support of the efforts of Lockheed Idaho Technology Company (LITCO) to vitrify high-level waste calcines. Tests were conducted with three classes of LITCO glass formulations: Formula 127 (fluorine-bearing), Formula 532 (fluorine-free), and 630 series (both single- and mixed-alkali) glasses. The test matrices included, as appropriate, the Product Consistency Test Method B (PCTB), the Materials Characterization Center Test 1 (MCC-1), and the Argonne vapor hydration test (VHT). Test durations ranged from 7 to $183 \mathrm{~d}$. In 7-d PCT-Bs, normalized mass losses of major glass-forming elements for the LITCO glasses are similar to, or lower than, normalized mass losses obtained for other domestic candidate waste glasses. Formula 532 glasses form zeolite alteration phases relatively early in their reaction with water. The formation of those phases increased the dissolution rate. In contrast, the Formula 127 glass is highly durable and forms alteration phases only after prolonged exposure to water in tests with very high surface area to volume ratios; these alteration phases have a relatively small effect on the rate of glass corrosion. No alteration phases formed within the maximum test duration of $183 \mathrm{~d}$ in PCT-Bs with the 630 series glasses. The corrosion behavior of the mixed-alkali 630 series glasses is similar to that of 630 series glasses containing sodium alone. In VHTs, both single- and mixed-alkali glasses form zeolite phases that increase the rate of glass reaction. The original 630 series glasses and those based on a revised surrogate calcine formulation react at the same rate in PCT-Bs and form the same major alteration phases in VHTs.
\end{abstract}




\section{INTRODUCTION}

The purpose of this project was to measure the intermediate and long-term durability of vitrified waste forms developed by Lockheed Idaho Technology Co. (LITCO) for the immobilization of calcined radioactive wastes at Idaho National Engineering Laboratory. Objectives of this work include the following:

- Provide LITCO with information that can be used to determine the source term of radioactive components for performance assessment calculations;

- Assist LITCO in optimizing waste form compositions;

- Delineate the corrosion mechanisms of vitreous waste forms;

- Determine the approach to solution saturation as a glass reacts with water;

- Determine the identities and order of appearance of crystalline alteration phases formed during glass corrosion;

- Determine whether a glass made with a mixture of lithium and sodium is less durable than a glass made with sodium alone.

Testing was initiated in fiscal year (FY) 1994 with two ILITCO glasses, Formula 127 and Formula 532 [ELLISON-1995]. During FY 1995, testing continued on these glasses. Work was also performed to characterize the corrosion behavior of four other glasses: $630.6 \mathrm{~L}, 630.6 \mathrm{LM}$, $631.6 \mathrm{~L}$, and 631.6LM. The notations " 630 " and "631" refer to different calcine compositions. The "L" and "LM" refer to glasses containing sodium or a mix of sodium and lithium, respectively. On the basis of consultations with Argonne, LITCO prepared new versions of these "630 series" glasses that contained the minor calcine components $\mathrm{Mg}, \mathrm{Sn}$, and $\mathrm{Pb}$. These elements are potentially important in alteration phase formation. The revised glass formulations are designated 630R.6L, 630R.6LM, 631R.6L, and 631R.6LM. All corrosion tests of LITCO glass compositions were completed during FY 1995. This is a final report summarizing test results obtained for all glasses analyzed in the Argonne testing program.

The objective of waste immobilization is to limit the release of radioactive elements to the environment. In a repository, the most important avenue for release of radionuclides from a waste glass into the environment is reaction of the glass with groundwater. Such reactions physically and chemically alter the surface of the glass and release glass components into the aqueous phase. Over many years of corrosion tests with waste glasses, a picture has emerged of the corrosion path typically followed by borosilicate glasses. Glasses are unstable with respect to an assemblage of alteration phases and are thermodynamically driven to transform into those phases. The stability of glasses is due to the kinetic inhibition of that transformation. Contact with water provides an energetically favorable pathway for glass to transform to alteration phases by a dissolution/precipitation process. The kinetics of the conversion of glass to alteration phases is affected by the dissolution rate of the glass and the precipitation of the alteration phases. The dissolution rate of a glass is known to depend on the glass composition, the temperature, the solution $\mathrm{pH}$, and the activity of orthosilicic acid in the solution, and will change as the glass dissolves in solution and as alteration phases form. The transformation of glass to alteration phases is conveniently described in a reaction progress plot, which is shown in Fig. 1. The Stage I rate of reaction occurs when corrosion products in solution are very dilute and don't affect the rate. As the reaction proceeds, the buildup of corrosion products in solution reduces the chemical potential gradient between silicon in the waste form and silicon in the water (as silicic acid), and the rate of reaction decreases. The near-zero rate obtained when the solution 


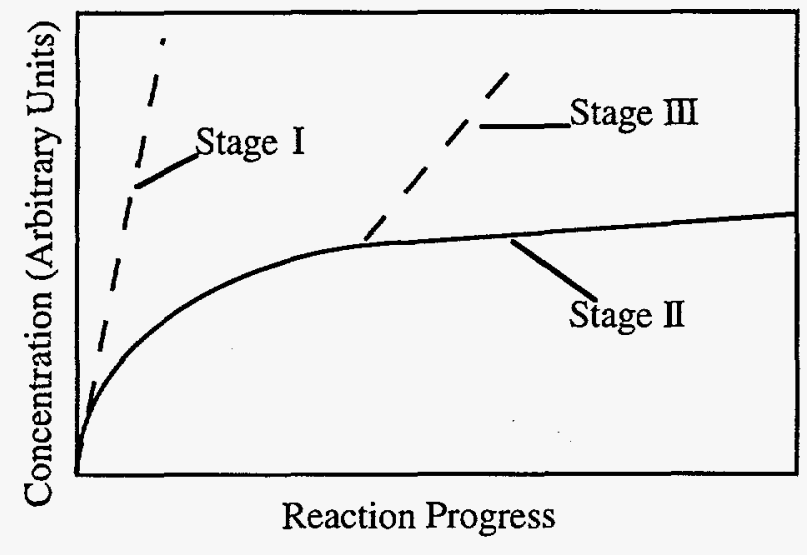

Fig. 1.

Schematic Representation of the Reaction Path of Glass Corrosion

becomes saturated is referred to as the Stage II rate. Because glass is metastable, the solution does not become saturated in a thermodynamic sense, but in a kinetic sense wherein the rate of the reaction releasing orthosilicic acid from the glass becomes equal to the rate of a reverse reaction in which orthosilicic acid recondenses on the surface of the glass. The equilibrium constant is usually modeled with that of a pure silica polymorph, such as chalcedony, for calculations [see, e.g., STRACHAN-1994; BOURCIER-1994; McGRAIL-1995]. Under some conditions, the concentrations of dissolved glass components become high enough that precipitation of alteration phases occurs. If the rate at which glass components are removed from solution by the precipitation of alteration phases exceeds the rate at which they are released from the glass, then the chemical affinity for glass corrosion will be controlled by the chemical potential gradient between the glass and the alteration phase. This is referred to as Stage III. To conduct a performance assessment and model glass behavior, it is necessary to know the dissolution rates in all stages of the reaction of waste glass with water: when the rate is controlled by the intrinsic stability of the glass (Stage I), by the saturation chemistry (Stage II), and by the precipitation of alteration phases (Stage III).

These rates are measured in different laboratory tests in which the silicic acid concentration remains very low (Stage I), approaches saturation (Stage II), or becomes controlled by alteration phases (Stage III). In the present tests, different silicic acid concentrations are obtained by varying the ratio of sample surface area to solution volume $(S / V)$ at which a test is performed. When $S / V$ is low $\left(\right.$ e.g., $10 \mathrm{~m}^{-1}$ ), dissolved glass components remain at low concentrations in solution for extended periods of time. Thus, low $S / V$ tests are used to determine the Stage I rate of waste glass reaction with water. At higher S/V, dissolved glass components quickly approach saturation levels for particular corrosion products; therefore, Stage II is probed by performing high S/V corrosion tests. Over the long term at high S/V, the solution becomes saturated with respect to corrosion products, which in turn causes the precipitation of alteration phases. The rate of glass reaction after alteration phases form is the Stage III rate of corrosion. The rate of glass reaction with water can be accelerated by combining high $\mathrm{S} / \mathrm{V}$ with elevated temperature. Such tests provide information about the composition of the solution at saturation or, when no solution is recovered, the identities and order of appearance of crystalline alteration phases. The VHT is used to provide a qualitative measure of the tendency of a glass to reach Stage II reaction, it does not provide a rate of reaction.

The test protocols adopted for testing LITCO glasses were designed to provide information about all three stages in waste form corrosion. The Materials Characterization Center Test 1 (MCC-1) was performed on Formula 127 at low S/V for 3, 7, and $16 \mathrm{~d}$ to 
determine the relative reactivities of the glasses and the fluorite inclusions. Product Consistency Tests at much higher $S / V$ were performed on all glass formulations to monitor the approach to the saturation corrosion rate. The Argonne National Laboratory VHT was performed at high temperatures to determine the identities and order of appearance of crystalline alteration phases. 


\section{EXPERIMENTAL APPROACH}

The test methodology involved reacting samples with water at elevated temperatures and different $S / \mathrm{V}$. The tests employed in this effort are the MCC-1 test, PCT-B, and the VHT. In the MCC-1 test, a monolithic sample with a known geometric surface area is polished to 600 grit, then reacted at $90^{\circ} \mathrm{C}$ with a volume of deionized water such that $\mathrm{S} / \mathrm{V}$ is $10 \mathrm{~m}^{-1}$. At low $\mathrm{S} / \mathrm{V}$ and short reaction times, the solution remains dilute, and the reaction between solution and glass is dominated by the intrinsic durability of the glass. The release of components to solution is expressed as the normalized elemental mass loss, $\mathrm{NL}_{\mathrm{i}}$, defined as

$$
N L_{i}=\frac{\text { concentration of } i}{f_{i} \bullet S / V}
$$

where $f_{i}$ is the weight fraction of element $i$ in the glass, and $S / V$ is the ratio of sample surface area to solution volume. The value of $\mathrm{NL}_{\mathrm{i}}$ is an estimate of the mass of glass that has reacted to produce the amount of the cation released to solution. Several MCC-1 tests were performed with Formula 127 glass. It is known that, even for very durable glasses, the solution composition changes enough to affect reaction rates after $28 \mathrm{~d}$ at $90^{\circ} \mathrm{C}$ with $\mathrm{S} / \mathrm{V}=10 \mathrm{~m}^{-1}$. Therefore, shorter runs of 3,7 , and $16 \mathrm{~d}$ at $\mathrm{S} / \mathrm{V}=8.5 \mathrm{~m}^{-1}$ were performed to characterize the corrosion behavior in dilute solutions. Solutions were analyzed with inductively coupled plasma atomic emission spectroscopy (ICP-AES) or inductively coupled plasma mass spectrometry (ICP-MS).

The PCT is a static dissolution test conducted by reacting crushed glass in water at a temperature of $90^{\circ} \mathrm{C}$ or less. Crushed glass is used to attain a high $\mathrm{S} / \mathrm{V}$. At the end of the test, the leachate solution is passed through a $450 \mathrm{~nm}$ filter to remove suspended glass particles. We analyzed the filtered solutions with ICP-AES or ICP-MS. We also examined the reacted solids with a scanning electron microscope (SEM) and other surface analytical techniques.

The PCT procedure specifies the use of a particular glass/water mass ratio. The S/N of a PCT is estimated based on the mass ratio and the specific surface area of the crushed glass used in the test. The specific surface area is estimated based on the sieve fraction and the density of the glass. Most high-level waste glasses have densities near $2.7 \mathrm{~g} / \mathrm{mL}$, so that mass ratios of 1:10 and $1: 1$ yield $S / V$ ratios of about 2000 and $20,000 \mathrm{~m}^{-1}$. While we did not measure the density of the LITCO glasses, we expect they have densities that are higher than $2.7 \mathrm{~g} / \mathrm{mL}$ based on their compositions. Therefore, the actual S/V of the tests with the LITCO glasses are probably less than reported and, consequently, the normalized mass losses are probably higher than reported (since the actual glass surface area in the test is less than estimated). The uncertainty in the specific surface area will not affect the comparison of LITCO glasses, but will affect comparison of LITCO glasses with other waste glasses.

The high $\mathrm{S} / \mathrm{V}$ values used in the PCTs provide a convenient means of accelerating saturation of a solution: the dissolution of a proportionally smaller amount of glass over a short period of time produces similar changes in solution composition as those produced in lower $\mathrm{S} / \mathrm{V}$ tests over much longer times. Such tests therefore highlight the effect that solution chemistry has on the corrosion of glass. Since the concentrations of glass components in solution are high, the normalized mass loss to solution observed in the PCTs provides information about the Stage II rate of corrosion. If the test duration is long enough, these tests can also provide information about alteration phase formation and the Stage III corrosion rate.

In the VHT, a monolithic sample is placed in contact with water vapor in a sealed vessel at an elevated temperature. At relative humidities above $\sim 90 \%$, a thin film of water forms on the sample, resulting in an extremely high $S / V$ and very rapid saturation of the solution with glass 
corrosion products. This results in rapid formation of crystalline alteration phases. Over time, the crystalline phases may enter into reactions with one another, producing a more stable phase assemblage in the process. At the end of a test, the surface of the reacted sample is examined to identify the crystalline alteration phases that have formed and to estimate the rate of reaction. The phases are identified with SEM, analytical electron microscopy (AEM), and X-ray diffraction. Because the solution evaporates when the test is terminated, solution analyses cannot be performed. The abundance of alteration phases is used to monitor the extent of reaction. The same phases are expected to form, and to have the same effect on corrosion rate, whether tests are performed at high or low temperature; thus, tests are generally performed at high temperature to accelerate corrosion.

Vapor hydration tests can provide quantitative information about the rate of glass corrosion, but, more importantly, they provide qualitative information about the identities and order of appearance of crystalline alteration phases. These factors are potentially important to the Stage III corrosion rate, for if the rate of crystal growth exceeds the rate of glass corrosion in the absence of the crystal, then the rate of corrosion may accelerate when the crystal is present. This information is essential for long-term modeling of glass behavior. 


\section{RESULTS: FORMULA 127 GLASS}

\section{A. Test Matrix}

The test matrix employed to evaluate the corrosion behavior of Formula 127 glass is shown in Table 1. Vapor hydration tests were conducted at $200^{\circ} \mathrm{C}$ for $7,14,28$, and 56 days to promote the formation of alteration phases. These tests were run to identify the alteration phases that formed and measure their effect on glass corrosion. The matrix also includes PCT-Bs conducted at $2000 \mathrm{~m}^{-1}$ for 7,70 , and $140 \mathrm{~d}$, and PCT-Bs conducted at $20,000 \mathrm{~m}^{-1}$ for 28,98 , and $183 \mathrm{~d}$. Tests were conducted at $20,000 \mathrm{~m}^{-1}$ by reacting equal masses of $-100+200$ mesh glass and deionized water and by reacting $-200+325$ mesh glass with twice its mass in deionized water. The PCT-Bs were used to measure the glass corrosion behavior in concentrated solutions. We also performed MCC-1 tests at $\mathrm{S} / \mathrm{V}=8.5 \mathrm{~m}^{-1}$ for test durations of 3,7 , and $16 \mathrm{~d}$ to characterize the glass corrosion behavior in dilute solutions.

Table 1. Test Matrix for Formula 127 Glass

\begin{tabular}{llcccc} 
Test Number & Procedure & $\mathrm{T},{ }^{\circ} \mathrm{C}$ & Duration, days & $\mathrm{S} / \mathrm{N}, \mathrm{m}^{-1}$ & Sieve Fraction \\
\hline W127-1 & VHT & 200 & 7 & n.d. ${ }^{{ }^{1}}$ & n.a. ${ }^{{ }^{\prime}}$ \\
W127-2 & VHT & 200 & 14 & n.d. & n.a. \\
W127-3 & VHT & 200 & 28 & n.d. & n.a. \\
W127-4 & VHT & 200 & 56 & n.d. & n.a. \\
W127-5 & PCT-B & 90 & 7 & 2000 & $-100+200$ \\
W127-6 & PCT-B & 90 & 70 & 2000 & $-100+200$ \\
W127-7 & PCT-B & 90 & 140 & 2000 & $-100+200$ \\
W127-8 & PCT-B & 90 & 28 & 20,000 & $-100+200$ \\
W127-11 & PCT-B & 90 & 98 & 20,000 & $-100+200$ \\
W127-10 & PCT-B & 90 & 183 & 20,000 & $-100+200$ \\
W127-13 & PCT-B & 90 & 28 & 20,000 & $-200+325$ \\
W127-16 & PCT-B & 90 & 98 & 20,000 & $-200+325$ \\
W127-15 & PCT-B & 90 & 183 & 20,000 & $-200+325$ \\
W127-17 & MCC-1 & 90 & 3 & 8.5 & n.a. \\
W127-18 & MCC-1 & 90 & 7 & 8.5 & n.a. \\
W127-19 & MCC-1 & 90 & 16 & 8.5 & n.a. \\
\hline
\end{tabular}

${ }^{2}$ n.d. = not determined.

${ }^{b}$ n.a. $=$ not applicable.

\section{B. Sample Characteristics}

The sample characteristics of Formula 127 have been described in detail in an earlier report [ELLISON-1995], and only a brief review will be provided here. Formula 127 contains crystalline fluorite $\left(\mathrm{CaF}_{2}\right)$ in the form of large $(1-4 \mathrm{~mm})$ skeletal crystals and very small $(1-3 \mu \mathrm{m})$ spherulites. Confirmation that the crystal is fluorite was obtained by electron diffraction. The morphologies of the fluorite crystals indicate they formed during quench from a melt. The crystals are estimated to comprise 5-10 volume percent of the glass. An electron backscatter image of a polished monolith of unreacted Formula 127 glass is shown in Fig. 2; the fluorite crystals appear as either small white blobs or large, skeletal needles. The composition of Formula 127 given by Staples et al. [STAPLES-1983] is shown in Table 2. The high fluoride and $\mathrm{ZrO}_{2}$ concentrations and low $\mathrm{B}_{2} \mathrm{O}_{3}$ concentration of Formula 127 are unusual compared with other candidate high-level waste glasses, but are similar to the concentrations of these 
components in the 630 series glasses. Therefore, the corrosion behavior of Formula 127 glass is a convenient reference with which to compare the corrosion behavior of other candidate glasses derived from LITCO calcined wastes.

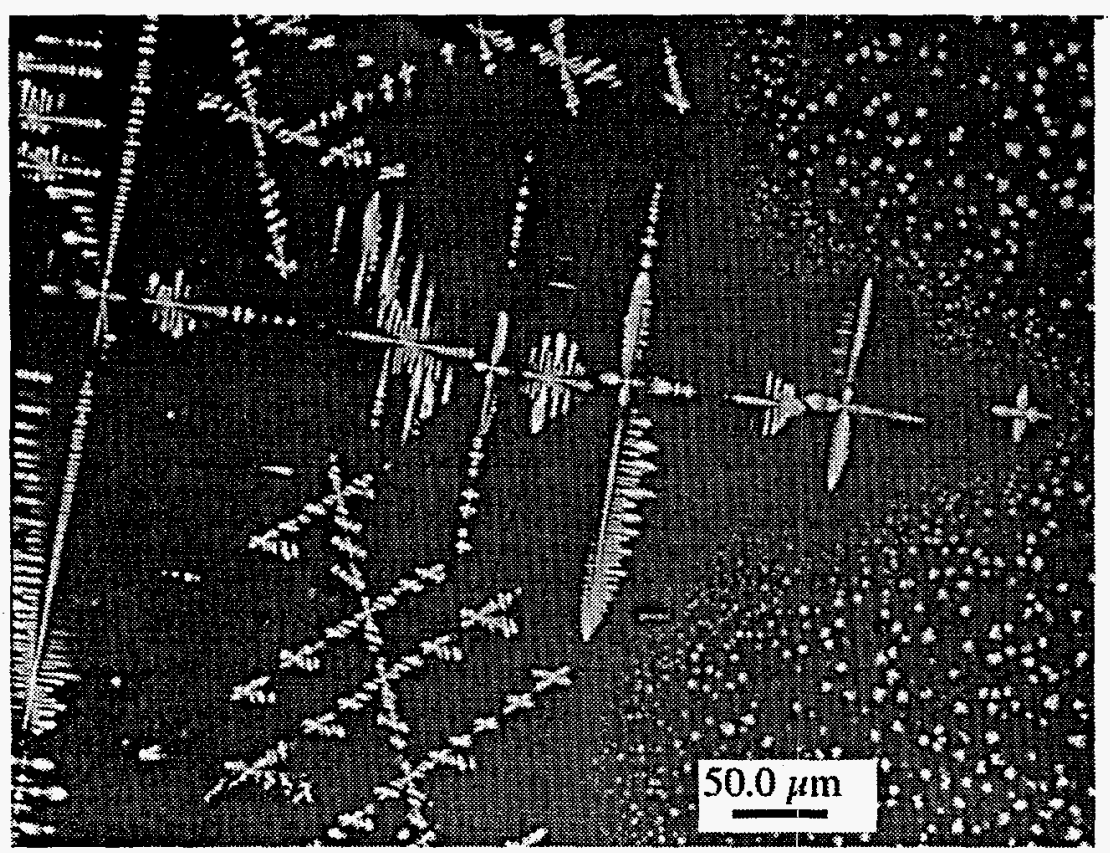

Fig. 2. Electron Backscatter Image of a Polished Monolith of Formula 127 Glass. White needles and patches are fluorite quench crystals.

Table 2. Composition of Formula 127 Glass (from [STAPLES-1983])

\begin{tabular}{|c|c|c|c|c|c|}
\hline \multicolumn{3}{|c|}{ Elements } & \multicolumn{3}{|c|}{ Oxide and Halide Components } \\
\hline Component & at $\%$ & $\mathrm{wt} \%$ & Component: & $\mathrm{mol} \%$ & wt\% \\
\hline $\mathrm{Al}$ & 4.1 & 5.08 & $\mathrm{Al}_{2} \mathrm{O}_{3}$ & 6.1 & 9.2 \\
\hline B & 1.3 & 0.65 & $\mathrm{~B}_{2} \mathrm{O}_{3}^{3}$ & 1.9 & 2 \\
\hline $\mathrm{Ca}$ & 5.2 & 9.57 & $\mathrm{CaF}_{2}^{2}$ & 17.3 & 20.0 \\
\hline $\mathrm{Cu}$ & 0.6 & 1.75 & $\mathrm{CuO}^{\circ}$ & 1.8 & 2.1 \\
\hline $\mathrm{Li}$ & 3.6 & 1.15 & $\mathrm{Li}_{2} \mathrm{O}$ & 5.4 & 2.4 \\
\hline $\mathrm{Na}$ & 4.1 & 4.33 & $\mathrm{Na}_{2}^{2} \mathrm{O}$ & 4.3 & 4.0 \\
\hline $\mathrm{Si}$ & 18.2 & 23.47 & $\mathrm{NaF}$ & 3.6 & 2.2 \\
\hline $\mathrm{Zr}$ & 1.8 & 7.54 & $\mathrm{SiO}_{2}$ & 54.2 & 48.3 \\
\hline$F$ & 11.6 & 10.12 & $\mathrm{ZrO}_{2}^{2}$ & 5.4 & 9.8 \\
\hline $\mathrm{O}$ & 49.5 & 36.36 & & & \\
\hline
\end{tabular}


C. Test Results

1. Materials Characterization Center Type-1 Test Results

Table 3 shows the $\mathrm{pH}$ and elemental concentrations of solutions obtained from 3 , 7, and $16 \mathrm{~d}$ MCC-1 tests performed with Formula 127 glass. Solution concentrations of major cation components were analyzed with ICP-MS. Uncertainties are $\pm 15 \%$ for most elements (higher uncertainties occur for calcium because of the coincidence of the masses of ${ }^{40} \mathrm{Ca}$ and ${ }^{40} \mathrm{Ar}$ ). Table 4 shows normalized mass losses for each element as obtained from these tests. These values decrease in the order $\mathrm{B}>\mathrm{Li}, \mathrm{Na}>\mathrm{Si}>\mathrm{Al} \gg \mathrm{Cu} \gg \mathrm{Zr}$. Based on the value of $\mathrm{NL}(B)$ in the 3-d test, the glass is reacting with water at a average rate of $3.3 \mathrm{~g} /\left(\mathrm{m}^{2} \cdot \mathrm{d}\right)$. The rates based on the normalized mass losses of $\mathrm{Si}, \mathrm{Na}$, and $\mathrm{Li}$ for this test are $1.3,2.2$, and $2.3 \mathrm{~g} /\left(\mathrm{m}^{2} \bullet \mathrm{d}\right)$, respectively, substantially less than the normalized release obtained for boron.

Table 3. Final $\mathrm{pH}$ and Solution Compositions (mg/L) Obtained from MCC-1 Tests Performed on Formula 127 Glass

\begin{tabular}{lccc}
\hline Test & W127-17 & W127-18 & W127-19 \\
Test Type & MCC-1 & MCC-1 & MCC-1 \\
Duration, days & 3 & 7 & 16 \\
S/V, m -1 $_{\text {Final pH }}$ & 8.5 & 8.5 & 8.5 \\
Analysis Method & 7.72 & 7.69 & 7.74 \\
\hline $\mathrm{Al}$ & ICP-MS & ICP-MS & ICP-MS \\
$\mathrm{B}$ & 0.64 & 0.78 & 0.91 \\
$\mathrm{Ca}$ & 0.55 & 0.63 & 0.74 \\
$\mathrm{Cu}$ & 2.2 & 2.9 & 3.1 \\
$\mathrm{Li}$ & 0.032 & 0.034 & 0.030 \\
$\mathrm{Na}$ & 0.68 & 0.77 & 0.91 \\
$\mathrm{Si}$ & 2.4 & 2.7 & 3.4 \\
$\mathrm{Zr}$ & 7.7 & 9.2 & 11.1 \\
\hline
\end{tabular}

Table 4. Normalized Mass Losses $\left(\mathrm{g} / \mathrm{m}^{2}\right)$ Obtained from MCC-1 Tests Performed on Formula 127 Glass

\begin{tabular}{lccc}
\hline Test & W127-17 & W127-18 & W127-19 \\
Test Type & MCC-1 & MCC-1 & MCC-1 \\
Duration, days & 3 & 7 & 16 \\
$\mathrm{~S} / \mathrm{N}, \mathrm{m}^{-1}$ & 8.5 & 8.5 & 8.5 \\
Final pH & 7.72 & 7.69 & 7.74 \\
\hline $\mathrm{Al}$ & 1.5 & 1.8 & 2.1 \\
$\mathrm{~B}$ & 10 & 11 & 13 \\
$\mathrm{Ca}$ & 2.8 & 3.5 & 3.8 \\
$\mathrm{Cu}$ & 0.22 & 0.23 & 0.20 \\
$\mathrm{Li}$ & 7.0 & 7.9 & 9.3 \\
$\mathrm{Na}$ & 6.4 & 7.4 & 9.4 \\
$\mathrm{Si}$ & 3.9 & 4.6 & 5.6 \\
$\mathrm{Zr}$ & 0.002 & 0.003 & 0.009 \\
\hline
\end{tabular}


Figure 3 is a plot of the normalized mass losses based on $\mathrm{Al}, \mathrm{B}, \mathrm{Li}, \mathrm{Na}$, and $\mathrm{Si}$ in MCC-1 tests as a function of test duration, for Formula 127 glass. From the figure, it is obvious that even after three days, the reaction progress of the glass has already proceeded past Stage I (Fig. 1). It is interesting that in these very short-term, low S/V tests, the normalized mass losses of $\mathrm{Li}$ and $\mathrm{Na}$ are nearly the same, whereas in the much higher S/V PCT-Bs (see next section), the normalized release of $\mathrm{Li}$ is invariably greater than that of $\mathrm{Na}$. The observation that the release rate of $B$ between 3 and 16 days, which is about $0.2 \mathrm{~g} /\left(\mathrm{m}^{2} \bullet \mathrm{d}\right)$, is more than twice the release rate of $\mathrm{Si}$, which is about $0.08 \mathrm{~g} /\left(\mathrm{m}^{2} \bullet \mathrm{d}\right)$, indicates that the solution chemistry is slowing the glass dissolution rate. That is, corrosion has reached Stage II within 16 days.

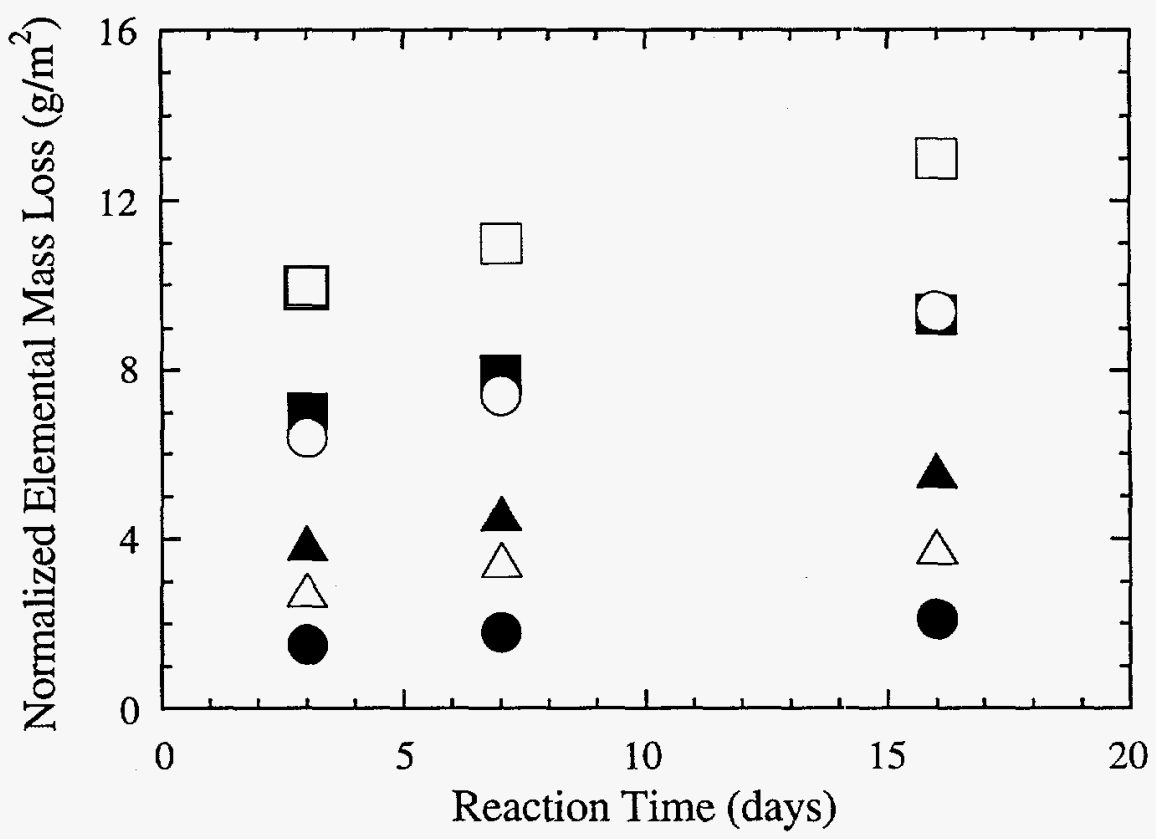

Fig. 3. Normalized Mass Losses in MCC-1 Tests of Formula 127 Glass: (•) $\mathrm{Al},(\square) \mathrm{B},(\Delta) \mathrm{Ca},(\boldsymbol{\square}) \mathrm{Li},(\mathrm{O}) \mathrm{Na}$, and (A) Si

\section{Product Consistency Test Results}

Cation concentrations in solutions from PCT-Bs are shown in Table 5, along with the approximate $\mathrm{S} / \mathrm{V}$ of the test and the final $\mathrm{pH}$ of the test solutions. Uncertainties in the cation analyses are the same as those for the MCC-1 solution analyses (Sec. III.C.1). Normalized mass losses are shown in Table 6. Normalized mass losses of $\mathrm{Al}, \mathrm{B}, \mathrm{Li}, \mathrm{Na}$, and $\mathrm{Si}$ obtained in 2000 $\mathrm{m}^{-1}$ and $20,000 \mathrm{~m}^{-1}$ PCT-Bs are shown in Figs. 4 and 5, respectively.

In the $2000 \mathrm{~m}^{-1}$ PCT-Bs (Fig. 4), the normalized mass losses decrease in the order $\mathrm{Li}, \mathrm{B}>\mathrm{Na}>\mathrm{Si}>\mathrm{Ca}, \mathrm{Al}$. The concentrations of $\mathrm{Ca}$ and $\mathrm{Si}$ increase between 70 and 140 days, but the concentrations of other components decrease during that period. The final $\mathrm{pH}$ of test W127-7 is lower than that obtained for any other PC test, which is consistent with the lower normalized mass losses observed for most elements in this test. The normalized mass losses are on the order of $0.4-0.7 \mathrm{~g} / \mathrm{m}^{2}$ for the most soluble glass components ( $\mathrm{Li}, \mathrm{B}$, and $\mathrm{Na}$ ). 
Cation concentrations in $20,000 \mathrm{~m}^{-1}$ tests performed with the $-100+200$ sieve fraction are similar to those obtained in tests performed with the $-200+325$ sieve fraction. The concentrations in tests at $20,000 \mathrm{~m}^{-1}$ with both fractions are substantially greater than the values measured in the $2000 \mathrm{~m}^{-1}$ tests. This is an indication that tests at $20,000 \mathrm{~m}^{-1}$ attained a more evolved state of glass corrosion. The concentrations of these elements show a smooth, steady increase over time. The normalized mass losses of glass components vary in the same order at all S/N. Normalized mass losses for $\mathrm{Al}, \mathrm{B}, \mathrm{Li}, \mathrm{Na}$, and $\mathrm{Si}$ are shown in Fig. 5.

After termination of a PCT-B, the solids recovered were examined with SEM. No silicate-bearing alteration phases were found in any of the tests conducted at $S / V=2000 \mathrm{~m}^{-1}$, or

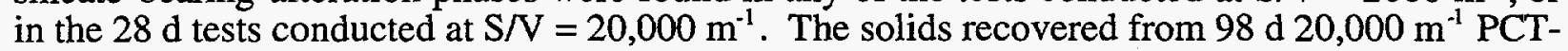
Bs and tests of longer duration contained calcium silicate alteration phases. For the most part, the calcium silicates form in situ, directly from leached glass, usually on high-surface-energy sites such as spurs of fractured glass. Discrete calcium silicate crystals (nonauthogenic) also were found in $182 \mathrm{~d}$ tests. The only other alteration phase identified in PCT-B samples was a clay material found on a grain recovered from test W127-11 (Fig. 6). The clay is sandwiched between unreacted glass and a particle of iron or steel. The iron-bearing particle was probably a contaminant within the glass. The amount of clay around the iron-bearing particle was greater than that generally observed at glass surfaces. This may indicate that iron accelerated the rate of corrosion of Formula 127 glass, or that etching of the clay was impeded by the presence of the iron.

There is no indication of an abrupt increase in the rate of glass corrosion in any of the tests. The possibility that such an increase might occur in tests of longer duration was not explored because only a small amount of glass was available for testing. However, the results of the analysis of solids recovered from PCT-Bs and VHTs (see below) suggest that early-forming calcium silicate crystals have already driven the corrosion into Stage III. This rate of reaction is low relative to the rates observed for glasses of the type prepared by the Defense Waste Processing Facility (DWPF) [EBERT-1994]. However, the formation of other phases at longer times may lead to a further increase in the dissolution rate.

There is evidence that exposed fluorite grains grow during the course of the tests. The grains of freshly crushed Formula 127 glass are smooth, with fluorite crystals apparently cleaving parallel to the glass surface as the glass breaks. In the samples recovered from PCT-Bs, however, most fluorite grains protrude above the surface of the glass, and most are surrounded by small depressions indicative of selective dissolution of the glass. Figure 7 is an SEM image of a particle of glass recovered from PCT-B W127-6. The glass around the fluorite grain is preferentially dissolved, while the fluorite grain itself protrudes above the surface of the glass. Detailed AEM analysis of the material surrounding spherulitic fluorite grains confirms that the glass immediately adjacent to the fluorite crystals is preferentially dissolved relative to glass far from fluorite grains (Fig. 8). No evidence of a leached, reacted layer was found on any of the PCT-B samples. 
Table 5. Final pH and Solution Concentrations (mg/L) from PCT-Bs Performed with Formula 127 Glass

\begin{tabular}{lccccccccc}
\hline Test & W127-5 & W127-6 & W127-7 & W127-8 & W127-13* & W127-11 & W127-16* & W127-10 & W127-15* \\
Duration, days & 7 & 70 & 140 & 28 & 28 & 98 & 98 & 182 & 182 \\
$\mathrm{~S} / \mathrm{V}, \mathrm{m}^{-1}$ & 2000 & 2000 & 2000 & 20,000 & 20,000 & 20,000 & 20,000 & 20,000 & 20,000 \\
Final pH & 9.93 & 10.02 & 9.21 & 10.92 & 11.13 & 9.57 & 9.96 & 9.93 & 10.02 \\
\hline $\mathrm{Al}$ & $<1.3$ & $<1.0$ & 1.0 & $<2.1$ & $<1.4$ & 1.5 & 1.3 & 1.3 & 1.4 \\
$\mathrm{~B}$ & 6.9 & 8.6 & 6.4 & 24 & 29 & 33 & 34 & 48 & 42 \\
$\mathrm{Ca}$ & 4.4 & 3.2 & 4.1 & 1.2 & 1.4 & n.d. & n.d. & n.d. & n.d. \\
$\mathrm{Cu}$ & $<0.1$ & $<0.1$ & 0.004 & $<0.2$ & $<0.1$ & $<0.0$ & $<0.0$ & $<0.1$ & $<0.0$ \\
$\mathrm{Li}$ & 11 & 16 & 15 & 48 & 58 & 66 & 70 & 87 & 84 \\
$\mathrm{Na}$ & 30 & 41 & 38 & 115 & 141 & 149 & 161 & 197 & 191 \\
$\mathrm{Si}$ & 36 & 42 & 53 & 91 & 107 & 126 & 130 & 147 & 137 \\
$\mathrm{Zr}$ & $<0.3$ & $<0.2$ & 0.001 & $<0.4$ & $<0.3$ & $<0.1$ & $<0.1$ & $<0.1$ & $<0.1$ \\
\hline${ }^{\mathrm{n}} \mathrm{nd}=$ not determined. & & & & & & & & &
\end{tabular}

an.d. = not determined. 
Table 6. Normalized Mass Losses $\left(\mathrm{g} / \mathrm{m}^{2}\right)$ from PCT-Bs Performed with Formula 127 Glass

\begin{tabular}{lccccccccccc}
\hline Test & W127-5 & W127-6 & W127-7 & W127-8 & W127-13 & W127-11 & W127-16 & W127-10 & W127-15 \\
Duration, days & 7 & 70 & 140 & 28 & 28 & 98 & 98 & 182 \\
S/V, m ${ }^{-1}$ & 2000 & 2000 & 2000 & 20,000 & 20,000 & 20,000 & 20,000 & 20,000 & 20,000 \\
Final pH & 9.93 & 10.02 & 9.21 & 10.92 & 11.13 & 9.57 & 9.96 & 9.93 & 10.02 \\
\hline Al & $<0.013$ & $<0.010$ & 0.010 & $<0.002$ & $<0.001$ & 0.001 & 0.001 & 0.001 & 0.001 \\
B & 0.54 & 0.67 & 0.50 & 0.18 & 0.22 & 0.25 & 0.26 & 0.37 & 0.33 \\
$\mathrm{Ca}$ & 0.023 & 0.017 & 0.021 & $6 \mathrm{E}-04$ & $7 \mathrm{E}-04$ & n.d. ${ }^{a}$ & n.d. & n.d. & n.d. \\
$\mathrm{Cu}$ & $<3.8 \mathrm{E}-3$ & $<3.0 \mathrm{E}-3$ & $1.2 \mathrm{E}-4$ & $<5.9 \mathrm{E}-4$ & $<4.1 \mathrm{E}-4$ & $<1.3 \mathrm{E}-4$ & $<1.1 \mathrm{E}-4$ & $<1.6 \mathrm{E}-4$ & $<9.2 \mathrm{E}-5$ \\
$\mathrm{Li}$ & 0.48 & 0.69 & 0.63 & 0.21 & 0.25 & 0.29 & 0.31 & 0.38 & 0.37 \\
$\mathrm{Na}$ & 0.34 & 0.47 & 0.44 & 0.13 & 0.16 & 0.17 & 0.19 & 0.23 & 0.22 \\
$\mathrm{Si}$ & 0.077 & 0.089 & 0.113 & 0.019 & 0.023 & 0.027 & 0.028 & 0.031 & 0.029 \\
$\mathrm{Zr}$ & $<1.8 \mathrm{E}-3$ & $<1.4 \mathrm{E}-3$ & $8.4 \mathrm{E}-6$ & $<2.7 \mathrm{E}-4$ & $<1.9 \mathrm{E}-4$ & $<6.2 \mathrm{E}-5$ & $<5.2 \mathrm{E}-5$ & $<7.6 \mathrm{E}-5$ & $<4.3 \mathrm{E}-5$ \\
\hline
\end{tabular}




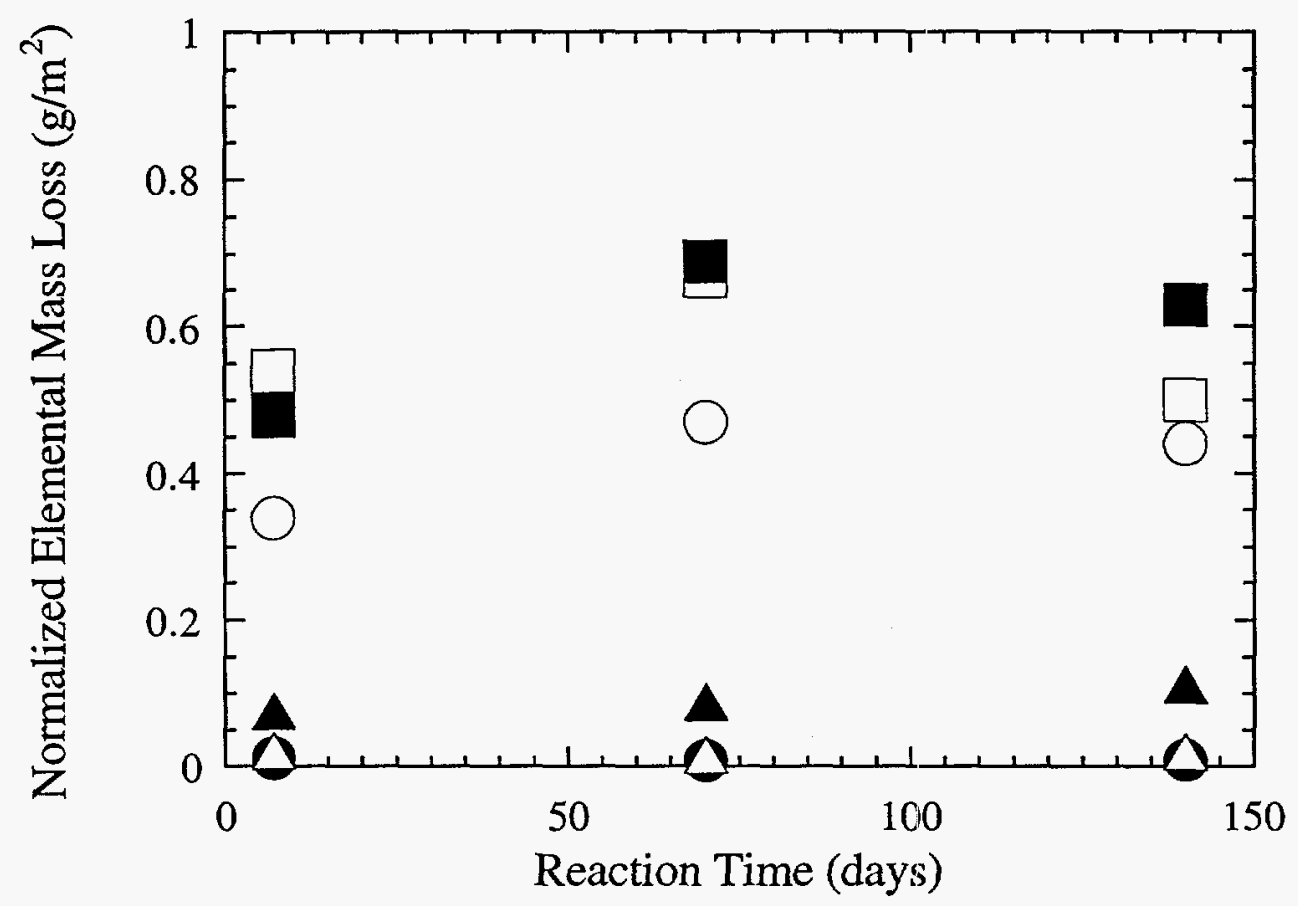

Fig. 4. Normalized Mass Losses in PCT-Bs of Formula 127 Glass at $\mathrm{S} / \mathrm{V}=2000 \mathrm{~m}^{-1}$ : $(\bullet) \mathrm{Al},(\square) \mathrm{B},(\Delta) \mathrm{Ca},(\mathbf{\square}) \mathrm{Li},(\mathrm{O}) \mathrm{Na}$, and $(\Delta) \mathrm{Si}$

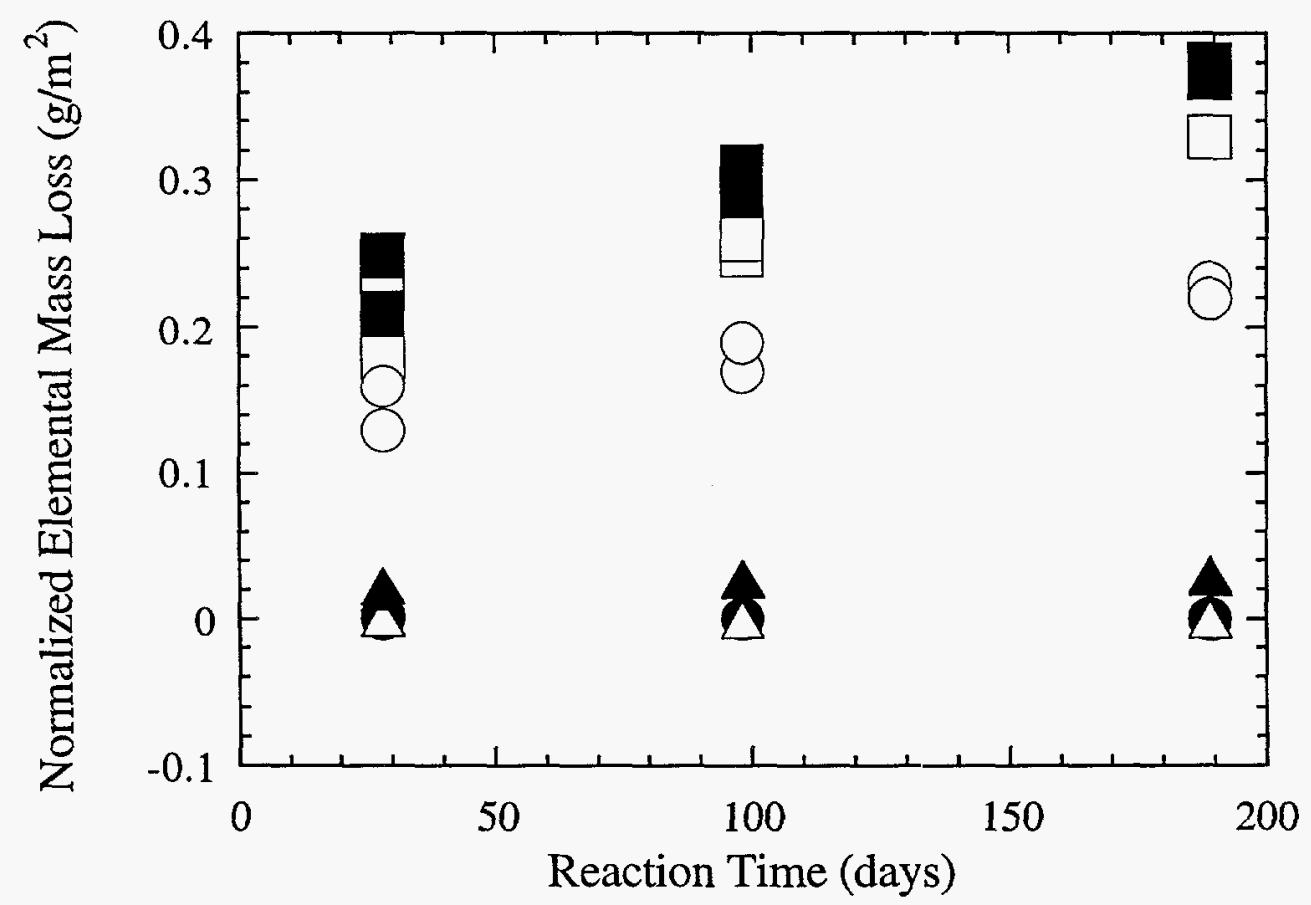

Fig. 5. Normalized Mass Losses in PCT-Bs of Formula 127 Glass at $\mathrm{S} / \mathrm{V}=20,000 \mathrm{~m}^{-1}$ : (•) $\mathrm{Al},(\square) \mathrm{B},(\Delta) \mathrm{Ca},(\mathbf{\square}) \mathrm{Li},(\mathrm{O}) \mathrm{Na}$, and $(\mathbf{\Delta}) \mathrm{Si}$ 


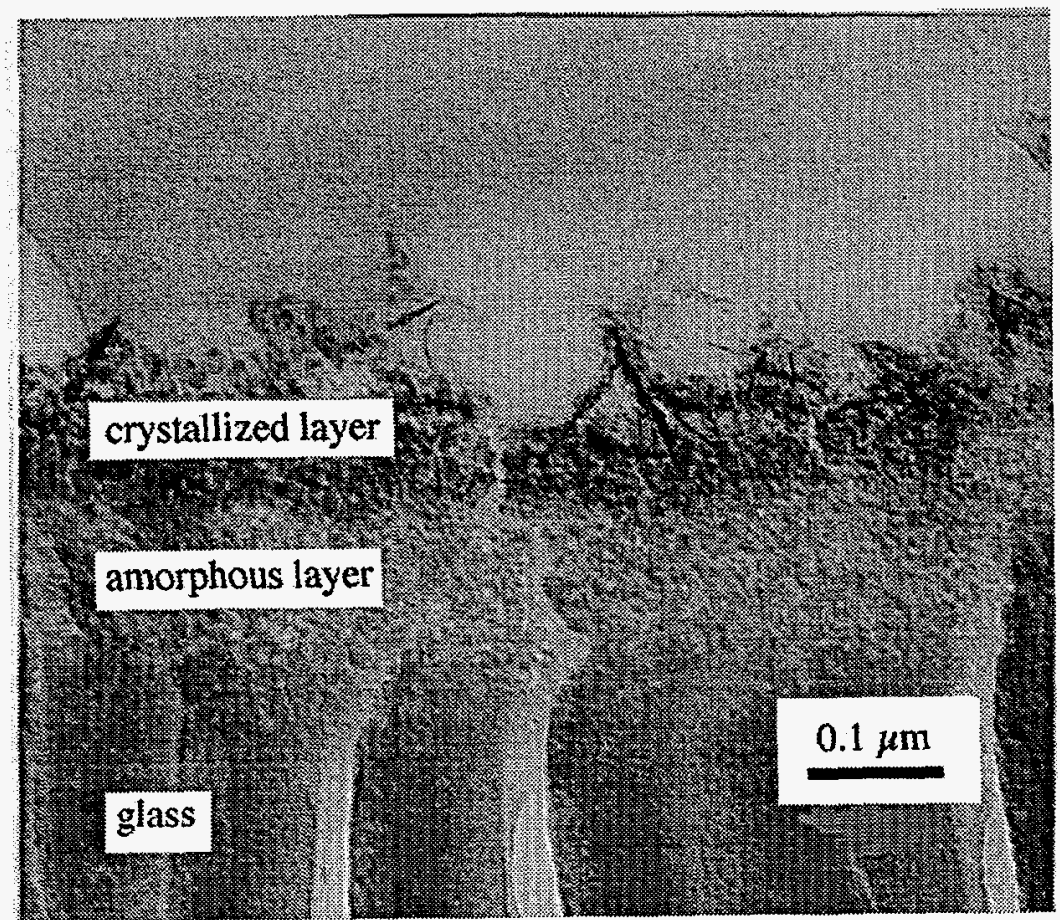

Fig. 6. Transmission Electron Micrograph of a Clay Layer Formed where Formula 127 Glass was in Contact with Iron, from the PCT-B W127-11

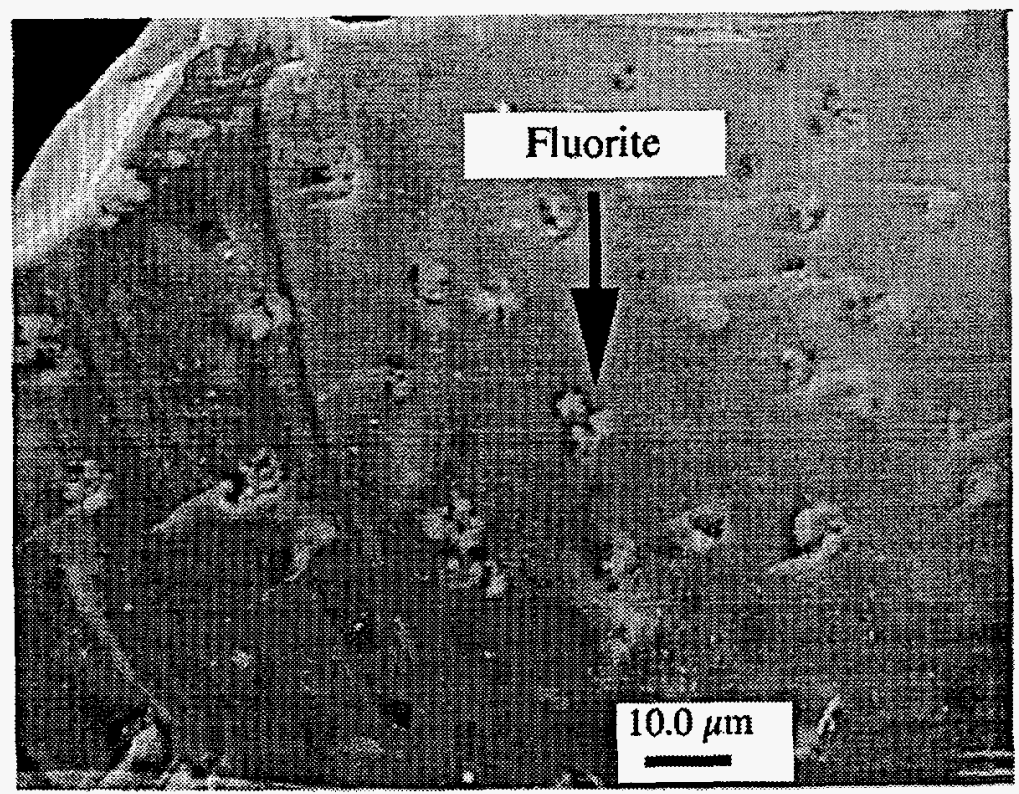

Fig. 7. A SEM Image of a Glass Particle Recovered from PCT-B of Formula 127 Glass (test W127-6: $70 \mathrm{~d}, \mathrm{~S} / \mathrm{V}=2000 \mathrm{~m}^{-1}$ ), Showing Dissolution around Fluorite Grain 


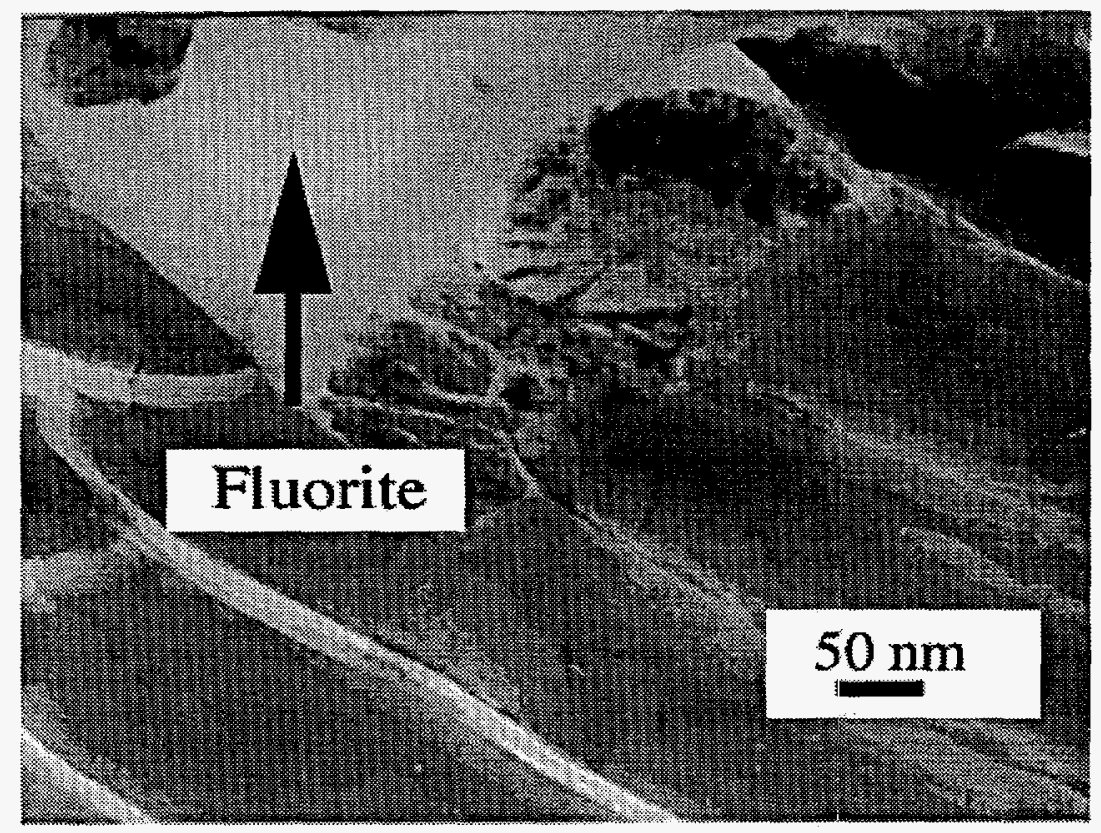

Fig. 8. Transmission Electron Micrograph of a Near-Surface Fluorite Grain Recovered from PCT-B with Formula 127 Glass (test W127-11: $98 \mathrm{~d}, \mathrm{~S} / \mathrm{N}=20,000 \mathrm{~m}^{-1}$ ). The white patch with straight boundaries is a fluorite grain. The glass immediately surrounding it has been preferentially leached relative to the bulk.

Grain mounts were made of samples from all PCT-Bs conducted for Formula 127 glass. The grains were cross-sectioned for analysis of the depth of aqueous attack. The alteration depth was estimated from the solution results by dividing NL(B) by the density of the sample. This calculation provides an equivalent depth in micrometers of the total extraction of B. The value of NL(B) was $0.7 \mathrm{~g} / \mathrm{m}^{2}$ in test W $127-6$, and if the bulk density of the Formula 127 glass is assumed to be $2.7 \mathrm{~g} / \mathrm{cm}^{3}$, the extraction depth is $0.27 \mu \mathrm{m}$ for B release. The depth to which the sample was etched is given by the Si extraction depth. The extraction depth for $\mathrm{Si}$ from this test is about $0.03 \mu \mathrm{m}$. The difference between the depths for $\mathrm{Si}$ and B extraction is the approximate layer thickness, which for this test is $0.24 \mu \mathrm{m}$. This layer is too thin to resolve with an SEM, and therefore it is not surprising that no evidence of a reacted layer is seen in any of the PCT-Bs terminated thus far for Formula 127 glass. Though this estimated surface layer thickness is well within the detection limits of AEM, no evidence of a reacted surface layer was found in AEM analysis of PCT-B samples of Formula 127 glass. This suggests that most of the mass loss is due to preferential dissolution around fluorite grains.

An interesting result seen in cross-sectioned PCT samples is that individual grains of glass had fractured about their borders. The depth to which the fracturing extends varies directly with the duration of the experiment, though in a qualitative rather than quantitative way. Cross sections through most grains from test W127-7 showed evidence of breakage throughout their entire volume. On the other hand, cross sections taken through the unreacted glass were clean, with no disruption of the surface of the grains. This suggests that the outer layers of the glass have been embrittled by reaction with water. On the basis of the VHT results discussed below, it is suggested that water percolates extensively into the bulk glass, possibly through hydroxyl exchange for fluoride, without the release of glass components. 


\section{Vapor Hydration Test Results}

The purpose of the VHT is to greatly accelerate the corrosion progress and hasten the formation of alteration phases. As with the PCT-B samples, cross-sectioning of VH test samples results in partial disintegration of the material near the surface of the monoliths, indicating that the reacted glass is more fragile than the unaltered glass. It also was found that VH test samples sealed in epoxy pulled back from the epoxy over time, leaving a gap around the periphery of the monoliths. Both the width of the gap and the degree of disruption of the surface of the cross-sections produced by polishing the samples increased with the duration of the hydration test, although, as with the PCT-B, this fragility is only a qualitative indication of extensive hydration of the sample. In the most extreme case, the gap was nearly $20 \mu \mathrm{m}$ around the entire monolith, indicating a 3-4\% volume contraction over time. This contraction provides further evidence that Formula 127 glass is extensively infiltrated with water in hydrothermal tests. Depending on how much fluoride is exchanged out of the bulk glass in this process, hydrolysis might change the bulk chemistry of the glass enough to influence its corrosion behavior.

The first two phases to appear in VHTs are calcium silicates, one with a $\mathrm{Ca}: \mathrm{Si}$ ratio near 1:1 and another with a $\mathrm{Ca}: \mathrm{Si}$ ratio $>2: 1$. A crystal rich in $\mathrm{Si}, \mathrm{O}$, and $\mathrm{F}$ also forms early in the hydration tests; it probably contains $\mathrm{Li}$, as well. A phase apparently containing only $\mathrm{Ca}$ and $\mathrm{O}$ also forms, but it is so irregular in shape and so low in concentration that it may be $\mathrm{Ca}(\mathrm{OH})_{2}$ precipitated as an evaporite. At longer times, the Ca-Si phase with high calcium concentration disappears, and the phase with $\mathrm{Ca}: \mathrm{Si}$ of $1: 1$ appears to be in a reaction relationship with calcite, $\mathrm{CaCO}_{3}$. The predominant calcium-bearing phase thereafter is calcite, which grows to $50-100 \mu \mathrm{m}$ in diameter after $56 \mathrm{~d}$.

The source of the $\mathrm{CO}_{2}$ needed to form calcite is uncertain. The total $\mathrm{CO}_{2}$ content of air is approximately $0.5 \%$; if this were completely consumed to form calcite, then the amount of $\mathrm{CO}_{2}$ present in the $22 \mathrm{~mL}$ test vessel would permit formation of approximately $1 \mathrm{mg}$ of calcite. In the $56 \mathrm{~d} \mathrm{VH}$ test sample, however, the amount of calcite appears to exceed this. An alternative possibility is that high concentrations of fluoride may aid in retention of $\mathrm{CO}_{2}$ during fabrication of the glass. The presence of $\mathrm{CO}_{2}$ in fluoride-bearing glasses would result from the reagents used to simulate the calcine and the glass but would not be expected during fabrication of an actual waste glass from a combination of calcine and frit. Thus, if fluoride really does aid in $\mathrm{CO}_{2}$ retention, then the presence of calcite in VHTs of Formula 127 glass may not be representative of what would form during hydration of an actual waste glass.

Zirconium also appears in crystalline alteration phases, in a $\mathrm{Ca}-\mathrm{Zr}-\mathrm{F}$ phase (possibly $\mathrm{CaZrF}_{6}$ ) and in a $\mathrm{Ca}-\mathrm{Zr}-\mathrm{Si}-\mathrm{O}-\mathrm{F}$ phase. Silicon is concentrated mainly in the latter alteration phase. Representative SEM images of some of the alteration phases formed during vapor hydration of Formula 127 glass are shown in Fig. 9.

Though these phases are widespread and, in the case of calcite, grow to nearly macroscopic size, only a relatively small amount of glass has reacted in these tests. This suggests that the phases formed thus far are not likely to have a very substantial impact on the rate of glass corrosion or the rates of release of radionuclides. At least in the case of calcium silicate, which forms after $98 \mathrm{~d}$ in 20,000 PCT-Bs, the effect on the rate of glass corrosion is small (Fig. 5). 
(a)

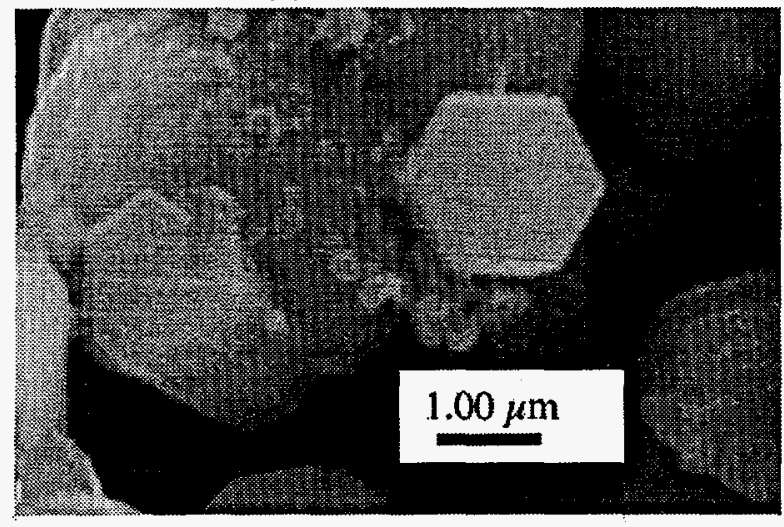

(b)

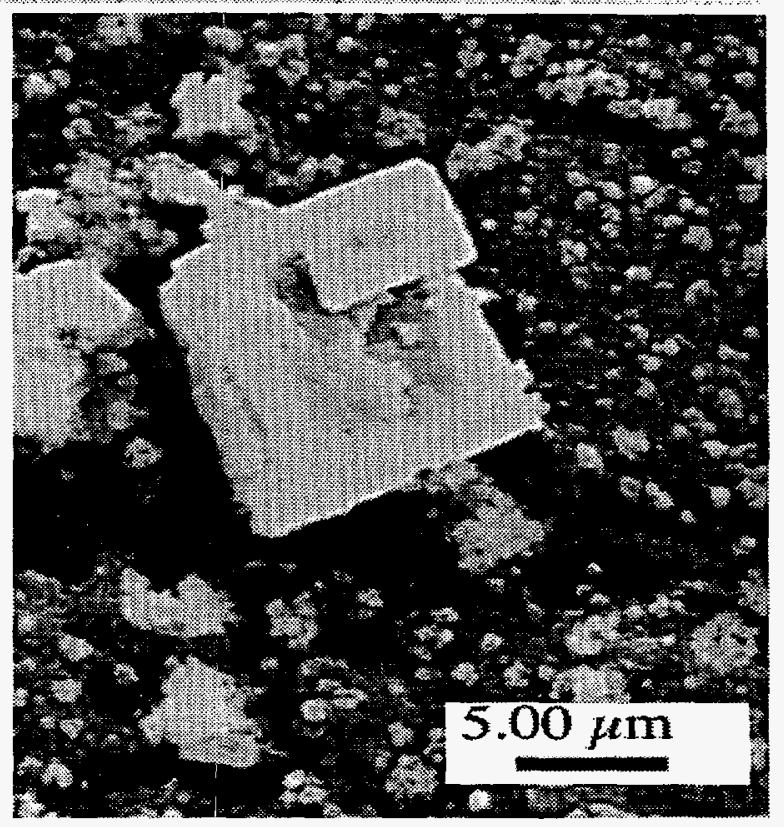

(c)

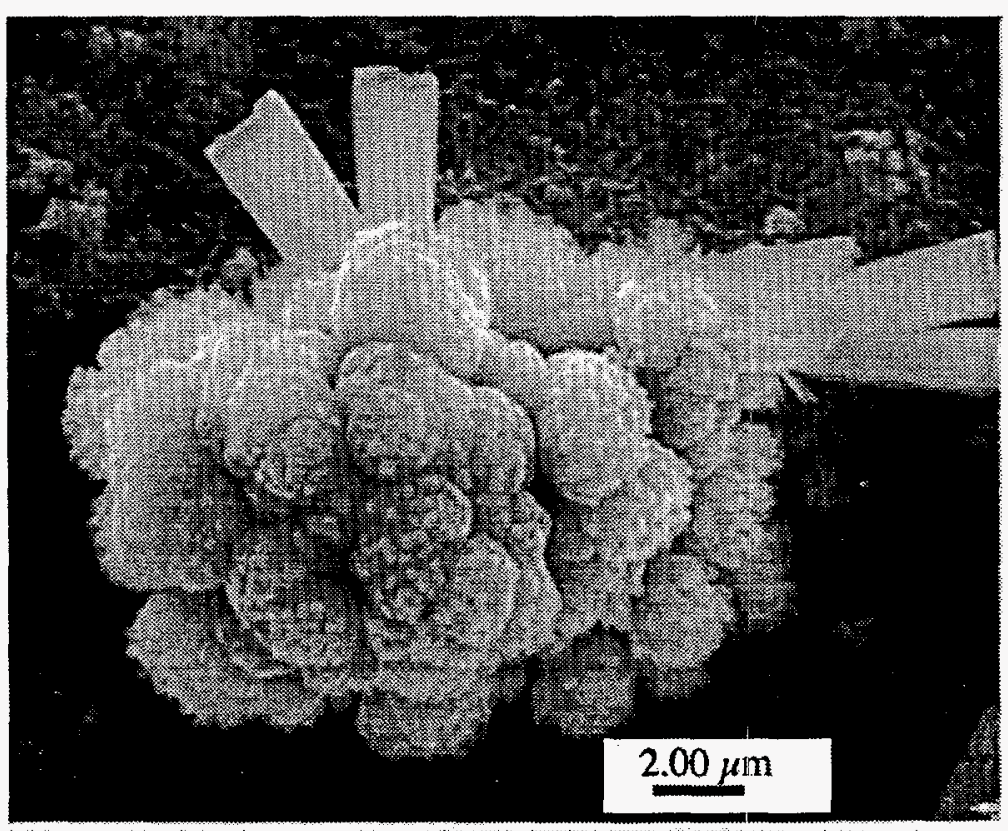

Fig. 9. Scanning Electron Micrographs of Alteration Phases Formed as a Result of Reaction of Formula 127 Glass with Water Vapor at $200^{\circ} \mathrm{C}$ : (a) Ca-Si-F-O, with Pillars of Ca-Zr$\mathrm{O}$; (b) $\mathrm{CaCO}_{3}$; and (c) Ca-Si-F-O Phase on Blades of Ca-Zr-Si-O. 


\section{RESULTS: FORMULA 532 GLASS}

\section{A. Test Matrix}

The test matrix employed to evaluate the corrosion behavior of Formula 532 is shown in Table 7. The matrix includes $2000 \mathrm{~m}^{-1}$ PCT-Bs conducted for periods of $7,30,49$, and $182 \mathrm{~d}$; $20,000 \mathrm{~m}^{-1}$ PCT-Bs conducted for periods of 49, 98, and $182 \mathrm{~d}$; and VHTs conducted for periods of $7,14,28,49$, and $56 \mathrm{~d}$. The PC-Bs were conducted with crushed glass in the $-100+200$ mesh size fraction, and the VHTs were conducted with monolithic samples.

Table 7. Test Matrix for Formula 532 Glass

\begin{tabular}{lccccc}
\hline Test Number & Procedure & $\mathrm{T},{ }^{\circ} \mathrm{C}$ & Duration, days & $\mathrm{S} / \mathrm{N}, \mathrm{m}^{-1}$ & Sieve Fraction \\
\hline W532-1 & VHT & 200 & 7 & n.d. $^{\mathrm{a}}$ & n.a. $^{\mathrm{b}}$ \\
W532-2 & VHT & 200 & 14 & n.d. & n.a. \\
W532-3 & VHT & 200 & 28 & n.d. & n.a. \\
W532-12 & VHT & 200 & 49 & n.d. & n.a. \\
W523-4 & VHT & 200 & 56 & n.d. & n.a. \\
W532-5 & & & & & \\
W532-6 & PCT-B & 90 & 7 & 2000 & $-100+200$ \\
W532-7 & PCT-B & 90 & 30 & 2000 & $-100+200$ \\
W532-8 & PCT-B & 90 & 49 & 2000 & $-100+200$ \\
W532-9 & PCT-B & 90 & 182 & 2000 & $-100+200$ \\
W532-10 & PCT-B & 90 & 49 & 20,000 & $-100+200$ \\
W532-11 & PCT-B & 90 & 98 & 20,000 & $-100+200$ \\
\hline
\end{tabular}

${ }^{a}$ n.d. = not determined

${ }^{\mathrm{b}}$ n.a. $=$ not applicable.

\section{B. Sample Characteristics}

The sample characteristics of the Formula 532 glass are described in detail elsewhere [1], and only a brief review will be provided here. Formula 532 glass was received in the alumina crucible in which it was formed. It is a transparent, deep-blue glass with swirls of much darker glass and relatively large $(1-5 \mu \mathrm{m})$ regions of light-colored undissolved or partially reacted material. Images obtained with SEM and AEM of crushed glass reveal that 5-10\% of the bulk material is an aluminosilicate crystalline phase identified by electron diffraction as virgilite, $\mathrm{LiAlSi}_{3} \mathrm{O}_{8}$, [FRENCH-1978]. Virgilite crystals are assumed to have settled out of the melt because no quench textures are found. Detailed AEM analysis also revealed the presence of isolated grains of a copper-titanium bearing phase, and crystals of rutile, $\mathrm{TiO}_{2}$ (Fig. 10).

The as-batched composition of Formula 532 glass provided by LITCO is reported in Table 8. One of the components in the glass was referred to as "alumina calcine," which we took to be pure $\mathrm{Al}_{2} \mathrm{O}_{3}$ both in Table 8 and in calculating normalized release rates. To the extent that other cations are present in the surrogate calcine, the normalized release for $\mathrm{Al}_{2} \mathrm{O}_{3}$ will increase and the release of other cations will decrease. 
(a)

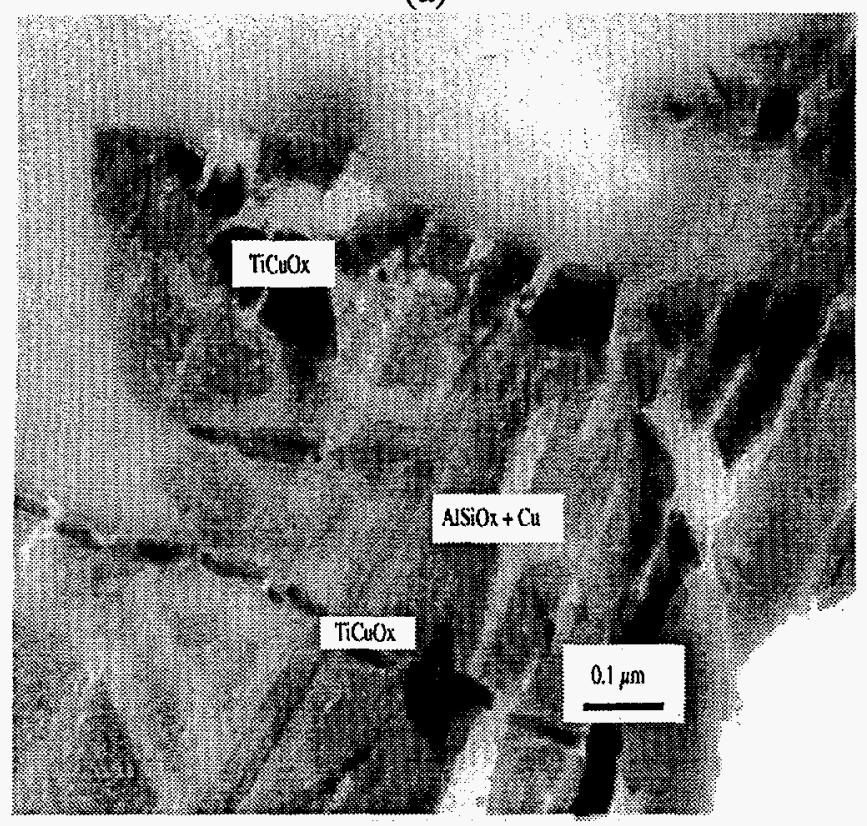

(b)

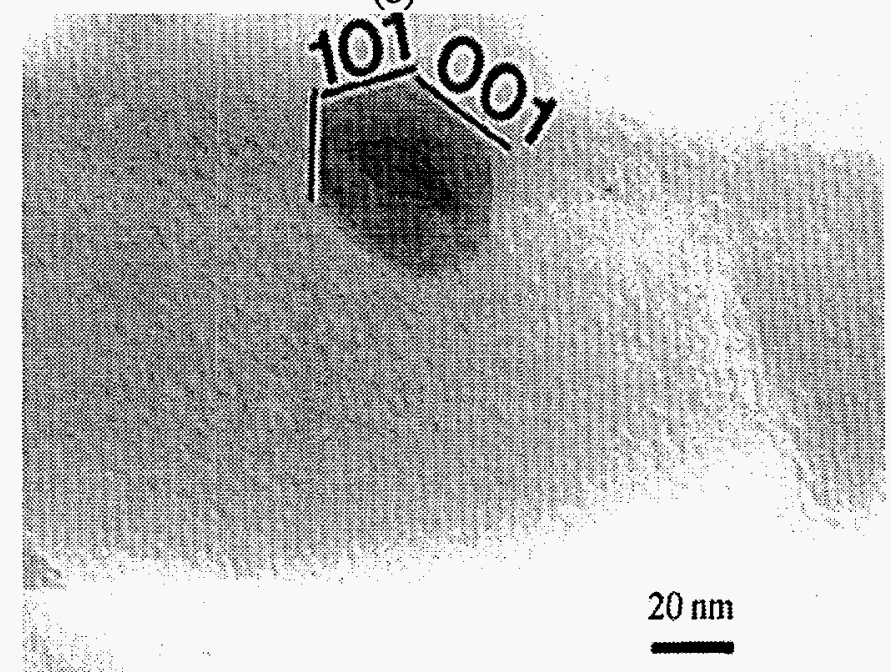

Fig. 10. Transmission Electron Micrograph of (a) Ti-Cu-O Phase and (b) $\mathrm{TiO}_{2}$, Present in Unreacted Formula 532 Glass.

Table 8. As-Batched Composition of Formula 532 Glass

Elements

\begin{tabular}{lrrrrrr}
\hline & & & & & & \\
\cline { 6 - 7 } \cline { 6 - 7 } Component & at\% & wt\% & & Component & mol\% & wt\% \\
\hline $\mathrm{Al}$ & 7.95 & 11.64 & & $\mathrm{Al}_{2} \mathrm{O}_{3}{ }^{2}$ & 13.7 & 6.1 \\
$\mathrm{~B}$ & 5.34 & 3.14 & & $\mathrm{~B}_{2} \mathrm{O}_{3}$ & 9.2 & 1.9 \\
$\mathrm{Cu}$ & 0.46 & 1.60 & & $\mathrm{CuO}$ & 1.6 & 1.8 \\
$\mathrm{Li}$ & 8.75 & 3.30 & & $\mathrm{Li}_{2} \mathrm{O}$ & 15.1 & 5.4 \\
$\mathrm{Na}$ & 4.22 & 5.27 & & $\mathrm{Na}_{2} \mathrm{O}$ & 7.3 & 4.3 \\
$\mathrm{Si}$ & 14.28 & 21.78 & & $\mathrm{SiO}_{2}$ & 49.2 & 54.2 \\
$\mathrm{Ti}$ & 1.18 & 3.06 & & $\mathrm{TiO}_{2}$ & 4.0 & 5.4 \\
$\mathrm{O}$ & 57.81 & 50.22 & & & & \\
\hline
\end{tabular}

"Assumes "alumina calcine" is pure $\mathrm{Al}_{2} \mathrm{O}_{3}$.

\section{Test Results}

1. Product Consistency Test Results

Solution $\mathrm{pH}$ and cation concentrations obtained from PCT solution analyses from the Formula 532 tests are shown in Table 9, and normalized mass losses for the cations are 
Table 9. Final $\mathrm{pH}$ and Solution Compositions (mg/L) Obtained from PCT-Bs Performed with Formula 532 Glass

\begin{tabular}{lccccccc}
\hline Test & W532-5 & W532-6 & W532-7 & W532-8 & W532-9 & W532-10 & W532-11 \\
Test Type & PCT-B & PCT-B & PCT-B & PCT-B & PCT-B & PCT-B & PCT-B \\
$\begin{array}{l}\text { Duration, } \\
\text { days }\end{array}$ & 7 & 30 & 49 & 182 & 49 & 98 & 182 \\
$\mathrm{~S} / \mathrm{N}, \mathrm{m}^{-1}$ & 2000 & 2000 & 2000 & 2000 & 20,000 & 20,000 & 20,000 \\
Final pH & 9.51 & 9.61 & 9.41 & 9.52 & 9.68 & 9.69 & 9.75 \\
Analysis & & & & & & & \\
Method & ICP-MS & ICP-MS & ICP-MS & ICP-MS & ICP-MS & ICP-AES & ICP-MS \\
\hline $\mathrm{Al}$ & 47 & 54 & 55 & 54 & 32 & 28 & 27 \\
$\mathrm{~B}$ & 83 & 84 & 92 & 149 & 817 & 1097 & 1213 \\
$\mathrm{Cu}$ & 1.7 & 2.4 & 2.7 & 3.6 & 0.1 & 0.2 & $(0.4)$ \\
$\mathrm{Li}$ & 45 & 53 & 57 & 76 & 440 & 580 & 487 \\
$\mathrm{Na}$ & 50 & 38 & 37 & 34 & 245 & 236 & 176 \\
$\mathrm{Si}$ & 81 & 96 & 88 & 93 & 52 & 73 & 43 \\
$\mathrm{Ti}$ & n.d. & n.d. & n.d. & 0.0 & n.d. & 0.1 & 3.5 \\
\hline
\end{tabular}

${ }^{a}$ n.d. $=$ not detected

shown in Table 10. Normalized mass losses for $\mathrm{Al}, \mathrm{B}, \mathrm{Ca}, \mathrm{Li}, \mathrm{Na}$, and $\mathrm{Si}$ obtained from tests conducted at $\mathrm{S} / \mathrm{V}=2000 \mathrm{~m}^{-1}$ are shown in Fig. 11 , and for tests conducted at $\mathrm{S} / \mathrm{V}$ of approximately $20,000 \mathrm{~m}^{-1}$ in Fig. 12 . The normalized release for B is the greatest of any element, followed by that for $\mathrm{Li}, \mathrm{Na}, \mathrm{Al}$, and $\mathrm{Si}$. The release for $\mathrm{Al}$ is much greater than that observed for other candidate waste glass compositions, such as Formula 127. The normalized release of Al, $\mathrm{B}, \mathrm{Ca}$, and $\mathrm{Li}$ increase s over time, but the normalized release of $\mathrm{Na}$ and $\mathrm{Si}$ decreases from the 30 $\mathrm{d}$ to the $49 \mathrm{~d}$ PCT-Bs conducted at $\mathrm{S} / \mathrm{V}=2000 \mathrm{~m}^{-1}$ and remains flat thereafter. The decline is probably due to the formation of a zeolite, as discussed below.

Table 10. Normalized Mass Losses $\left(\mathrm{g} / \mathrm{m}^{2}\right)$ Obtained from PCT-Bs Performed with Formula 532 Glasses

\begin{tabular}{lccccccc}
\hline Test & W532-5 & W532-6 & W532-7 & W532-8 & W532-9 & W532-10 & W532-11 \\
Test Type & PCT-B & PCT-B & PCT-B & PCT-B & PCT-B & PCT-B & PCT-B \\
$\begin{array}{l}\text { Duration, } \\
\text { days }\end{array}$ & 7 & 30 & 49 & 182 & 49 & 98 & 182 \\
$\mathrm{~S} / \mathrm{N}, \mathrm{m}^{-1}$ & 2000 & 2000 & 2000 & 2000 & 20,000 & 20,000 & 20,000 \\
Final pH & 9.51 & 9.61 & 9.41 & 9.52 & 9.68 & 9.69 & 9.75 \\
\hline $\mathrm{Al}$ & 0.20 & 0.23 & 0.24 & 0.23 & 0.014 & 0.012 & 0.011 \\
$\mathrm{~B}$ & 1.32 & 1.34 & 1.47 & 2.37 & 1.30 & 1.75 & 1.93 \\
$\mathrm{Cu}$ & 0.055 & 0.076 & 0.085 & 0.113 & 0.000 & 0.001 & $(0.001)$ \\
$\mathrm{Li}$ & 0.68 & 0.80 & 0.86 & 1.15 & 0.67 & 0.88 & 0.74 \\
$\mathrm{Na}$ & 0.47 & 0.37 & 0.35 & 0.32 & 0.23 & 0.22 & 0.17 \\
$\mathrm{Si}$ & 0.19 & 0.22 & 0.20 & 0.21 & 0.012 & 0.017 & 0.010 \\
$\mathrm{Ti}$ & n.d. $^{\text {a }}$ & n.d. & n.d. & 3E-04 & n.d. & $6 \mathrm{E}-03$ & 0.006 \\
\hline
\end{tabular}

${ }^{a}$ n.d. $=$ not detected. 


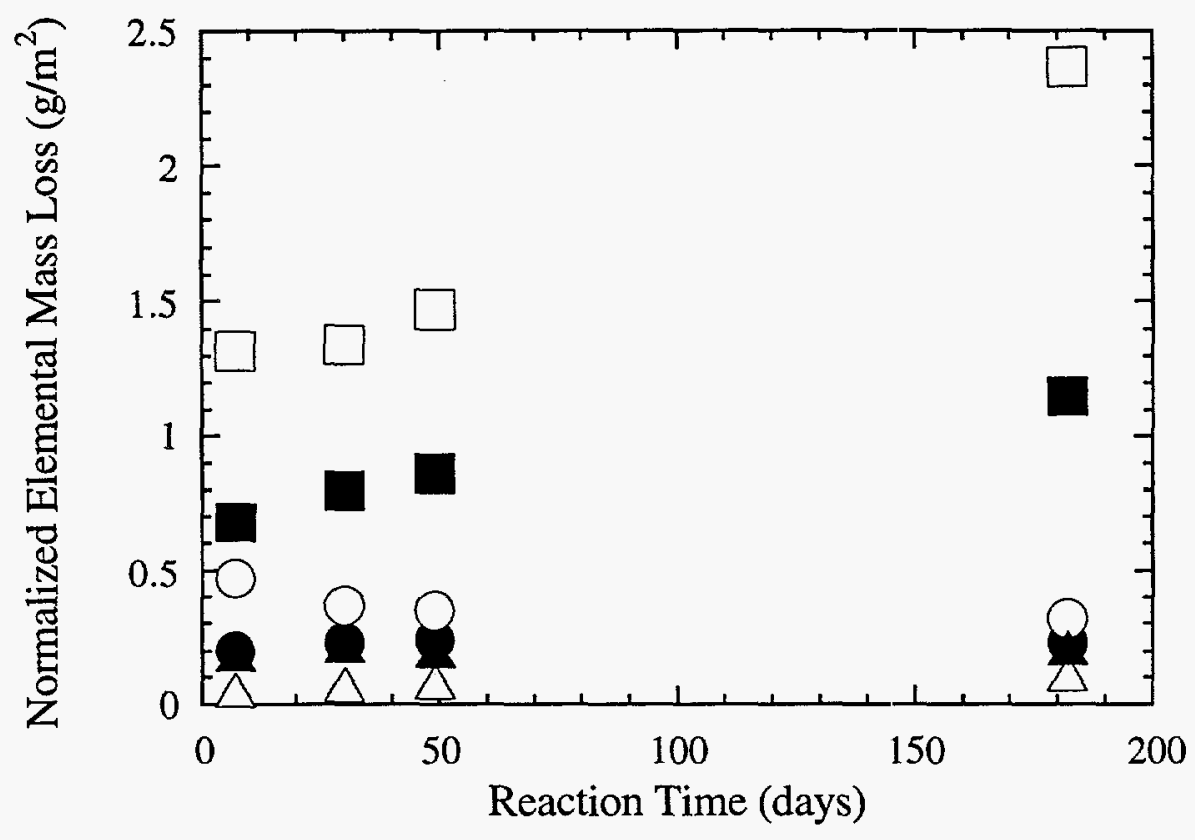

Fig. 11. Normalized Mass Losses in PCT-Bs of Formula 532 Glass at $\mathrm{S} / \mathrm{V}=2000 \mathrm{~m}^{-1}:(\mathbf{A}) \mathrm{Al}$, ( $\square) \mathrm{B},(\Delta) \mathrm{Ca},(\mathbf{a}) \mathrm{Li},(\mathrm{O}) \mathrm{Na}$, and (A) $\mathrm{Si}$

In $30 \mathrm{~d}$ PCT-Bs at $2000 \mathrm{~m}^{-1}$, the reaction resulted in the formation of a crystalline alteration phase that is a cubic $\mathrm{Na}-\mathrm{Al}-\mathrm{Si}$ phase with a $\mathrm{Na}$ :Al atomic ratio of $1: 1$, tentatively identified as the zeolite analcime. Very small crystals were also found with a Ti:Al atomic ratio of $1: 2$, probably $\mathrm{TiAl}_{2} \mathrm{O}_{5}$. Once the zeolite appears, the concentrations of $\mathrm{Na}, \mathrm{Al}$, and $\mathrm{Si}$ in solution fall to very low, relatively constant values. The solution $\mathrm{pH}$ likewise shows little variation with time after the formation of the zeolite. However, the actual mass of glass that has reacted with solution, as indicated by $\mathrm{Li}$ and $\mathrm{B}$ normalized release, clearly increases over time. The aluminosilicate phase was present in all test samples recovered from $20,000 \mathrm{~m}^{-1}$ tests, and the strong linearity of the data for all elements in $20,000 \mathrm{~m}^{-1}$ test solutions shows that this phase exerts a controlling influence on the rate of glass corrosion in these tests as well.

These results indicate that after a very short time, Formula 532 glass begins to react with water at the Stage III rate, the rate of glass corrosion in the presence of crystalline corrosion products. The Stage III rates obtained in $2000 \mathrm{~m}^{-1}$ and $20,000 \mathrm{~m}^{-1}$ PCT-Bs are both approximately $0.007 \mathrm{~g} /\left(\mathrm{m}^{2} \cdot \mathrm{d}\right)$.

\section{Vapor Hydration Test Results}

A detailed discussion of the VHT results for Formula 532 was presented in a previous report [ELLISON-1995]. In summary, the first alteration phase to form has an X-ray energy dispersive spectroscopy (EDS) spectrum showing $\mathrm{Al}, \mathrm{Si}$, and $\mathrm{O}$, but it likely contains $\mathrm{Li}$ as well. This phase nucleates as small trapezoidal crystals but quickly grows into spherulitic "bunches" (Fig. 13). By $28 \mathrm{~d}$, the bunches completely cover the surface of the monolith. A NaAl-Si phase also forms (Fig. 13) and grows into relatively large (1-2 mm) crystals. This crystal was identified as analcime with X-ray diffraction. Where the altered glass is visible beneath these alteration phases, it is covered with a mat of clay. After $49 \mathrm{~d}$, the reacted glass shows alternating layers of the $\mathrm{Li}-\mathrm{Al}-\mathrm{Si}-\mathrm{O}$ phase and a comparatively Na-rich, partially crystalline layer. After $56 \mathrm{~d}$, no unaltered glass remains. 
The formation of aluminosilicate minerals has a substantial impact on the rate of corrosion of Formula 532 glass. Comparison of Fig. 12 with Fig. 5 shows that after $182 \mathrm{~d}$ at $20,000 \mathrm{~m}^{-1}$, the mass of Formula 532 glass that has reacted with water is approximately six times greater than the mass of Formula 127 glass that has reacted with water. This comparatively high rate of reaction is driven by the presence of the zeolite alteration phases. Once these phases form in VHTs, the rate of glass corrosion greatly increases.

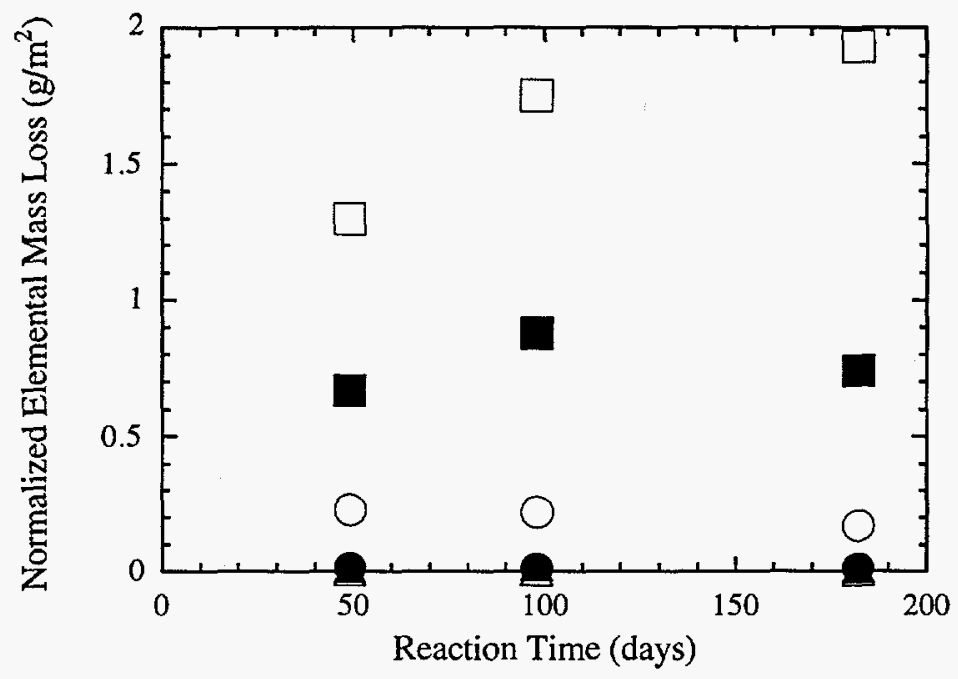

Fig. 12. Normalized Mass Losses in PCT-Bs of Formula 532 Glass at $\mathrm{S} / \mathrm{V}=20,000 \mathrm{~m}^{-1}$ : (•) $\mathrm{Al},(\square) \mathrm{B},(\Delta) \mathrm{Ca},(\mathbf{\square}) \mathrm{Li},(\mathrm{O}) \mathrm{Na}$, and $(\boldsymbol{\Delta}) \mathrm{Si}$

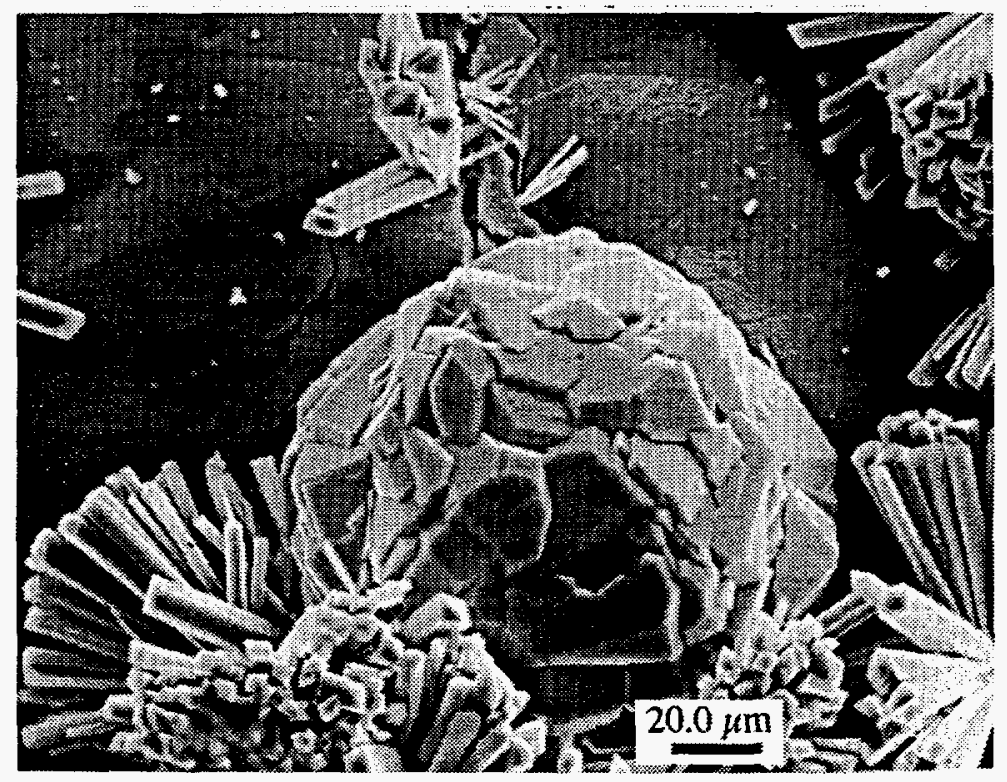

Fig. 13. Electron Photomicrographs of Alteration Phases Formed during VHT of Formula 532 Glass. The spherical phase is analcine and the columnar phase is a Li-bearing zeolite. 


\section{RESULTS: 630 SERIES GLASSES}

\section{A. Test Matrix}

The PCT-B and VHT matrices employed to evaluate the corrosion behavior of the original 630 series glasses $630.6 \mathrm{~L}, 630.6 \mathrm{LM}, 631.6 \mathrm{~L}$, and $631.6 \mathrm{LM}$ are shown in Tables 11 and 12. The PCT-B matrix includes $2000 \mathrm{~m}^{-1}$ tests conducted for periods of 7,30 , and $70 \mathrm{~d}$ and $20,000 \mathrm{~m}^{-1}$ tests conducted for periods of 28,98 , and $183 \mathrm{~d}$. These tests were conducted in deionized water contained within Teflon reaction vessels. Duplicate tests were performed for all glasses at $\mathrm{S} / \mathrm{V}$ of $2000 \mathrm{~m}^{-1}$ for test durations of $70 \mathrm{~d}$. For the two mixed-alkali (LM) glasses, duplicate $20,000 \mathrm{~m}^{-1}$ PCT-Bs also were performed for test durations of 28 and $183 \mathrm{~d}$. The duplicate 28-d tests with these glasses were done in steel vessels to determine what effect vessel material has on the experimentally determined rate of glass corrosion. In addition, these two glasses, 630.6LM and 631.6LM, were subjected to $20,000 \mathrm{~m}^{-1}$ PCT-Bs lasting $56 \mathrm{~d}$. For the sodium-only glasses (L), duplicate tests lasting $98 \mathrm{~d}$ were done at $20,000 \mathrm{~m}^{-1}$. The VHTs (Table 12) were conducted for periods of $7,14,28$, and $56 \mathrm{~d}$ at $200^{\circ} \mathrm{C}$. Two $56 \mathrm{~d}$ VHTs were performed with monoliths of glasses $630.6 \mathrm{LM}$ and $631.6 \mathrm{LM}$ at a temperature of $150^{\circ} \mathrm{C}$. Finally, a suite of tests was performed with glasses formulated with a revised calcine composition. The test matrix used in these tests is shown in Table 13. This matrix was designed with test conditions matching those used in tests with the original calcine composition to directly measure the effect of the different calcines.

\section{B. Sample Characteristics}

The 630 series glasses were received from LITCO in the alumina crucibles in which they were formed. The glasses were easily removed, indicating that the melts did not strongly wet the crucibles. The boules extracted from the crucibles were cut along the major axis (top to bottom), and a $2-\mathrm{mm}$ thick slab was retained for archival purposes. The cross sections showed that there was substantial compositional heterogeneity in all of the 630 series glasses. The material near the bottom of the boules included an abundance of crystalline material, while a thin layer of clear, crystal-free glass formed the top surface of the boules of most of the 630 series glasses. Crystals were oriented in the center of the boules, parallel to the major axis, along flow patterns consistent with convective flow. The convection cells were clearly established before the glass solidified, indicating they were present when the glass was in the furnace and were not produced while the glasses were annealed.

As with Formula 127, the dominant crystal phase in all the 630 series glasses is calcium fluoride, $\mathrm{CaF}_{2}$ (fluorite). The mixed-alkali compositions 630.6LM and 630R.6LM also contained an alkali aluminosilicate phase. On the basis of a comparison of the EDS spectrum of this crystal with that of the crystalline phase found in Formula 532, we believe the aluminosilicate phase is the lithium aluminosilicate virgilite, $\mathrm{LiAISi}_{3} \mathrm{O}_{8}$. These crystals were euhedral and equant, with equilibrium crystal faces. This morphology contrasts with that of fluorite crystals found in Formula 127 glass, which showed the skeletal and spherulitic morphology of quench crystals. This observation is taken to mean that the fluorite and virgilite crystals in the 630 series glasses formed in the melts rather than during quenching. This conclusion is consistent with the convection cells observed in cross sections of the boules recovered from the crucibles, as discussed above. In addition, several of the 630 series glasses contained regions that appeared to be "anomalously" enriched in cadmium relative to other regions in the same glasses. These regions may contain very small crystals of cadmium oxide or another cadmium-rich phase, although discrete crystals of $\mathrm{CdO}$ or any other cadmium phase were found. 
Table 11. Matrix of PCT-Bs Used to Evaluate the Original 630 Series Glasses $^{\mathrm{a}}$

\begin{tabular}{llcrr}
\hline Test Number & Glass & $\mathrm{T},{ }^{\circ} \mathrm{C}$ & Duration, days & $\mathrm{S} / \mathrm{V}, \mathrm{m}^{-1}$ \\
\hline P30-1 & $630.6 \mathrm{~L}$ & 90 & 7 & 2000 \\
P30-2 & $630.6 \mathrm{~L}$ & 90 & 30 & 2000 \\
P30-3 & $630.6 \mathrm{~L}$ & 90 & 70 & 2000 \\
P30-4 & $630.6 \mathrm{~L}$ & 90 & 70 & 2000 \\
P30-5 & $630.6 \mathrm{~L}$ & 90 & 28 & 20,000 \\
P30-6 & $630.6 \mathrm{~L}$ & 90 & 98 & 20,000 \\
P30-7 & $630.6 \mathrm{~L}$ & 90 & 98 & 20,000 \\
P30-8 & $630.6 \mathrm{~L}$ & 90 & 183 & 20,000 \\
\hline P30M-1 & $630.6 \mathrm{LM}$ & 90 & 7 & 2000 \\
P30M-2 & $630.6 \mathrm{LM}$ & 90 & 30 & 2000 \\
P30M-3 & $630.6 \mathrm{LM}$ & 90 & 70 & 2000 \\
P30M-4 & $630.6 \mathrm{LM}$ & 90 & 70 & 2000 \\
P30M-5 & $630.6 \mathrm{LM}$ & 90 & 28 & 20,000 \\
P30M-6 & $630.6 \mathrm{LM}$ & 90 & 28 & $20,000^{\mathrm{b}}$ \\
P30M-7 & $630.6 \mathrm{LM}$ & 90 & 56 & 20,000 \\
P30M-8 & $630.6 \mathrm{LM}$ & 90 & 98 & 20,000 \\
P30M-9 & $630.6 \mathrm{LM}$ & 90 & 98 & 20,000 \\
P30M-10 & $630.6 \mathrm{LM}$ & 90 & 183 & 20,000 \\
P30M-11 & $630.6 \mathrm{LM}$ & 90 & 183 & 20,000 \\
\hline P31-1 & $631.6 \mathrm{~L}$ & 90 & 7 & 2000 \\
P31-2 & $631.6 \mathrm{~L}$ & 90 & 30 & 2000 \\
P31-3 & $631.6 \mathrm{~L}$ & 90 & 70 & 2000 \\
P31-4 & $631.6 \mathrm{~L}$ & 90 & 70 & 2000 \\
P31-5 & $631.6 \mathrm{~L}$ & 90 & 28 & 20,000 \\
P31-6 & $631.6 \mathrm{~L}$ & 90 & 98 & 20,000 \\
P31-7 & $631.6 \mathrm{~L}$ & 90 & 98 & 20,000 \\
P31-8 & $631.6 \mathrm{~L}$ & 90 & 183 & 20,000 \\
P31-9 & $631.6 \mathrm{~L}$ & 90 & 7 & 2000 \\
P31-10 & $631.6 \mathrm{~L}$ & 90 & 30 & 2000 \\
P31-11 & $631.6 \mathrm{~L}$ & 90 & 70 & 2000 \\
P31-12 & $631.6 \mathrm{~L}$ & 90 & 70 & 2000 \\
P31-13 & $631.6 \mathrm{~L}$ & 90 & 28 & 20,000 \\
\hline P31M-1 & $631.6 \mathrm{LM}$ & 90 & 7 & 2000 \\
P31M-2 & $631.6 \mathrm{LM}$ & 90 & 30 & 2000 \\
P31M-3 & $631.6 \mathrm{LM}$ & 90 & 70 & 20000 \\
P31M-4 & $631.6 \mathrm{LM}$ & 90 & 70 & 20,000 \\
P31M-5 & $631.6 \mathrm{LM}$ & 90 & 28 & $20,000^{\mathrm{b}}$ \\
P31M-6 & $631.6 \mathrm{LM}$ & 90 & 56 & 20,000 \\
P31M-7 & $631.6 \mathrm{LM}$ & 90 & 98 & 20,000 \\
P31M-8 & $631.6 \mathrm{LM}$ & 90 & 183 & 20,000 \\
P31M-9 & $631.6 \mathrm{LM}$ & 90 & 183 & 20,000 \\
P31M-10 & $631.6 \mathrm{LM}$ & 90 & & \\
P31M-11 & $631.6 \mathrm{LM}$ & 90 & & \\
\hline Tests c0 & & 98 & \\
\hline
\end{tabular}

${ }^{a}$ Tests conducted in Teflon reaction vessels except where noted.

${ }^{b}$ Test conducted in steel reaction vessel. 
Table 12. Matrix of VHTs Used to Evaluate the Original 630 Series Glasses $^{\mathrm{a}}$

\begin{tabular}{llccc}
\hline Test Number & Glass & $\mathrm{T},{ }^{\circ} \mathrm{C}$ & Duration, days & $\mathrm{S} / \mathrm{V}, \mathrm{m}^{-1}$ \\
\hline V30-1 & $630.6 \mathrm{~L}$ & 200 & 7 & n.a. \\
V30-2 & $630.6 \mathrm{~L}$ & 200 & 14 & n.a. \\
V30-3 & $630.6 \mathrm{~L}$ & 200 & 28 & n.a. \\
V30-4 & $630.6 \mathrm{~L}$ & 200 & 56 & n.a. \\
\hline V30M-1 & $630.6 \mathrm{LM}$ & 200 & 7 & n.a. \\
V30M-2 & $630.6 \mathrm{LM}$ & 200 & 14 & n.a. \\
V30M-3 & $630.6 \mathrm{LM}$ & 200 & 28 & n.a. \\
V30M-4 & $630.6 \mathrm{LM}$ & 200 & 56 & n.a. \\
V30M-5 & $630.6 \mathrm{LM}$ & 200 & 56 & n.a. \\
\hline V31-1 & $631.6 \mathrm{~L}$ & 200 & 7 & n.a. \\
V31-2 & $631.6 \mathrm{~L}$ & 200 & 14 & n.a. \\
V31-3 & $631.6 \mathrm{~L}$ & 200 & 28 & n.a. \\
V31-4 & $631.6 \mathrm{~L}$ & 200 & 56 & n.a. \\
\hline V31M-1 & $631.6 \mathrm{LM}$ & 200 & 7 & n.a. \\
V31M-2 & $631.6 \mathrm{LM}$ & 200 & 14 & n.a. \\
V31M-3 & $631.6 \mathrm{LM}$ & 200 & 28 & n.a. \\
V31M-4 & $631.6 \mathrm{LM}$ & 200 & 56 & n.a. \\
V31M-5 & $631.6 \mathrm{LM}$ & 200 & 56 & n.a. \\
\hline
\end{tabular}

${ }^{\mathrm{a}}$ All tests conducted in a steel reaction vessel.

${ }^{\mathrm{b}}$ n.a. $=$ not applicable.

Table 13. Test Matrix for Revised 630 Series Glasses

\begin{tabular}{llcrccc}
\hline Test Number & Glass & Procedure & $\mathrm{T},{ }^{\circ} \mathrm{C}$ & $\begin{array}{c}\text { Duration, } \\
\text { days }\end{array}$ & $\mathrm{S} / \mathrm{V}, \mathrm{m}^{-1}$ & $\begin{array}{c}\text { Vessel } \\
\text { Material }\end{array}$ \\
\hline P30R-1 & 630R.6L & PCT-B & 90 & 7 & 2000 & Teflon \\
P30R-2 & 630R.6L & PCT-B & 90 & 28 & 20,000 & Teflon \\
P30R-3 & 630R.6L & PCT-B & 90 & 98 & 20,000 & Teflon \\
\hline P30MR-1 & 630R.6LM & PCT-B & 90 & 7 & 2000 & Teflon \\
P30MR-2 & 630R.6LM & PCT-B & 90 & 28 & 20,000 & Teflon \\
P30MR-3 & 630R.6LM & PCT-B & 90 & 98 & 20,000 & Teflon \\
\hline P31R-1 & 631R.6L & PCT-B & 90 & 7 & 2000 & Teflon \\
P31R-2 & 631R.6L & PCT-B & 90 & 28 & 20,000 & Teflon \\
P31R-3 & 631R.6L & PCT-B & 90 & 98 & 20,000 & Teflon \\
\hline P31MR-1 & 631R.6LM & PCT-B & 90 & 7 & 2000 & Teflon \\
P31MR-2 & 631R.6LM & PCT-B & 90 & 28 & 20,000 & Teflon \\
P31MR-3 & 631R.6LM & PCT-B & 90 & 98 & 20,000 & Teflon \\
\hline & & & & & & \\
V30R-1 & 630R.6L & VHT & 200 & 28 & n.a. & Steel \\
V30R-2 & 630R.6L & VHT & 200 & 56 & n.a. & Steel \\
\hline V30MR-1 & 630R.6LM & VHT & 200 & 28 & n.a. & Steel \\
V30MR-2 & 630R.6LM & VHT & 200 & 56 & n.a. & Steel \\
\hline V31R-1 & 631R.6L & VHT & 200 & 28 & n.a. & Steel \\
V31R-2 & 631R.6L & VHT & 200 & 56 & n.a. & Steel \\
\hline V31MR-1 & 631R.6LM & VHT & 200 & 28 & n.a. & Steel \\
V31MR-2 & 631R.6LM & VHT & 200 & 56 & n.a. & Steel \\
\hline
\end{tabular}

\footnotetext{
${ }^{a}$ n.a. = not applicable.
} 
A small amount of each glass was dissolved in mineral acids and analyzed with ICPAES. The as-batched and measured compositions are presented in Tables 14 and 15 for glasses formulated using the original and revised calcine compositions, respectively. The measured cation totals are consistently lower than expected from the as-batched estimate. This may be due to the formation of precipitates in the glass and the resulting inhomogeneity. If segregation of $\mathrm{CaF}_{2}$ were responsible for the low cation totals in the 630 series glasses, then the measured cation sums should be greater than the as-batched values, rather than less. An alternative possibility is that the decomposition of carbonates used to make the glasses was incomplete in the presence of high concentrations of fluoride ions. 
Table 14. As-Batched and Measured Compositions (Mass \%) of the Original 630 Series Glasses

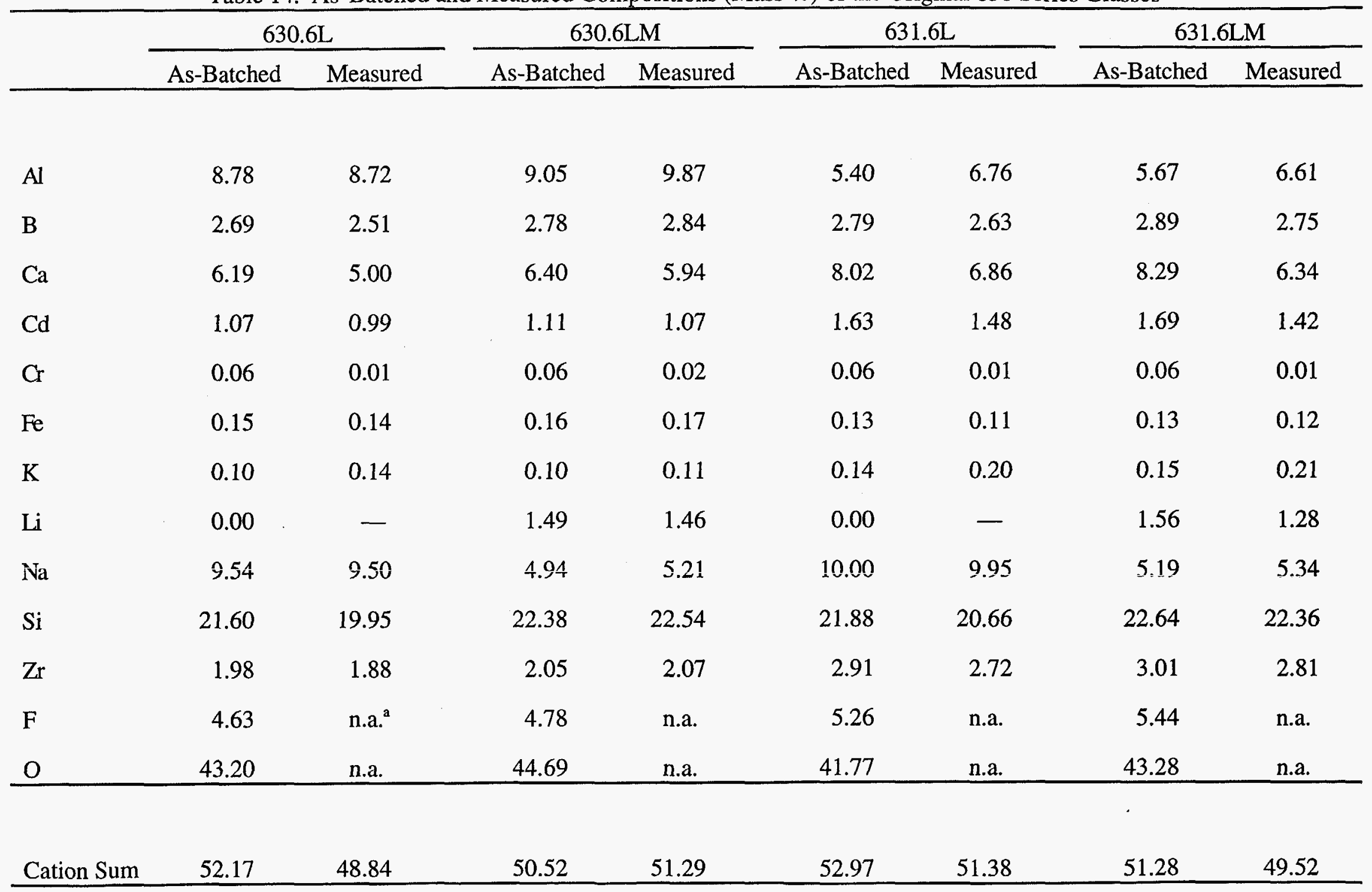

an.a. = not analyzed. 
Table 15. As-Batched and Measured Compositions (Mass \%) of the Revised 630 Series Glasses

\begin{tabular}{|c|c|c|c|c|c|c|c|c|}
\hline & \multicolumn{2}{|c|}{$630.6 \mathrm{~L}$} & \multicolumn{2}{|c|}{ 630.6LM } & \multicolumn{2}{|c|}{$631.6 \mathrm{~L}$} & \multicolumn{2}{|c|}{$631.6 \mathrm{LM}$} \\
\hline & As-Batched & Measured & As-Batched & Measured & As-Batched & Measured & As-Batched & Measured \\
\hline $\mathrm{Al}$ & 8.65 & 7.16 & 8.91 & 9.72 & 5.32 & 6.56 & 5.58 & 7.13 \\
\hline $\mathrm{B}$ & 2.65 & 2.34 & 2.74 & 2.63 & 2.75 & 2.47 & 2.84 & 2.57 \\
\hline $\mathrm{Ca}$ & 6.10 & 3.35 & 6.30 & 5.21 & 7.90 & 6.38 & 8.17 & 6.71 \\
\hline $\mathrm{Cd}$ & 1.05 & 0.81 & 1.09 & 0.89 & 1.61 & 1.43 & 1.66 & 1.43 \\
\hline $\mathrm{Cr}$ & 0.06 & 0.01 & 0.06 & 0.02 & 0.06 & 0.02 & 0.06 & 0.02 \\
\hline $\mathrm{Fe}$ & 0.15 & 0.14 & 0.16 & 0.16 & 0.12 & 0.13 & 0.13 & 0.16 \\
\hline $\mathrm{K}$ & 0.10 & 0.18 & 0.10 & 0.21 & 0.14 & 0.23 & 0.14 & 0.29 \\
\hline $\mathrm{Li}$ & - & - & 1.46 & 1.35 & - & - & 1.54 & 1.44 \\
\hline $\mathrm{Mg}$ & 0.30 & 0.45 & 0.30 & 0.54 & 0.30 & 0.55 & 0.30 & 0.61 \\
\hline $\mathrm{Na}$ & 9.39 & 8.14 & 4.86 & 5.01 & 9.85 & 9.62 & 5.12 & 5.24 \\
\hline $\mathrm{Pb}$ & 0.47 & 0.13 & 0.47 & 0.16 & 0.46 & 0.15 & 0.47 & 0.17 \\
\hline $\mathrm{Si}$ & 21.28 & 18.78 & 22.05 & 21.81 & 21.55 & 20.52 & 22.30 & 21.10 \\
\hline $\mathrm{Sn}$ & 0.39 & 0.06 & 0.40 & 0.07 & 0.39 & 0.08 & 0.40 & 0.10 \\
\hline $\mathrm{Zr}$ & 1.95 & 1.61 & 2.02 & 1.93 & 2.87 & 2.69 & 2.96 & 2.74 \\
\hline $\mathrm{F}$ & 4.56 & n.a. ${ }^{a}$ & 4.71 & n.a & 5.18 & n.a. & 5.36 & n.a. \\
\hline $\mathrm{O}$ & 42.89 & n.a. & 44.36 & n.a. & 41.48 & n.a. & 42.97 & n.a. \\
\hline Cation Sum & 52.55 & 43.17 & 50.93 & 49.73 & 53.34 & 50.84 & 51.67 & 49.71 \\
\hline
\end{tabular}

${ }^{\mathrm{a}}$ n.a. $=$ not analyzed. 
Two dissolutions of the revised calcine glass 630R.6L yielded solutions with substantially different compositions and cation sums much lower than the as-batched values. We used the as-batched composition for the release calculations for this glass. For all other glass compositions, the measured concentrations of cations were used to compute normalized release.

The distribution of primary crystalline phases is very heterogeneous on all length scales, from tens of micrometers to centimeters. Therefore, it is not possible to obtain an accurate estimate of the fraction of the glasses that is crystalline. It is clear, however, that the degree of crystallinity in the original 630 series glasses is different from that in the series based on the revised calcine: in particular, the glass $631.6 \mathrm{LM}$ contains a substantially higher fraction of crystalline material than 631R.6LM. Since the compositions of crystals are different from those of the bulk glass, crystal formation changes the composition of the bulk glass. These differences complicate any comparison of the behaviors of the glasses based on the original and revised surrogate calcine compositions.

\section{Test Results}

Testing of the original 630 series glasses commenced in April 1995. Testing of the revised calcine 630 series glasses started in June 1995. All PCT-Bs listed in Table 11 were terminated in September 1995. The longest tests performed with the original calcine glasses were $183 \mathrm{~d}$ in duration. The longest PCT-Bs performed with the revised calcine glasses were $98 \mathrm{~d}$ (Table 13). The ANL VHTs were run for 7, 14, 28, and $56 \mathrm{~d}$ with the original calcine glasses (Table 12), and 28 and $56 \mathrm{~d}$ with the revised calcine glasses (Table 13). No MCC-1 tests were performed with these glasses.

\section{Product Consistency Test Results}

Solution $\mathrm{pH}$ and cation concentrations obtained from $2000 \mathrm{~m}^{-1}$ PCT solution analyses are shown in Table 16, and normalized mass losses for the cations are shown in Table 17. Solution $\mathrm{pH}$ and cation concentrations obtained from $20,000 \mathrm{~m}^{-1}$ PCT solution analyses are shown in Table 18, and normalized mass losses for the cations are shown in Table 19. Solution $\mathrm{pH}$ and cation concentrations obtained from PCT-Bs of the revised calcine glasses are shown in Table 20, and normalized mass losses for the cations are shown in Table 21 . Normalized mass losses were obtained by using the measured compositions of the glass (Tables 14 and 15) for all glasses except 630R.6L, as noted above. The as-batched composition was used for 630R.6L. In using this approach, the heterogeneity of the glass is not taken into account during the normalization calculation.

Normalized mass losses of $\mathrm{Al}, \mathrm{B}, \mathrm{Li}, \mathrm{Na}$, and $\mathrm{Si}$ for the original 630 series glasses obtained in $2000 \mathrm{~m}^{-1}$ PCT-Bs are compared with those obtained for Formula 127 in Fig. 14. Normalized mass losses of $\mathrm{Al}, \mathrm{B}, \mathrm{Li}, \mathrm{Na}$, and $\mathrm{Si}$ for the original 630 series glasses obtained in $20,000 \mathrm{~m}^{-1}$ PCT-Bs are compared with those obtained for Formula 127 glass in Fig. 15. These data can be compared to determine the relative reactivities of Formula 127 glass and the 630 series glasses, the L and LM glasses, and the glasses made with the 630 and 631 calcines. The reactivities of the different glasses are compared based on the values of NL(B), NL(Li), NL(Na), and NL(Si). These are all higher in tests with Formula 127 glass than with any of the 630 series glasses, which means that Formula 127 glass is more reactive than any of the 630 glasses. The $\mathrm{NL}(\mathrm{Al})$ values of the 127 glass are lower than the NL(Al) values of the 630 glasses. The NL(Al) values are not reliable indicators of the extent of reaction because of the low solubility of $\mathrm{Al}$ and the formation of alteration phases. 
Table 16. Final $\mathrm{pH}$ and Solution Compositions (mg/L) from $2000 \mathrm{~m}^{-1}$ PCT-Bs Performed with the Original 630 Series Glasses (values in parentheses represent detection limits)

\begin{tabular}{|c|c|c|c|c|c|c|c|c|c|c|}
\hline Test & P30-1 & P30M-1 & P31-1 & P31-9 & P31M-1 & $\mathrm{P} 30-2$ & P30M-2 & P31-2 & P31-10 & P31M-2 \\
\hline $\begin{array}{l}\text { Duration, } \\
\text { days }\end{array}$ & 7 & 7 & 7 & 7 & 7 & 30 & 30 & 30 & 30 & 30 \\
\hline $\mathrm{S} / \mathrm{V}, \mathrm{m}^{-1}$ & 2128 & 2103 & 1998 & 2016 & 2047 & 2130 & 2105 & 2012 & 2016 & 2048 \\
\hline B & 4.2 & 2.4 & 5.8 & 5.1 & 6.2 & 3.5 & 2.4 & 5.2 & 4.8 & 9.8 \\
\hline $\mathrm{Ca}$ & 4.3 & 4.0 & 3.4 & 3.4 & 2.8 & 3.6 & 3.9 & 3.5 & 4.0 & 4.1 \\
\hline $\mathrm{Cd}$ & 0.025 & 0.014 & 0.028 & 0.018 & 0.016 & 0.018 & 0.013 & 0.015 & 0.021 & 0.023 \\
\hline K & 0.52 & $(0.40)$ & $(0.43)$ & $(0.36)$ & $(0.010)$ & 0.37 & 0.55 & 0.57 & 0.80 & 0.70 \\
\hline Li & 0.13 & 4.4 & $(0.075)$ & $(0.062)$ & 5.8 & 0.0 & 7.8 & 0.0 & 0.0 & 9.7 \\
\hline $\mathrm{Na}$ & 22 & 1.2 & 25 & 23 & 2.3 & 31 & 3.7 & 39 & 41 & 4.2 \\
\hline $\mathrm{Si}$ & 10 & 11 & 11 & 9.7 & 12 & 12 & 13 & 14 & 12 & 14 \\
\hline $\mathrm{Zr}$ & $(0.095)$ & $(0.10)$ & $(0.11)$ & $(0.089)$ & $(0.010)$ & $(0.020)$ & $(0.022)$ & $(0.021)$ & $(0.019)$ & 0.013 \\
\hline
\end{tabular}


Table 16 (contd.)

\begin{tabular}{lcccccccc}
\hline Test & P30-3 & P30-4 & P30M-3 & P30M-4 & P31-3 & P31-4 & P31-11 & P31-12 \\
Glass & $630.6 \mathrm{~L}$ & $630.6 \mathrm{~L}$ & $630.6 \mathrm{LM}$ & $630.6 \mathrm{LM}$ & $631.6 \mathrm{~L}$ & $631.6 \mathrm{~L}$ & $631.6 \mathrm{~L}$ & $631.6 \mathrm{~L}$ \\
$\begin{array}{l}\text { Duration, } \\
\text { days }\end{array}$ & 70 & 70 & 70 & 70 & 70 & 70 & 70 & 70 \\
$\mathrm{~S} / \mathrm{V}, \mathrm{m}^{-1}$ & 2166 & 2126 & 2137 & 2103 & 1654 & 2016 & 2050 & 2016 \\
Final pH & 7.93 & 8.36 & 8.12 & 7.9 & 8.59 & 8.13 & 8.51 & 8.34 \\
\hline $\mathrm{Al}$ & 8.8 & 10 & 7.2 & 7.4 & 8.6 & 7.5 & 9.1 & 8.3 \\
$\mathrm{~B}$ & 4.4 & 5.4 & 3.0 & 3.1 & 7.0 & 7.1 & 7.1 & 6.5 \\
$\mathrm{Ca}$ & 3.3 & 3.5 & 3.1 & 3.5 & 2.1 & 3.8 & 3.3 & 3.8 \\
$\mathrm{Cd}$ & 0.026 & 0.026 & 0.016 & 0.016 & 0.020 & 0.031 & 0.027 & 0.030 \\
$\mathrm{Cr}$ & $(0.035)$ & $(0.037)$ & $(0.040)$ & $(0.039)$ & $(0.033)$ & $(0.039)$ & $(0.038)$ & $(0.034)$ \\
$\mathrm{Fe}$ & $(0.17)$ & $(0.19)$ & $(0.20)$ & $(0.20)$ & $(0.16)$ & $(0.20)$ & $(0.19)$ & $(0.17)$ \\
$\mathrm{K}$ & 0.81 & 0.80 & 0.91 & 1.4 & 1.4 & 1.6 & 0.85 & 1.2 \\
$\mathrm{Li}$ & $(0.060)$ & $(0.065)$ & 6.9 & 7.2 & $(0.57)$ & $(0.068)$ & $(0.067)$ & $(0.059)$ \\
$\mathrm{Na}$ & 38 & 33 & $(0.99)$ & $(0.98)$ & 100 & 48 & 4.0 & 38 \\
$\mathrm{Si}$ & 11 & 11 & 13 & 13 & 12 & 12 & 13 & 12 \\
$\mathrm{Zr}$ & $(0.086)$ & $(0.093)$ & $(0.099)$ & $(0.098)$ & $(0.081)$ & $(0.098)$ & $(0.096)$ & $(0.084)$ \\
\hline
\end{tabular}


Table 17. Normalized Mass Losses $\left(\mathrm{g} / \mathrm{m}^{2}\right.$ ) from $2000 \mathrm{~m}^{-1}$ PCT-Bs Performed with the Original 630 Series Glasses (values in parentheses represent detection limits)

\begin{tabular}{|c|c|c|c|c|c|c|c|c|c|c|}
\hline Test & P30-1 & P30M-1 & P31-1 & P31-9 & P31M-1 & P30-2 & P30M-2 & P31-2 & P31-10 & P31M-2 \\
\hline $\mathrm{S} / \mathrm{V}, \mathrm{m}^{-1}$ & 2128 & 2103 & 1998 & 2016 & 2047 & 2130 & 2105 & 2012 & 2016 & 2048 \\
\hline B & 0.079 & 0.040 & 0.11 & 0.096 & 0.11 & 0.066 & 0.040 & 0.098 & 0.091 & 0.17 \\
\hline $\mathrm{Ca}$ & 0.040 & 0.032 & 0.025 & 0.024 & 0.022 & 0.034 & 0.031 & 0.025 & 0.029 & 0.032 \\
\hline $\mathrm{Cd}$ & 0.0012 & 0.00063 & 0.00093 & 0.00060 & 0.00055 & 0.00085 & 0.00060 & 0.00049 & 0.00070 & 0.00077 \\
\hline K & 0.18 & $(0.17)$ & $(0.11)$ & $(0.091)$ & $(0.0025)$ & 0.12 & 0.23 & 0.15 & 0.20 & 0.17 \\
\hline Li & & 0.14 & & & 0.22 & & 0.25 & & & 0.37 \\
\hline $\mathrm{Na}$ & 0.11 & 0.011 & 0.13 & 0.11 & 0.021 & 0.16 & 0.033 & 0.19 & 0.20 & 0.038 \\
\hline $\mathrm{Si}$ & 0.024 & 0.024 & 0.026 & 0.023 & 0.027 & 0.029 & 0.027 & 0.034 & 0.028 & 0.030 \\
\hline $\mathrm{Zr}$ & $(0.0024)$ & $(0.0023)$ & $(0.0020)$ & $(0.0016)$ & $(0.00018)$ & $(0.00050)$ & $(0.00052)$ & $(0.00038)$ & $(0.00035)$ & 0.00023 \\
\hline
\end{tabular}


Table 17 (contd.)

\begin{tabular}{|c|c|c|c|c|c|c|c|c|}
\hline Test & P30-3 & P30-4 & P30M-3 & P30M-4 & P31-3 & P31-4 & P31-11 & P31-12 \\
\hline Glass & $630.6 \mathrm{~L}$ & $630.6 \mathrm{~L}$ & $630.6 \mathrm{LM}$ & 630.6LM & $631.6 \mathrm{~L}$ & $631.6 \mathrm{~L}$ & $631.6 \mathrm{~L}$ & $631.6 \mathrm{~L}$ \\
\hline $\begin{array}{l}\text { Duration, } \\
\text { days }\end{array}$ & 70 & 70 & 70 & 70 & 70 & 70 & 70 & 70 \\
\hline Final $\mathrm{pH}$ & 7.93 & 8.36 & 8.12 & 7.9 & 8.59 & 8.13 & 8.51 & 8.34 \\
\hline $\mathrm{Al}$ & 0.047 & 0.055 & 0.034 & 0.035 & 0.077 & 0.055 & 0.066 & 0.061 \\
\hline B & 0.081 & 0.10 & 0.049 & 0.052 & 0.16 & 0.13 & 0.13 & 0.12 \\
\hline $\mathrm{a}$ & $(0.13)$ & $(0.14)$ & $(0.12)$ & $(0.12)$ & $(0.15)$ & $(0.14)$ & $(0.14)$ & $(0.12)$ \\
\hline $\mathrm{Fe}$ & $(0.056)$ & $(0.061)$ & $(0.055)$ & $(0.055)$ & $(0.086)$ & $(0.085)$ & $(0.082)$ & $(0.074)$ \\
\hline $\mathrm{K}$ & 0.27 & 0.27 & 0.38 & 0.59 & 0.45 & 0.40 & 0.21 & 0.30 \\
\hline $\mathrm{Li}$ & & & 0.22 & 0.24 & & & & \\
\hline $\mathrm{Na}$ & 0.18 & 0.17 & $(0.0089)$ & $(0.0090)$ & 0.62 & 0.24 & 0.20 & 0.19 \\
\hline
\end{tabular}




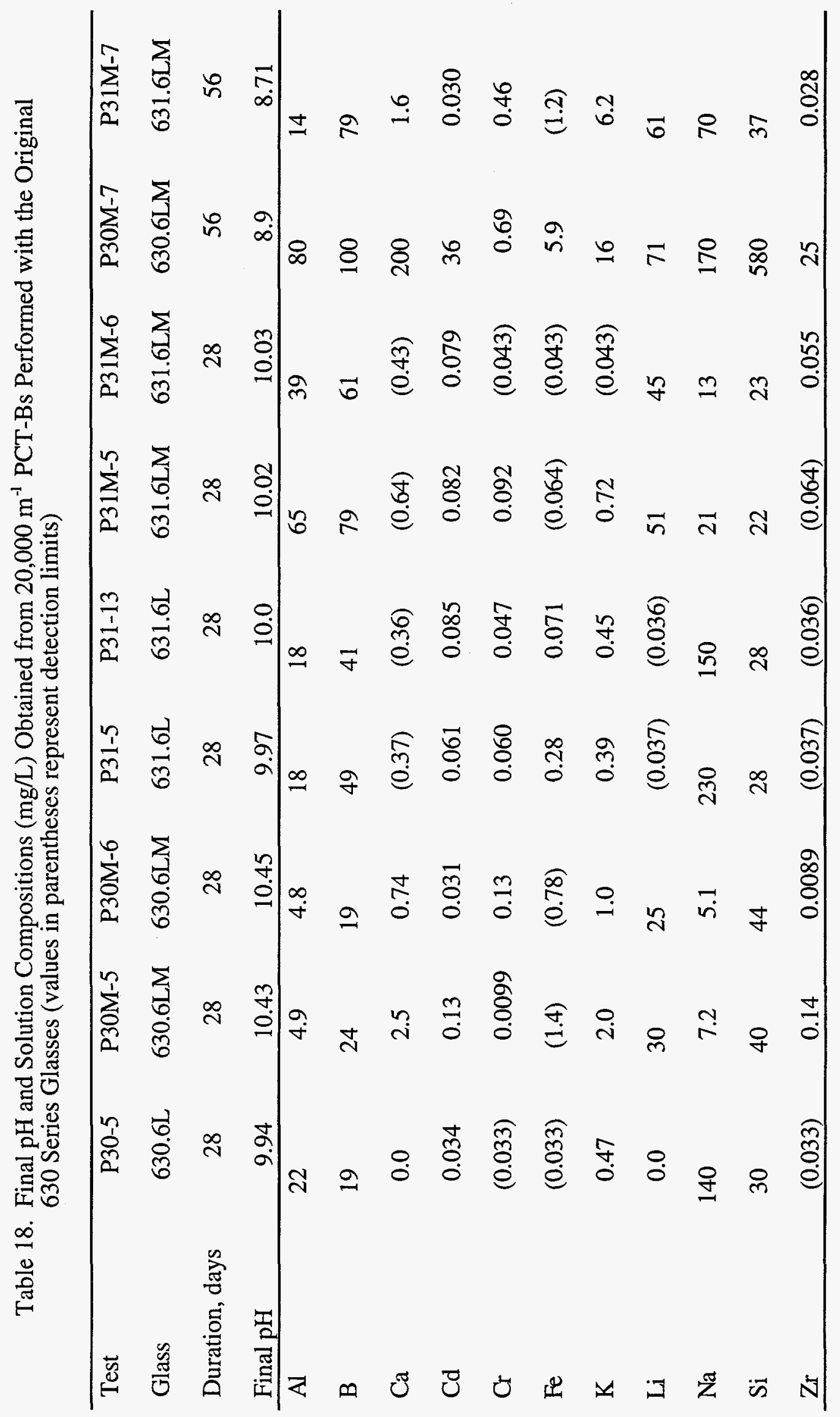




\begin{tabular}{|c|c|c|c|c|c|c|c|c|}
\hline Test & P30-6 & P30-7 & P30M-8 & P30M-9 & P31-6 & $\mathrm{P} 31-7$ & P31M-8 & P31M-9 \\
\hline Glass & $630.6 \mathrm{~L}$ & $630.6 \mathrm{~L}$ & $630.6 \mathrm{LM}$ & 630.6LM & $631.6 \mathrm{~L}$ & $631.6 \mathrm{~L}$ & 631.6LM & 631.6LM \\
\hline Duration, days & 98 & 98 & 98 & 98 & 98 & 98 & 98 & 98 \\
\hline Final $\mathrm{pH}$ & 9.36 & 9.4 & 9.3 & 8.76 & 10.1 & 9.9 & 9.82 & 9.6 \\
\hline $\mathrm{Al}$ & 19 & 18 & 7.9 & 5.1 & 2.0 & 21 & 52 & 47 \\
\hline B & 26 & 26 & 31 & 18 & 45 & 48 & 58 & 75 \\
\hline $\mathrm{Ca}$ & $(0.36)$ & $(0.36)$ & 2.9 & 0.66 & $(0.34)$ & 0.19 & $(0.43)$ & $(0.31)$ \\
\hline $\mathrm{Cd}$ & $(0.036)$ & 0.038 & 0.064 & 0.034 & $(0.14)$ & 0.074 & 0.11 & $(0.031)$ \\
\hline $\mathrm{Cr}$ & $(0.036)$ & $(0.036)$ & 0.020 & 0.026 & $(0.034)$ & 0.060 & 0.089 & 0.042 \\
\hline $\mathrm{Fe}$ & $(0.036)$ & 0.48 & (1.4) & $(0.58)$ & $(0.034)$ & 0.29 & $(0.043)$ & $(0.031)$ \\
\hline $\mathrm{K}$ & 1.8 & 2.4 & 10 & 4.1 & 1.9 & 3.4 & 0.75 & 1.9 \\
\hline $\mathrm{Li}$ & $(0.036)$ & $(0.036)$ & 51 & 38 & $(0.034)$ & $(0.029)$ & 52 & 60 \\
\hline $\mathrm{Na}$ & 130 & 140 & 11 & 6.6 & 190 & 200 & 22 & 19 \\
\hline $\mathrm{Si}$ & 30 & 28 & 39 & 45 & 34 & 29 & 21 & 24 \\
\hline $\mathrm{Zr}$ & $(0.036)$ & $(0.036)$ & 0.15 & 0.026 & $(0.034)$ & $(0.029)$ & 0.061 & 0.49 \\
\hline
\end{tabular}




\begin{tabular}{|c|c|c|c|c|c|c|}
\hline Test & P30-8 & P30M-10 & P30M-11 & P31-8 & P31M-10 & P31M-11 \\
\hline Glass & $630.6 \mathrm{~L}$ & 630.6LM & 630.6LM & $631.6 \mathrm{~L}$ & 631.6LM & 631.6LM \\
\hline Duration, days & 183 & 183 & 183 & 183 & 183 & 183 \\
\hline Final $\mathrm{pH}$ & 9.7 & 9.88 & 9.95 & 10.3 & 9.95 & 9.98 \\
\hline $\mathrm{Al}$ & 20 & 4.9 & 5.5 & 21 & 48 & 46 \\
\hline B & 28 & 19 & 20 & 51 & 80 & 75 \\
\hline $\mathrm{Ca}$ & 0.21 & 0.66 & 1.1 & $(0.35)$ & $(0.33)$ & $(0.28)$ \\
\hline $\mathrm{Cd}$ & 0.042 & 0.049 & 0.068 & 0.095 & 0.042 & 0.047 \\
\hline $\mathrm{Cr}$ & $(0.031)$ & 0.047 & 0.024 & 0.062 & 0.046 & 0.044 \\
\hline $\mathrm{Fe}$ & 0.20 & $(0.70)$ & $(0.58)$ & 0.21 & $(0.033)$ & $(0.028)$ \\
\hline $\mathrm{K}$ & 0.63 & 0.71 & 0.76 & 0.44 & $(0.033)$ & 0.047 \\
\hline $\mathrm{Li}$ & $(0.031)$ & 44 & 43 & $(0.035)$ & 68 & 66 \\
\hline $\mathrm{Na}$ & 150 & 7.5 & 7.4 & 230 & 20 & 20 \\
\hline $\mathrm{Si}$ & 31 & 41 & 46 & 31 & 24 & 25 \\
\hline $\mathrm{Zr}$ & $(0.031)$ & 0.021 & 0.017 & $(0.035)$ & $(0.16)$ & 0.034 \\
\hline
\end{tabular}




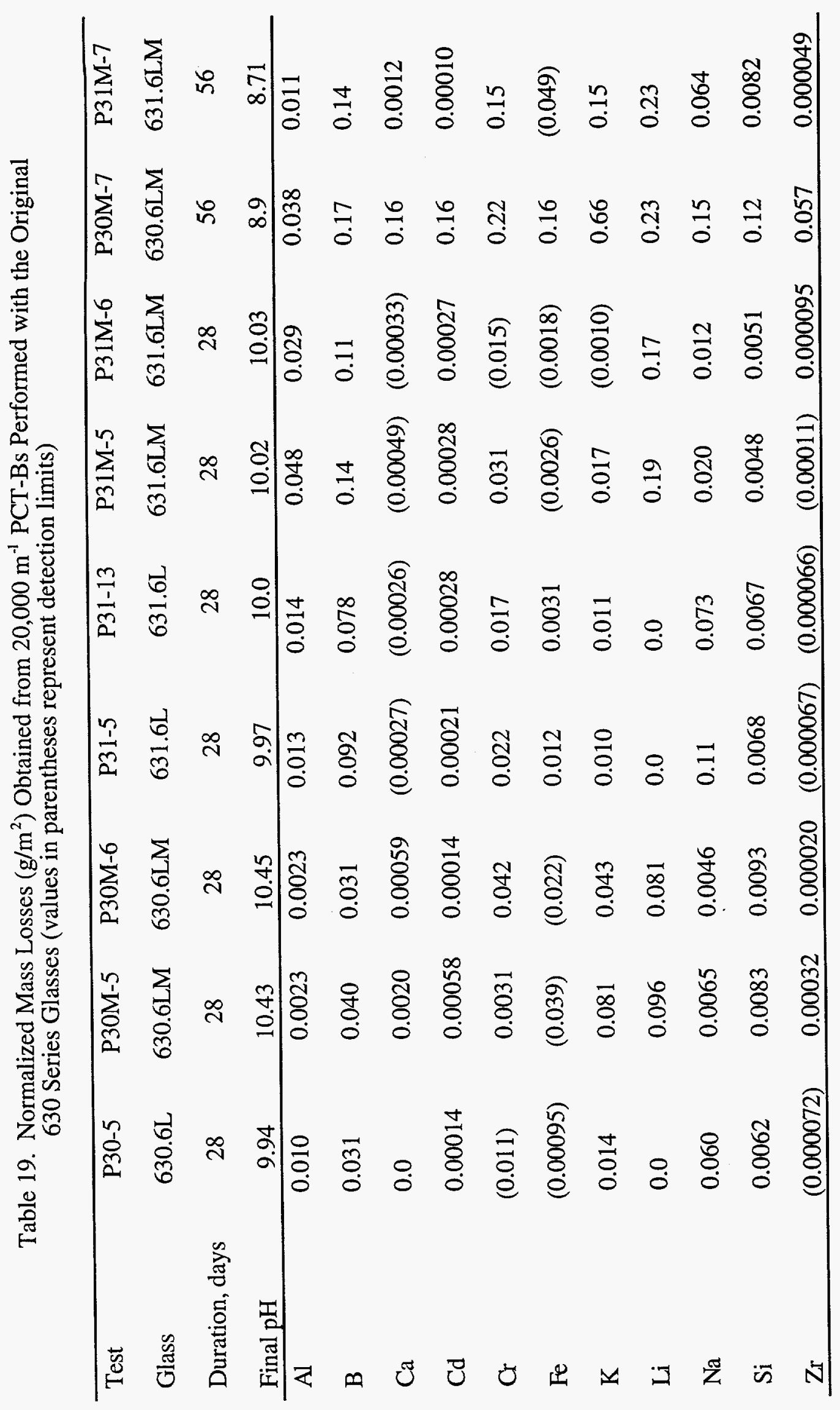




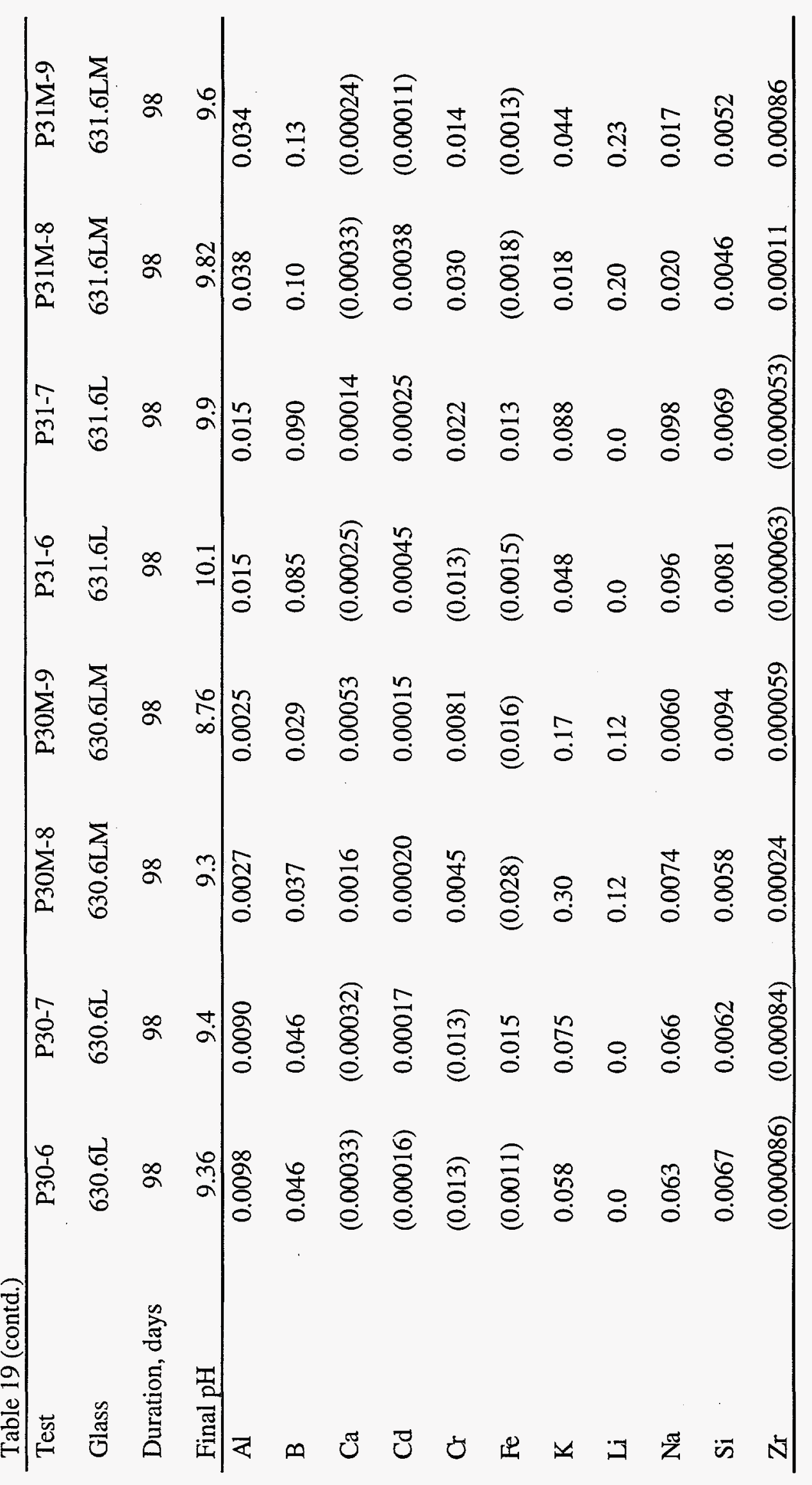




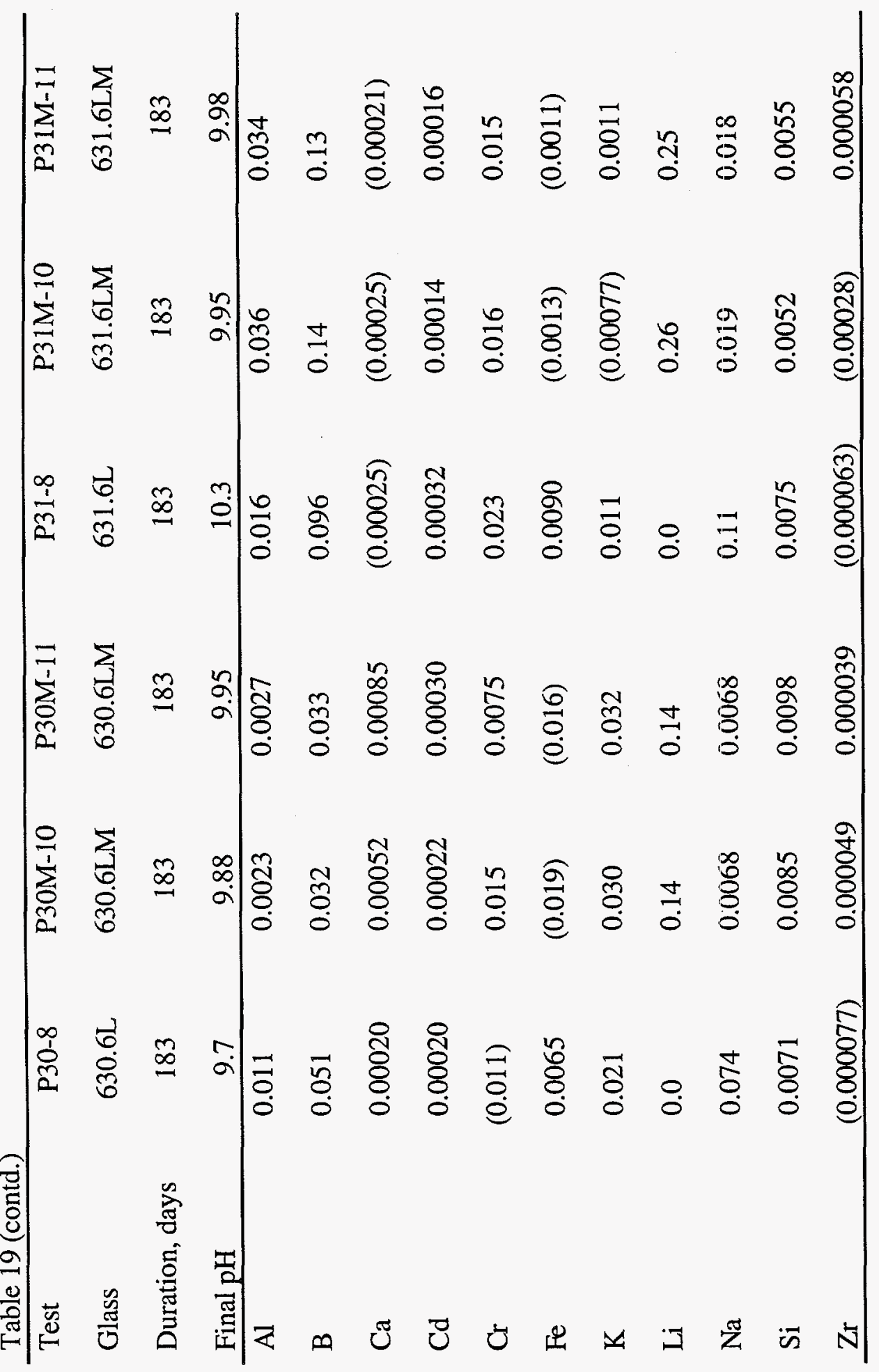


Table 20. Final $\mathrm{pH}$ and Solution Compositions (mg/L) Obtained from PCT-Bs Performed with the Revised 630 Series Glasses (values in parentheses represent detection limits)

\begin{tabular}{|c|c|c|c|c|c|c|c|c|c|c|c|c|}
\hline Test & PR30-1 & PR30M-1 & PR31-1 & PR31M-1 & PR30-2 & PR30M-2 & PR31-2 & PR31M-2 & PR30-3 & PR30M-3 & PR31-3 & PR31M-3 \\
\hline Glass & 630R.6L & 630R.6LM & 631R.6L & 631R.6LM & 630R.6L & 630R.6LM & 631R.6L & 631R.6LM & 630R.6L & 630R.6LM & 631R.6L & 631R.6LM \\
\hline $\begin{array}{l}\text { Duration, } \\
\text { days }\end{array}$ & 7 & 7 & 7 & 7 & 28 & 28 & 28 & 28 & 98 & 98 & 98 & 98 \\
\hline $\mathrm{S} / \mathrm{V}, \mathrm{m}^{-1}$ & 2128 & 2016 & 2104 & 2049 & 20,937 & 20,414 & 20,105 & 21,222 & 20,240 & 21,365 & 20,240 & 21,399 \\
\hline Final pH & 7.62 & 7.52 & 7.94 & 8.03 & 8.95 & 9.28 & 9.77 & 9.29 & 8.80 & 9.65 & 10.20 & 9.45 \\
\hline $\mathrm{Al}$ & 6.9 & 5.9 & 8.1 & 9.9 & 15 & 16 & 18 & 33 & 17 & 26 & 23 & 43 \\
\hline B & 3.7 & 2.7 & 4.8 & 12 & 20 & 11 & 32 & 110 & 28 & 18 & 40 & 140 \\
\hline $\mathrm{Ca}$ & 3.4 & 3.9 & 3.0 & 8.6 & 0.68 & 1.0 & 1.1 & 11 & 0.60 & 0.67 & 1.2 & 4.7 \\
\hline $\mathrm{Cd}$ & 0.023 & 0.021 & 0.012 & 0.013 & 0.023 & 0.071 & 0.061 & 0.0093 & 0.053 & 0.069 & 0.15 & 0.029 \\
\hline $\mathrm{Cr}$ & 0.0030 & 0.0011 & 0.026 & 0.014 & 0.018 & 0.0095 & 0.057 & 0.095 & 0.043 & 0.015 & 0.054 & 0.098 \\
\hline $\mathrm{Fe}$ & 0.047 & 0.058 & 0.090 & 0.11 & 0.082 & 0.011 & 0.14 & 0.12 & 0.14 & 0.11 & 0.071 & 0.037 \\
\hline K & n.a. & n.a. & n.a. & n.a. & n.a. & n.a. & n.a. & n.a. & n.a. & n.a. & n.a. & n.a. \\
\hline Li & 0.011 & 5.1 & 0.024 & 7.6 & 0.012 & 29 & 0.033 & 68 & 0.0069 & 45 & 0.018 & 99 \\
\hline $\mathrm{Mg}$ & 0.051 & 0.42 & 0.31 & 0.23 & 0.053 & 0.11 & 0.061 & 0.12 & 0.099 & 0.11 & 0.16 & 0.055 \\
\hline $\mathrm{Na}$ & 8.0 & 11 & 4.1 & 10 & 66 & 10 & 15 & 11 & 220 & 12 & 94 & 23 \\
\hline $\mathrm{Pb}$ & 1.3 & 2.6 & 1.3 & 3.3 & 2.3 & 9.5 & 2.5 & $(0.25)$ & 3.2 & 1.7 & 2.6 & 1.8 \\
\hline $\mathrm{Si}$ & 14,000 & 17,000 & 16,000 & 12,000 & 28,000 & 40,000 & 32,000 & 7000 & 30,000 & 57,000 & 39,000 & 12,000 \\
\hline Sn & 1.3 & 1.8 & 3.1 & 2.3 & 14 & 22 & 20 & 8.7 & 15 & 28 & 21 & 8.8 \\
\hline $\mathrm{Zr}$ & 3.0 & 2.6 & 1.8 & 2.7 & 13 & 100 & 9.4 & 0.98 & 27 & 31 & 24 & 240 \\
\hline
\end{tabular}

an.a. = not analyzed. 
Table 21. Normalized Mass Losses $\left(\mathrm{g} / \mathrm{m}^{2}\right)$ Obtained from PCT-Bs Performed with the Revised 630 Series Glasses (values in parentheses represent

\begin{tabular}{|c|c|c|c|c|c|c|c|c|c|c|c|c|}
\hline Test & PR30-1 & PR30M-1 & PR31-1 & PR31M-1 & PR30-2 & PR30M-2 & PR31-2 & PR31M-2 & PR30-3 & PR30M-3 & PR31-3 & PR31M-3 \\
\hline Glass & 630R.6L & 630R.6LM & 631R.6L & 631R.6LM & 630R.6L & 630R.6LM & $631 \mathrm{R} .6 \mathrm{~L}$ & 631R.6LM & 630R.6L & 630R.6LM & $631 \mathrm{R} .6 \mathrm{~L}$ & 631R.6LM \\
\hline $\begin{array}{l}\text { Duration, } \\
\text { days }\end{array}$ & 7 & 7 & 7 & 7 & 28 & 28 & 28 & 28 & 98 & 98 & 98 & 98 \\
\hline $\mathrm{S} / \mathrm{V}, \mathrm{m}^{-1}$ & 2128 & 2016 & 2104 & 2049 & 20,937 & 20,414 & 20,105 & 21,222 & 20,240 & 21,365 & 20,240 & 21,399 \\
\hline Final $\mathrm{pH}$ & 7.62 & 7.52 & 7.94 & 8.03 & 8.95 & 9.28 & 9.77 & 9.29 & 8.80 & 9.65 & 10.20 & 9.45 \\
\hline $\mathrm{Al}$ & 0.037 & 0.030 & 0.059 & 0.068 & 0.0084 & 0.0082 & 0.014 & 0.022 & 0.0096 & 0.013 & 0.018 & 0.028 \\
\hline B & 0.064 & 0.052 & 0.093 & 0.23 & 0.036 & 0.021 & 0.065 & 0.20 & 0.051 & 0.032 & 0.081 & 0.25 \\
\hline $\mathrm{Ca}$ & 0.026 & 0.037 & 0.022 & 0.063 & 0.00053 & 0.00094 & 0.00083 & 0.0077 & 0.00048 & 0.00060 & 0.00092 & 0.0032 \\
\hline $\mathrm{Cd}$ & 0.0010 & 0.0012 & 0.00039 & 0.00046 & 0.00010 & 0.00039 & 0.00021 & 0.000031 & 0.00025 & 0.00036 & 0.00051 & 0.000094 \\
\hline ar & 0.0023 & 0.0028 & 0.070 & 0.029 & 0.0014 & 0.0023 & 0.016 & 0.019 & 0.0035 & 0.0034 & 0.015 & 0.020 \\
\hline $\mathrm{Fe}$ & 0.014 & 0.018 & 0.033 & 0.034 & 0.0025 & 0.0032 & 0.0054 & 0.0037 & 0.0044 & 0.0031 & 0.0027 & 0.0011 \\
\hline K & n.d. ${ }^{a}$ & n.d. & n.d. & n.d. & n.d. & n.d. & n.d. & n.d. & n.d. & n.d. & n.d. & n.d. \\
\hline $\mathbf{L i}$ & 0.0 & 0.19 & 0.0 & 0.26 & 0.0 & 0.10 & 0.0 & 0.22 & 0.0 & 0.16 & 0.0 & 0.32 \\
\hline $\mathrm{Mg}$ & 0.048 & 0.038 & 0.027 & 0.018 & 0.00051 & 0.00099 & 0.00055 & 0.00091 & 0.00098 & 0.00097 & 0.0014 & 0.00042 \\
\hline $\mathrm{Na}$ & 0.039 & 0.11 & 0.020 & 0.096 & 0.033 & 0.010 & 0.0076 & 0.0097 & 0.11 & 0.012 & 0.049 & 0.020 \\
\hline $\mathrm{Pb}$ & 0.00030 & 0.00081 & 0.00039 & 0.00092 & 0.000055 & 0.00029 & 0.000081 & $(0.0000067)$ & 0.000080 & 0.000050 & 0.000084 & 0.000049 \\
\hline $\mathrm{Si}$ & 0.031 & 0.039 & 0.037 & 0.029 & 0.0061 & 0.0090 & 0.0077 & 0.0016 & 0.0069 & 0.012 & 0.0095 & 0.0028 \\
\hline $\mathrm{Sn}$ & 0.00060 & 0.0012 & 0.018 & 0.0011 & 0.00066 & 0.0014 & 0.0012 & 0.00042 & 0.00073 & 0.0018 & 0.0013 & 0.00042 \\
\hline $\mathrm{Zr}$ & 0.000070 & 0.000066 & 0.000032 & 0.000048 & 0.000031 & 0.00026 & 0.000017 & 0.0000017 & 0.000067 & 0.000075 & 0.000044 & 0.000041 \\
\hline
\end{tabular}


(a)

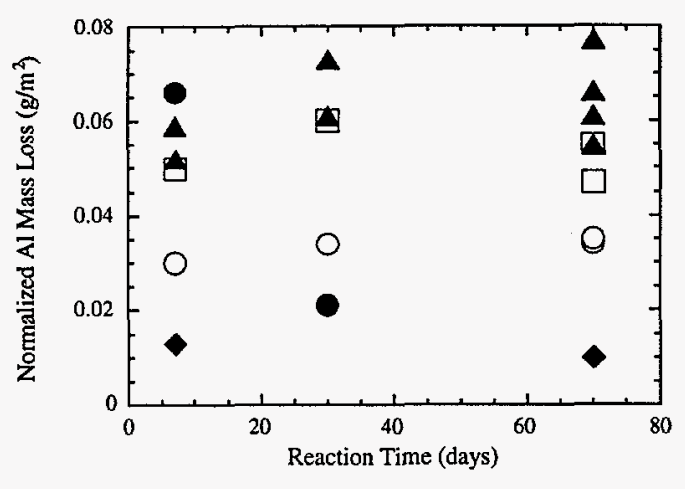

(c)

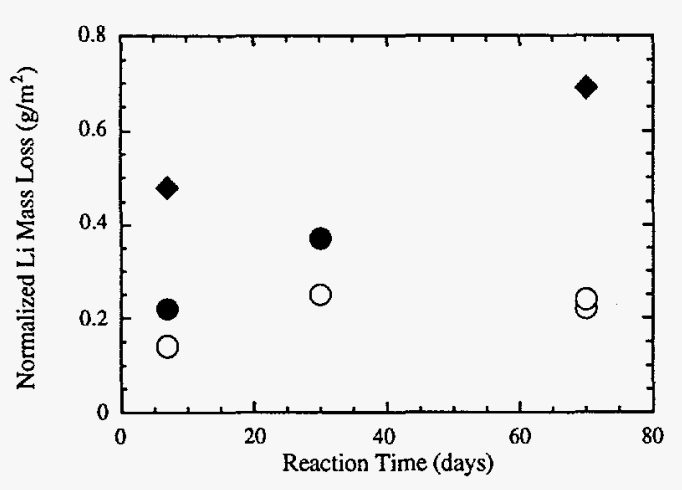

(e)

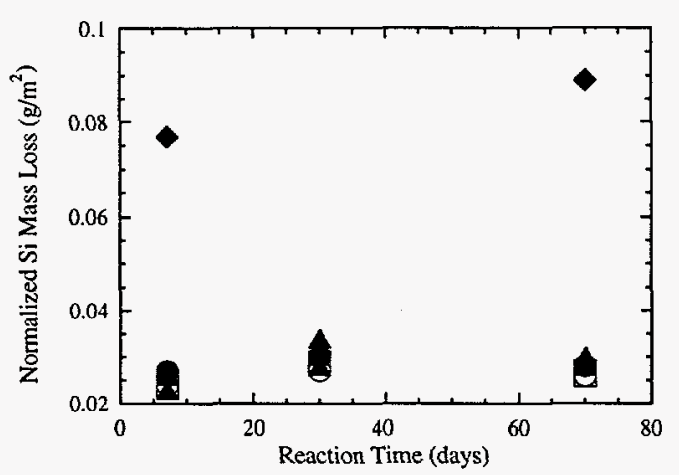

(b)

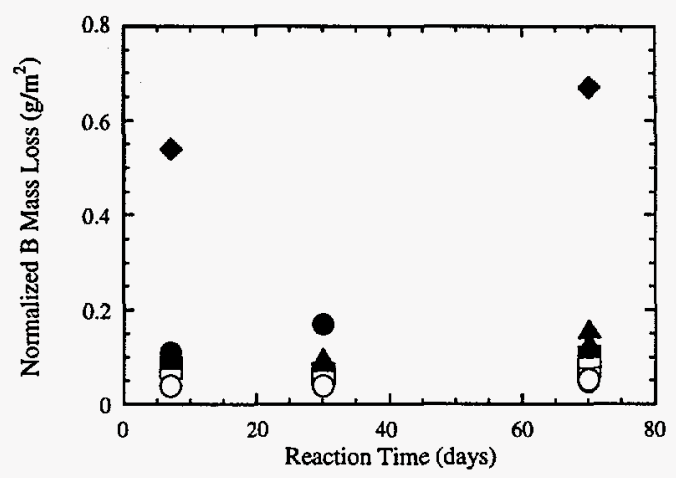

(d)

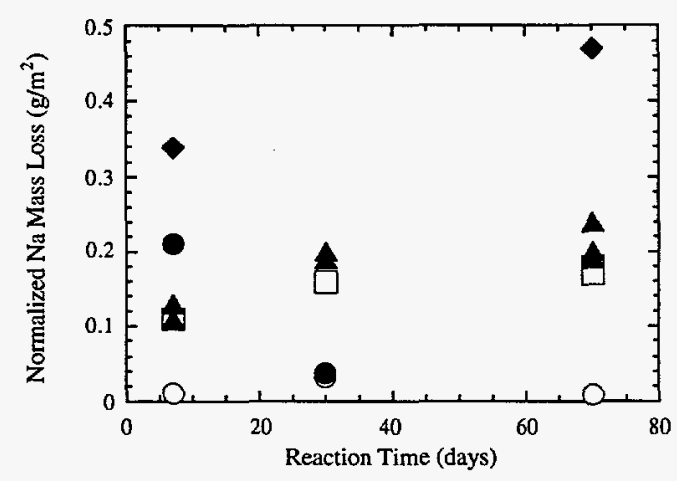

Fig. 14.

Comparison of Normalized Mass Losses for 630 Series and Formula 127 Glasses in PCT-Bs at $\mathrm{S} / \mathrm{V}=2000 \mathrm{~m}^{-1}$ : (a) Aluminum, (b) Boron, (c) Lithium, (d) Sodium, and (e) Silicon. (ㅁ)

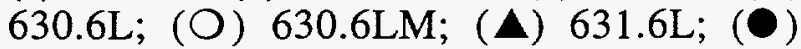
$631.6 \mathrm{LM} ;() 127$. 
(a)

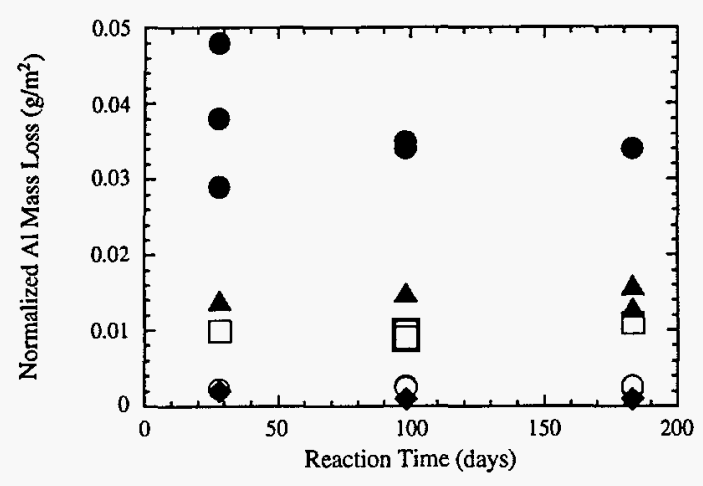

(c)

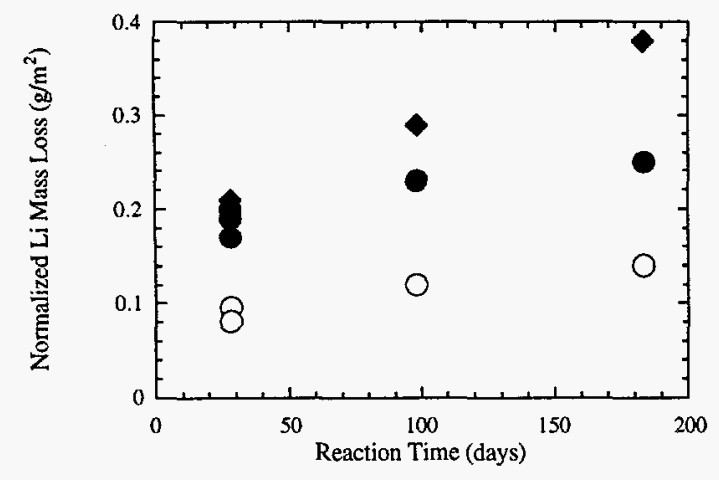

(e)

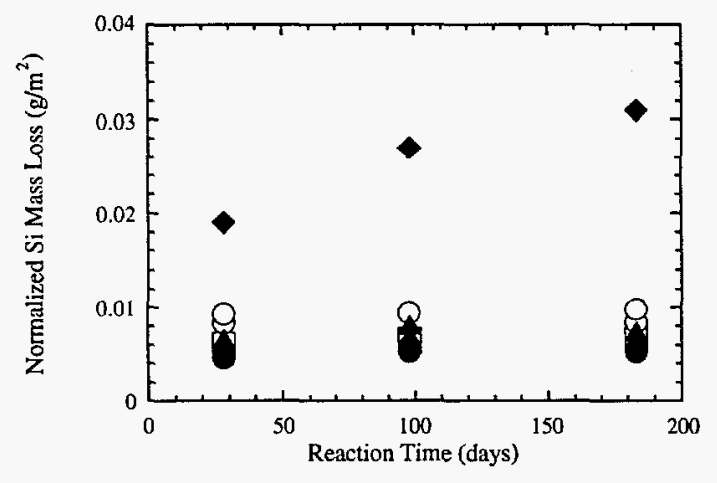

(b)

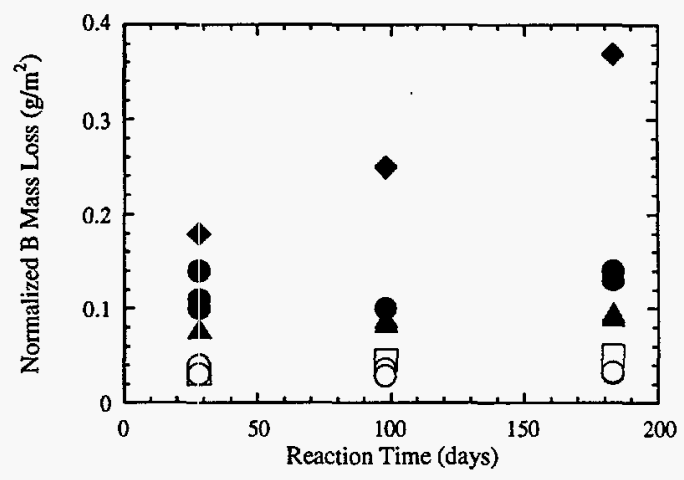

(d)

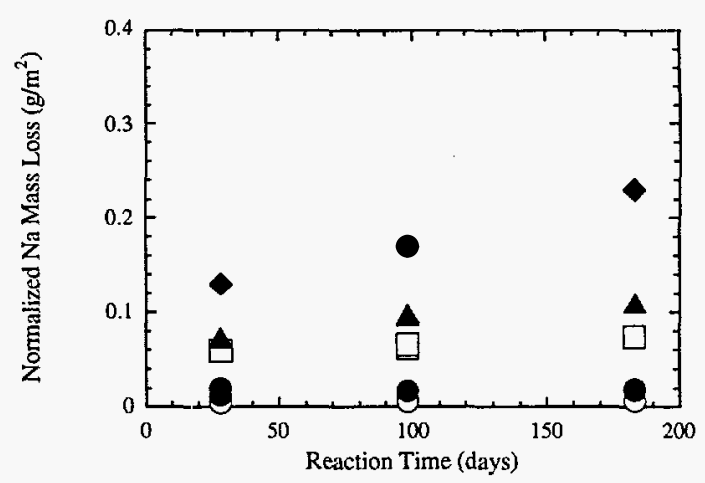

Fig. 15.

Comparison of Normalized Mass Losses for 630 Series and Formula 127 Glasses in PCT-Bs at $\mathrm{S} / \mathrm{V}=20,000 \mathrm{~m}^{-1}$ : (a) Aluminum, (b) Boron, (c) Lithium, (d) Sodium, and (e) Silicon. ( $\square$ ) 630.6L; (O) 630.6LM; (A) 631.6L; (O) 631.6LM; $(\diamond) 127$.

The values of NL(B) are similar for the $L$ and $\mathrm{LM}$ versions of the 630 and 631 calcine glasses, within the testing uncertainty, as are the values of NL(Si). The testing uncertainty is given by the reproducibility of the duplicate tests conducted for some time periods. However, the NL(Na) values of the $L$ glasses are consistently higher than those for the LM glasses. This is discussed below. Comparison of the NL(B), NL(Li), and NL(Na) in tests with the 630LM glass with those in tests with the 631LM glass shows that the glasses made with the 631 calcine formulation are slightly more reactive than glasses made with the 630 calcine. The 
difference is most obvious in the NL(Li) results, although these are affected by the relative amounts of $\mathrm{Li}, \mathrm{Na}$, and $\mathrm{Al}$ in the two glasses (see Discussion Section).

A very interesting result is that $\mathrm{NL}(\mathrm{Na})$ is substantially lower in tests with the glasses containing both $\mathrm{Li}$ and $\mathrm{Na}$ (LM series) than in the glasses that contain $\mathrm{Na}$ alone ( $\mathrm{L}$ series). This reflects the greater affinity of $\mathrm{Na}$ relative to $\mathrm{Li}$ for charge-balance of $\mathrm{Al}$ [ROY1984; ELLISON-1994].

In these charge-balance sites, a monovalent cation $\left(\mathrm{Na}^{+}\right.$or $\left.\mathrm{Li}^{+}\right)$becomes associated with a trivalent cation $\left(\mathrm{Al}^{3+}\right)$ to form a tetravalent unit that replaces $\mathrm{Si}^{4+}$ in the glass structure. It has been shown that the $\mathrm{Na}$ bonded to $\mathrm{Si}-\mathrm{O}$ groups is more easily released than $\mathrm{Na}$ associated with Al groups [SMETS-1982]. The number of charge-balance sites that can form depends on the amount of monovalent and trivalent cations that are present. The mole fraction of $\mathrm{Na}$ exceeds that of $\mathrm{Al}$ in both of the L glasses, but is less in the LM glasses (see Tables 14 and 15; the Na:Al mole fraction is 1.17 times the $\mathrm{Na}: \mathrm{Al}$ mass fraction). The ratio of the mole fraction ratio $\mathrm{Na}: \mathrm{Al}$ is greater than 1 in both the $630 \mathrm{~L}$ and $631 \mathrm{~L}$ glasses but less than 1 in both the 630LM and 631LM glasses. The $\mathrm{Na}$ that does not form charge-balance groups with $\mathrm{Al}$ instead forms highly reactive $\mathrm{Si}-\mathrm{O}-\mathrm{Na}$ groups. In tests with the $\mathrm{L}$ glass, the $\mathrm{Na}$ from $\mathrm{Si}-\mathrm{O}-\mathrm{Na}$ sites is released while the $\mathrm{Na}$ associated with $\mathrm{Al}$ groups is retained. In the LM glasses, all the $\mathrm{Na}$ and some of the $\mathrm{Li}$ occupies charge-balance sites in the glass. The remaining $\mathrm{Li}$ forms the more reactive $\mathrm{Si}-\mathrm{O}-\mathrm{Li}$ bonds. The $\mathrm{Li}$ from $\mathrm{Si}-\mathrm{O}-\mathrm{Li}$ sites is released during the test, while the $\mathrm{Li}$ and the $\mathrm{Na}$ from charge-balance sites is retained. The relative amounts of $\mathrm{Li}, \mathrm{Na}$, and $\mathrm{Al}$ in the glasses will affect the number of charge-balance sites in the different glasses and the relationship between $N L(\mathrm{Li}), N L(\mathrm{Na})$ and the extent of reaction. Qualitatively, this is why the $\mathrm{NL}(\mathrm{Na})$ values are much lower in tests with the L glasses than in tests with the LM glasses.

Evidence that $\mathrm{Li}$ is not as effective as $\mathrm{Na}$ as a charge-balancing cation is seen in the fact that normalized $\mathrm{Li}$ releases generally exceed those of any other cation in the 630 series glasses. In the glasses containing $\mathrm{Na}$ alone, $\mathrm{B}$ is released at the highest rate, and the release rate of $\mathrm{B}$ does not change appreciably when $\mathrm{Na}$ is replaced by Li. Since B is usually assumed to indicate the rate of matrix dissolution, the single alkali and mixed alkali glasses dissolve at about the same rate.

Figure 16 compares the normalized mass losses from the original 630 series glasses with those obtained from the revised 630 series in $20,000 \mathrm{~m}^{-1}$ PCT-Bs. Since the compositions have been affected differently by crystal fractionation induced during glass processing, it is probably not possible to evaluate the effects that the minor components $(\mathrm{Mg}, \mathrm{Pb}$, and $\mathrm{Sn}$ ) have u pon the rate of glass corrosion by direct comparison of the data. In fact, the reactivities of the original and revised calcine glasses cannot be distinguished based on the test results: the revised calcine glasses 630R.6LM and 631R.6LM release $\mathrm{B}$ and $\mathrm{Li}$ at a higher rate than original calcine glasses $630.6 \mathrm{LM}$ and $631.6 \mathrm{LM}$, whereas the revised calcine glasses 630R.6L and 631R.6L release $\mathrm{B}$ and $\mathrm{Na}$ at a lower rate than original calcine glasses $630.6 \mathrm{~L}$ and 631.6L. This variation is simply due to the uncertainties in testing. The presence of small amounts of $\mathrm{Mg}, \mathrm{Pb}$, and $\mathrm{Sn}$ is not expected to affect the results. Of key importance to the overall objectives of this testing program is the observation of low release rates for glasses with the original and revised surrogate formulation. 
(a)

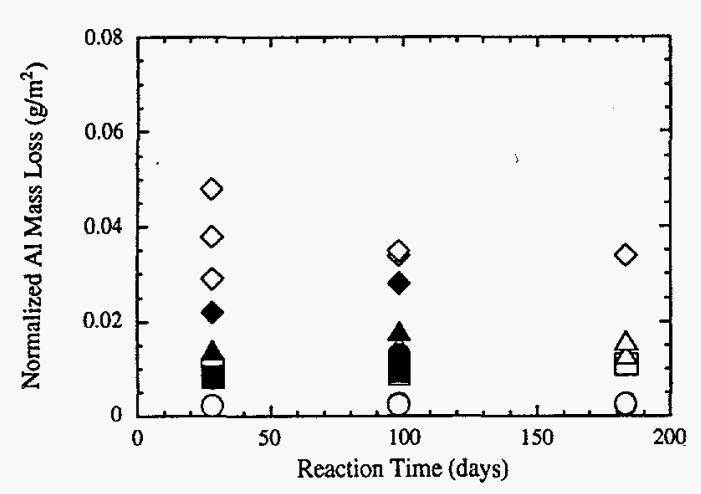

(c)

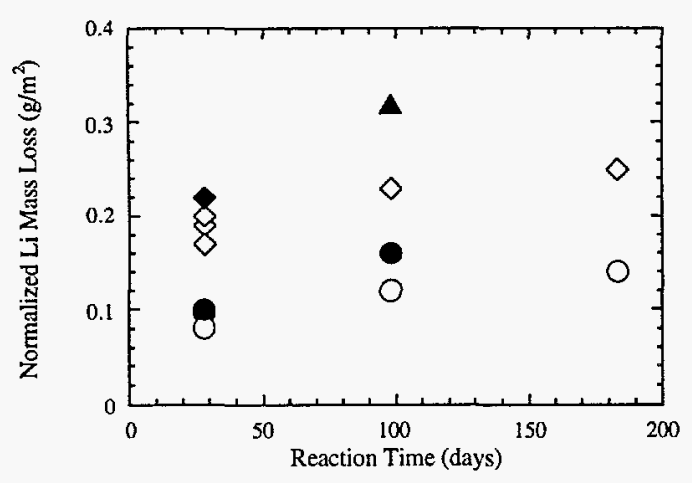

(e)

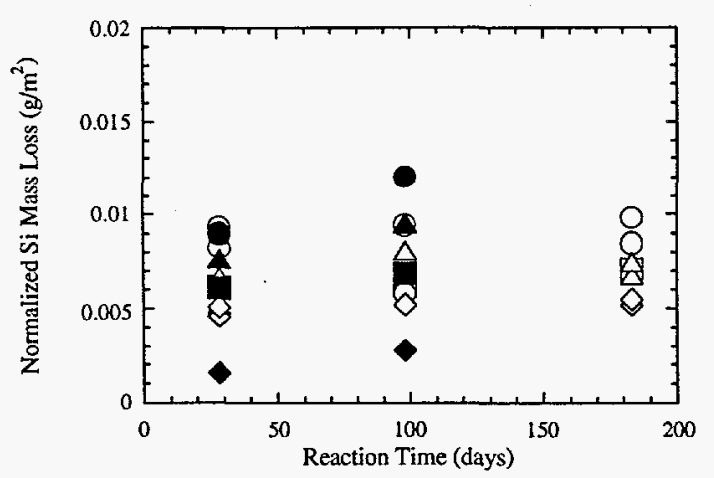

(b)

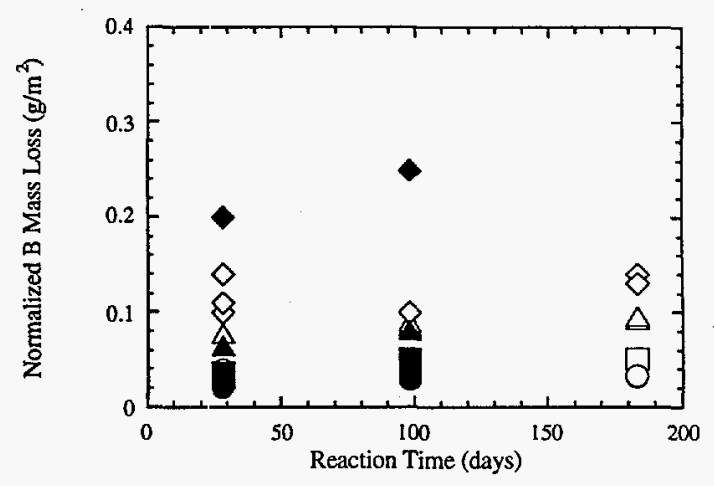

(d)

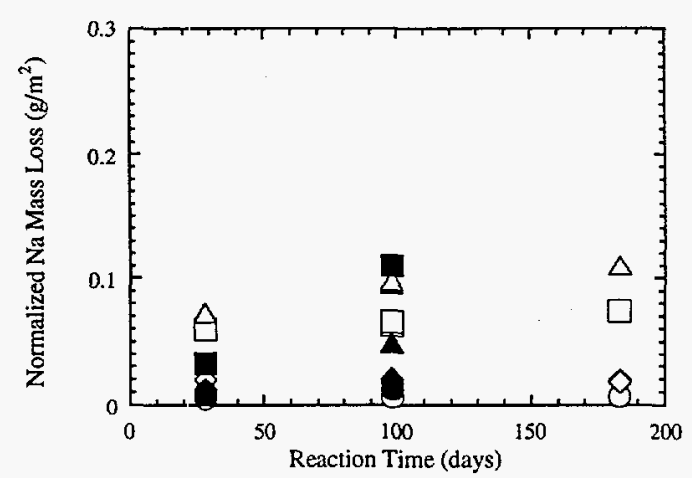

Fig. 16.

Comparison of Normalized Mass Losses for Original and Revised 630 Series Glasses in PCT-Bs at $S / V=20,000 \mathrm{~m}^{-1}$ : (a) Aluminum, (b) Boron, (c) Lithium, (d) Sodium, and (e) Silicon. (ㅁ) 630.6L; (घ) 630R.6L; (O) 630.6LM; (O) 630.6LM; (๑) 630R.6LM; $(\Delta)$

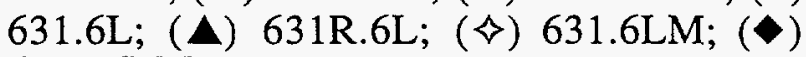
631R.6LM.

Two PCT-Bs (P30M-6 and P31M-6; see Tables 18 and 19) were performed with type 304L Stainless Steel vessels rather than Teflon vessels to determine the effect that steel vessels might have on glass reaction. The tests were performed at $20,000 \mathrm{~m}^{-1}$ for a duration of $28 \mathrm{~d}$. The results of tests conducted in Teflon and steel vessels are summarized in Table 22 . The respective values of $\mathrm{NL}(\mathrm{B}), \mathrm{NL}(\mathrm{Li})$, and $\mathrm{NL}(\mathrm{Si})$ are the same in tests conducted in Teflon and steel vessels, within the testing uncertainty, which indicates that the choice of vessel material does not have a measurable on glass reaction in PCT-Bs for this time period. 
Table 22. Comparison of Tests Conducted for 28 days at $20,000 \mathrm{~m}^{-1}$ in Teflon and Type 304L Stainless Steel Vessels

\begin{tabular}{lccccc}
\hline Test No. & Vessel & $\mathrm{pH}$ & $\mathrm{NL}(\mathrm{B})$ & $\mathrm{NL}(\mathrm{Li})$ & $\mathrm{NL}(\mathrm{Si})$ \\
\hline P30M-5 & Teflon & 10.43 & 0.040 & 0.096 & 0.0083 \\
P30M-6 & Steel & 10.45 & 0.031 & 0.081 & 0.0093 \\
P31M-5 & Teflon & 10.02 & 0.14 & 0.19 & 0.0048 \\
P31M-6 & Steel & 10.03 & 0.11 & 0.17 & 0.0051 \\
\hline
\end{tabular}

No alteration phases were detected in PCT-Bs conducted at $2000 \mathrm{~m}^{-1}$ or 20,000 $\mathrm{m}^{-1}$ with any of the 630 series glasses. Examination with SEM of the reacted glass from the longest tests showed the glass fragments retain sharp edges and points very much like those seen in the starting material. These high-energy surfaces would be expected to be among the first sites dissolved, and the fact that they are retained attests to the good durability of the glass. This result does not mean that alteration phases will not form eventually, rather that the tests were terminated before any had formed.

\section{Vapor Hydration Test Results}

Because alteration phases did not form in any of the PCT-Bs conducted on 630 series glasses, VHT results are used to evaluate what impact alteration phase formation might have on the rate of glass corrosion. Figure 17 shows optical photomicrographs of the surfaces of $630.6 \mathrm{~L}, 630.6 \mathrm{LM}$, and $631.6 \mathrm{~L}$ glasses after $28 \mathrm{~d}$ of reaction with water vapor at $200^{\circ} \mathrm{C}$. The crystals growing from the surfaces of the 630 series glasses are zeolites. Zeolites also covered the surfaces of revised-calcine glasses after reaction with water vapor. Zeolites had formed on glasses $630.6 \mathrm{LM}$ and $631.6 \mathrm{~L}$ within 7 days and on glasses $630.6 \mathrm{~L}$ and $631.6 \mathrm{LM}$ within 14 days. The size and abundance of the zeolites increased with the reaction time. Patches of Al-Si-O-Fbearing crystals and calcium aluminosilicate crystals can be seen. The EDS spectra of the Al-O$\mathrm{Si}-\mathrm{F}$ crystals are the same as those of crystals found in the early stages of the corrosion of Formula 127 glass, and they may be the same phase. No crystalline alteration phases were found on the sample from test V31M-5, although both samples have evaporite deposits on their surfaces.

The photomicrograph in Fig. 18 shows a cross-section of the near surface region of a sample of $631.6 \mathrm{~L}$ glass reacted in vapor at $200^{\circ} \mathrm{C}$ for 56 days. A large precipitated analcime crystal lies above a layer of hydrated glass. The hydrated glass is not easily distinguished in the SEM image, but is obvious when viewed with a light microscope. The layer is white, while the underlying glass is light green. Although the layer does not have a uniform thickness, it has penetrated about $0.2 \mathrm{~mm}$ into the sample, on average. A high magnification image of the surface layer away from the analcime is displayed in Fig. 19. The outer part of the layer is comprised of randomly oriented fibrous material that overlays a band of material that is enriched in Ca relative to the bulk glass. The band is probably reprecipitated fluorite $\left(\mathrm{CaF}_{2}\right)$. The hydrated layer lies below this band.

Close inspection of the SEM image indicates that the hydrated layer contains a random distribution of needle-like crystalline material, while the underlying glass is amorphous. A high-magnification images of the hydrated layer/glass interface is displayed in Fig. 20. It is likely that the needle-like features seen in the hydrated layer are primary phases that were present in the glass initially and were simply exposed during polishing of the cross section. That is, polishing the hydrated layer may have provided enough relief that the needles can be seen. The morphology of the included phase is similar to that seen in the Formula 127 glass. 
(a)

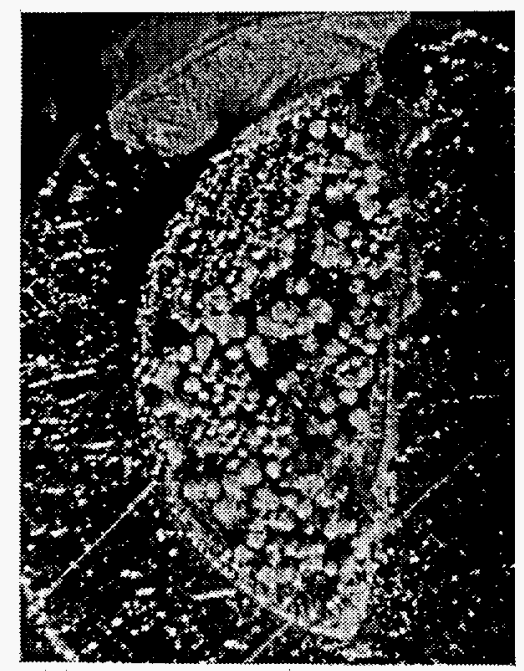

(c)

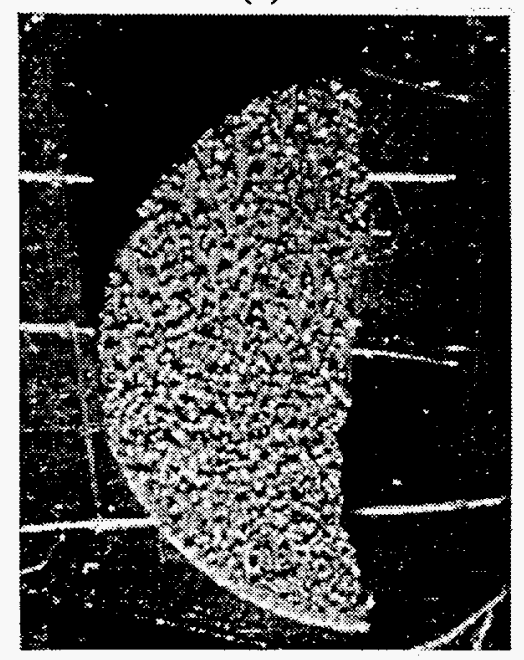

(b)

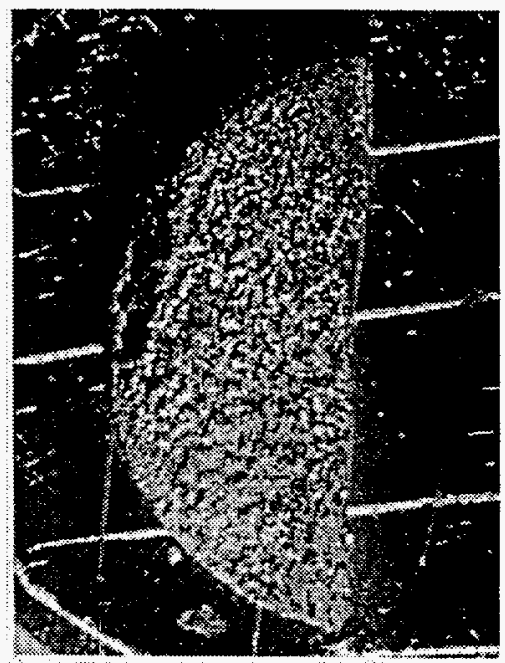

(d)

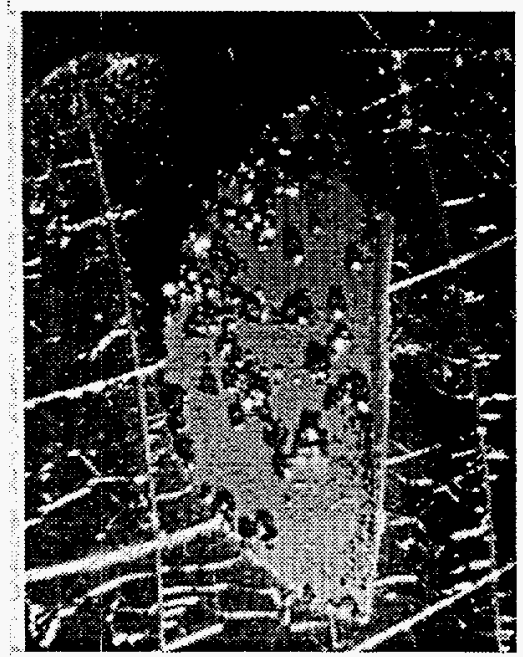

Fig. 17. Optical Photographs of the Surfaces of Samples of (a) 630.6L, (b) 630.6LM, (c) $631.6 \mathrm{~L}$, and (d) $631.6 \mathrm{LM}$ Recovered from VHTs at $200^{\circ} \mathrm{C}$. The diameters of all samples are about $1 \mathrm{~cm}$. 


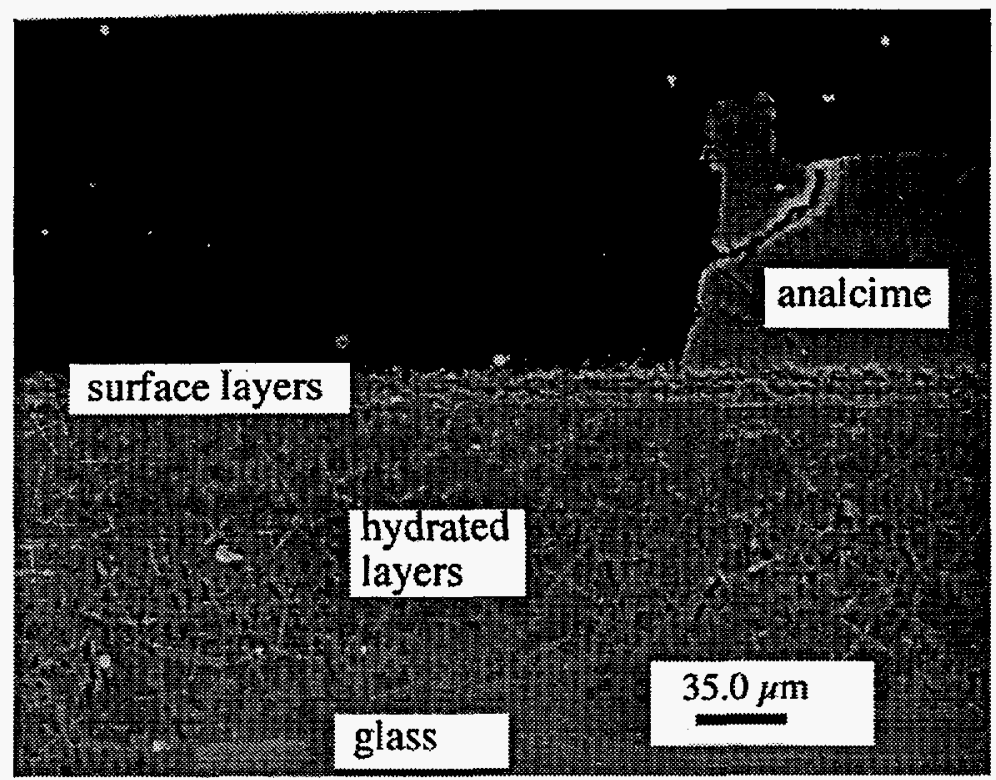

Fig. 18. Scanning Electron Photomicrographs of a Cross-Section through a Sample of 631.6L Glass Recovered from a 56-d VHT.

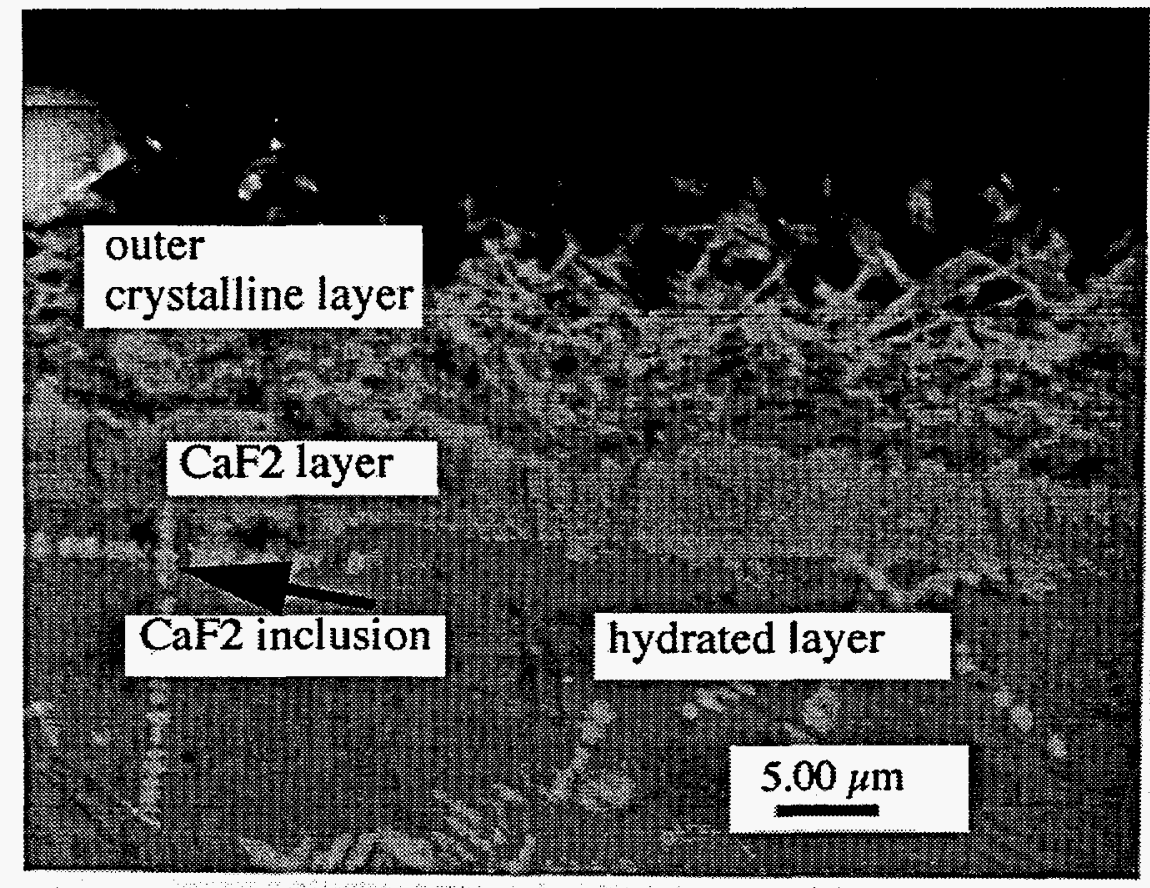

Fig. 19. High Magnification Image of Surface Layer. 


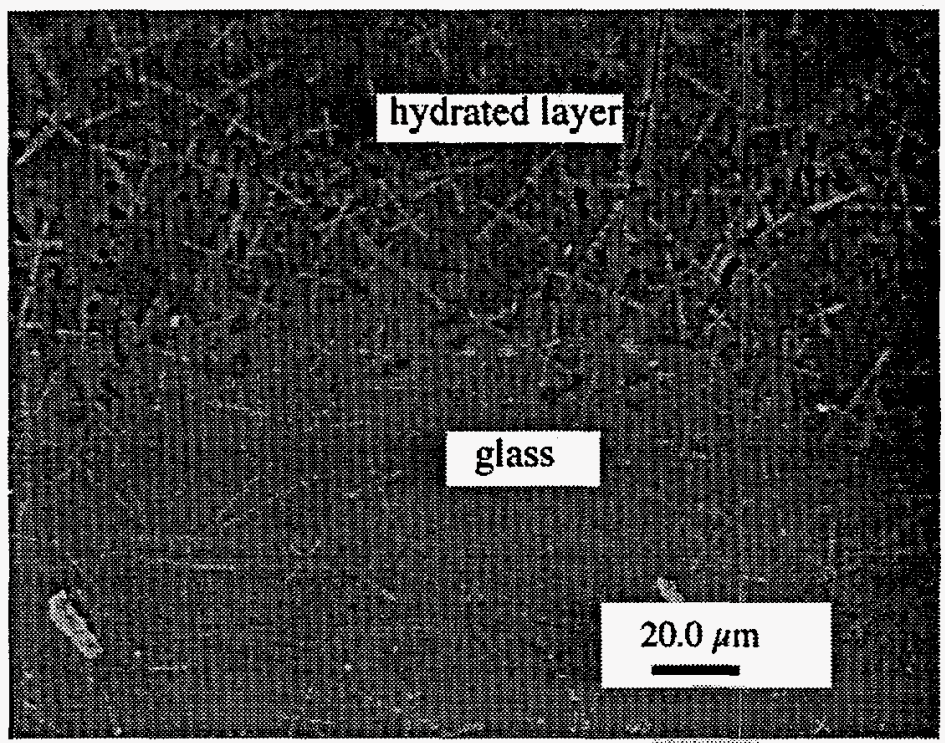

Fig. 20. High Magnification Image of Interface Between. Hydrated Layer and Glass

A lower bound of the hydration rate of this glass can be calculated by assuming that hydration occurred for the full test period and that the layer was $0.2 \mathrm{~mm}$ thick after 56 days. The hydration rate is about $3.6 \mu \mathrm{m} / \mathrm{d}$. The density of the $630.6 \mathrm{~L}$ glass was measured to be $2.56 \pm 0.014 \mathrm{~g} / \mathrm{cm}^{3}$, and the density of the $631.6 \mathrm{~L}$ glass is assumed to be the same. The normalized dissolution rate, based on the hydration layer thickness and the density of the glass, is calculated to be about $9 \mathrm{~g} /\left(\mathrm{m}^{2} \cdot \mathrm{d}\right)$ at $200^{\circ} \mathrm{C}$. The rate at $90^{\circ} \mathrm{C}$ is expected to be about $1000 \mathrm{X}$ lower, assuming an activation energy of about $80 \mathrm{~kJ} / \mathrm{mol}$, which is typical for waste glasses.

These VHTs provide qualitative insight into the long-term corrosion behavior of the 630 series glasses. They show that alteration phases include analcime, which has been observed to have formed during the corrosion of all $\mathrm{Na}$-Al-silicate waste glasses and is probably the phase that affects the glass dissolution rate to the greatest extent. Other zeolite-like phases incorporate $\mathrm{F}$. The effect of alteration phase formation on the glass corrosion rate is not as pronounced as the effects observed for other glasses [e.g., BAKEL-1995; EBERT-1991].

The alteration phases were not analyzed in detail for identification or measuring the disposition of minor components, such as $\mathrm{Mg}, \mathrm{Pb}$, or $\mathrm{Sn}$ in the revised calcine glasses, although the samples have been archived for future analyses. 


\section{DISCUSSION}

In Table 23, the $7 \mathrm{~d}$ PCT results for $\mathrm{B}, \mathrm{Li}, \mathrm{Na}$, and $\mathrm{Si}$ from tests with Formula 127 , Formula 532, and the 630 series glasses 630.6L, 630.6LM, 631.6L, and 631.6LM are compared with the results of $7 \mathrm{~d}$ PCTs obtained for the U.S. Department of Energy Hanford reference glass HW-39-4, with the Defense Waste Processing Facility reference glass SRL 202U, with the West Valley Demonstration Project reference glass WV-6, and with the environmental assessment glass SRL EA. The normalized mass losses were calculating assuming the $S / V$ was $2000 \mathrm{~m}^{-1}$ for all tests. However, as mentioned earlier, correction for the greater density of LITCO glasses will result in a slight increase in the NL values from the values presented in the table. The normalized mass losses of Formula 127 are similar to those of HW-39, SRL 202U, and WV-6, whereas normalized mass losses from Formula 532 are somewhat higher. Normalized mass losses from the 630 series glasses are all substantially lower than those from any of the other domestic candidate waste glasses. All candidate glasses, including Formula 532, show much greater leach resistance than SRL EA glass.

Table 23. Results of 7-Day PCTs Conducted at $90^{\circ} \mathrm{C}$ in Deionized Water with Several Reference Glasses

\begin{tabular}{|c|c|c|c|c|c|c|c|c|}
\hline \multirow[b]{2}{*}{ Glass } & \multicolumn{4}{|c|}{ Conc., mg/L } & \multicolumn{4}{|c|}{$\mathrm{NL}(\mathrm{i}), \mathrm{g} / \mathrm{m}^{2}$} \\
\hline & B & $\mathrm{Li}$ & $\mathrm{Na}$ & $\mathrm{Si}$ & B & $\mathrm{Li}$ & $\mathrm{Na}$ & $\mathrm{Si}$ \\
\hline Formula 127 & 6.9 & 11 & 30 & 36 & 0.54 & 0.48 & 0.34 & 0.077 \\
\hline Formula 532 & 83 & 45 & 50 & 81 & 1.32 & 0.68 & 0.47 & 0.19 \\
\hline $630.6 \mathrm{~L}$ & 4.2 & - & 22 & 10 & 0.079 & - & 0.11 & 0.024 \\
\hline 630.6LM & 2.4 & 4.4 & 1.2 & 11 & 0.040 & 0.14 & 0.011 & 0.024 \\
\hline $631.6 \mathrm{~L}^{\mathrm{a}}$ & 5.5 & - & 24 & 10 & 0.10 & - & 0.12 & 0.025 \\
\hline 631.6LM & 6.2 & 5.8 & 2.3 & 12 & 0.11 & 0.22 & 0.021 & 0.027 \\
\hline$H W-39-4^{a}$ & 25 & 16 & 62 & 98 & 0.44 & 0.49 & 0.40 & 0.21 \\
\hline SRL 202U ${ }^{a}$ & 18 & 15 & 53 & 112 & 0.39 & 0.40 & 0.42 & 0.26 \\
\hline $\mathrm{WV}^{\mathrm{a}}$ & 16 & 8 & 26 & 42 & 0.20 & 0.23 & 0.21 & 0.11 \\
\hline $\mathrm{SRL}_{\mathrm{EA}}{ }^{\mathrm{a}}$ & 587 & 190 & 1660 & 893 & 8.5 & 4.8 & 6.7 & 2.0 \\
\hline
\end{tabular}

${ }^{a}$ Average of two or more tests.

All of the materials received from LITCO as part of this testing program contained substantial amounts of crystalline material. Optical comparison of the 630 series glasses based on the original calcine with those based on the revised surrogate calcine suggest that the amount of crystallinity is either an extraordinarily strong function of composition, or, more likely, very sensitive to the ways in which the various compositions were processed during preparation. Crystallinity can probably be expected in an actual waste glass as well. Based on the WAPS for waste glasses, the acceptability of a waste glass will hinge in part upon complete identification of all crystalline phases likely to be present in the waste glass, and, moreover, it may be necessary to demonstrate that changes in the relative proportions of crystals and glasses have a negligible effect upon the corrosion behavior of the glass. It is suggested, then, that future test materials be passed through a time-temperature-transformation path comparable to the path followed in a canister.

The relative reactivities of glasses made with $\mathrm{Na}$ and with $\mathrm{Na}$ plus $\mathrm{Li}$ in PCT-Bs were consistent with the bonding of $\mathrm{Na}$ and $\mathrm{Li}$ in the glass. Two bonding sites are available to alkali metals in aluminosilicate glasses: either to oxygen bonded to Si or oxygen bonded to Al. Alkali metals and $\mathrm{Al}$ form a charge-balance (CB) group that substitutes into the silicate network. In the 
other bond, the alkali breaks the network by forming a non-bridging oxygen (NBO) bond. Alkali is held more strongly in the charge-balance site than to a non-bridging oxygen. Therefore, the alkali on a non-bridging oxygen is more susceptible to ion exchange with a proton-bearing species than the alkali in a charge-balance site.

Whether or not all the Al become charge-balanced depends on the amount of alkali in the glass. In all the 630 series glass, there is sufficient alkali to balance all the $\mathrm{Al}$. Because of size and charge density, $\mathrm{Na}$ is more effective than $\mathrm{Li}$ as a charge-balancing cation and so $\mathrm{Na}$ will associate with the $\mathrm{Al}$ preferentially to $\mathrm{Li}$. The $\mathrm{Na}$ or $\mathrm{Li}$ that is present in excess of $\mathrm{Al}$ will bond at non-bridging oxygen sites. As the different glasses react, the order of alkali release is expected occur as $\mathrm{Li}(\mathrm{NBO}), \mathrm{Na}(\mathrm{NBO})>\mathrm{Li}(\mathrm{CB})>\mathrm{Na}(\mathrm{CB})$. Based on the compositions, we calculate the distribution of bonds in the different glasses to be as summarized in Table 24 . Based on this distribution, the release of $\mathrm{Li}$ from 631.6LM glass is expected to occur to a greater extent than from $630.6 \mathrm{LM}$ glass because there is more $\mathrm{Li}$ in $\mathrm{NBO}$ sites in the 631.6LM glass. This is what is observed in tests at 2000 and $20,000 \mathrm{~m}^{-1}$ (see Fig. 14 and 15). Likewise, the greater amount of $\mathrm{Na}$ in NBO sites in the 631.6L glass than in the 630.6L glass suggests that the NL(Na) values will be slightly greater from the $631.6 \mathrm{~L}$ glass, which is also observed. Thus, the observed dissolution behavior of the Na-bearing and $\mathrm{Na}$ - and $\mathrm{Li}$-bearing glasses is consistent with the behavior predicted based on the glass compositions.

Table 24. Calculated Distribution of $\mathrm{Na}$ and $\mathrm{Li}$ between Non-Bridging Oxygen (NBO) and Charge-Balance (CB) Sites, in \% of Total Na or Li in Glass

\begin{tabular}{lccccc}
\hline & \multicolumn{3}{c}{$\mathrm{Na}$} & & \multicolumn{2}{c}{$\mathrm{Li}$} & \\
\cline { 2 - 4 } Glass & $\mathrm{NBO}$ & $\mathrm{CB}$ & & $\mathrm{NBO}$ & $\mathrm{CB}$ \\
\cline { 2 - 3 } 630.6L & $22 \%$ & $78 \%$ & & - & - \\
$630.6 \mathrm{LM}$ & $0 \%$ & $100 \%$ & & $67 \%$ & $3 \%$ \\
$631.6 \mathrm{~L}$ & $42 \%$ & & $58 \%$ & - & - \\
$631.6 \mathrm{LM}$ & $0 \%$ & $100 \%$ & $93 \%$ & $7 \%$ \\
\hline
\end{tabular}

The dissolution behavior of the glass matrices of the $\mathrm{Na}$-bearing and $\mathrm{Na}$ - and Li-bearing glasses is similar, as measured by $\mathrm{NL}(\mathrm{B})$ and $\mathrm{NL}(\mathrm{Si})$. This is because a similar number of CB and NBO bonds occur in each set of L and LM glass, although the 630 glasses have a greater number of $\mathrm{CB}$ sites than the 631 glasses, based on the amount of $\mathrm{Al}$ in each glass. Again, the greater amount of CB sites leads to the durability of the 630 glasses being slightly higher than that of the 631 glasses, based on NL(B).

In long-term PCT-Bs conducted at high S/V, Formula 127 eventually forms calcium silicate alteration phases. The same phases are the first to appear in short-term, high-temperature VHTs of Formula 127. Zeolite alteration phases form very quickly in PCT-B and VHTs of Formula 532, and they have a controlling role in the rate of glass corrosion. Thus, there is good concurrence between PCT-B and VHTs on the identities and order of appearance of alteration phases, illustrating the utility of the VHTs in determining what phases are likely to affect the advanced stages of glass corrosion. While no alteration phases were observed to have formed in long-term, high S/V PCT-Bs on any of the 630 series glasses, zeolite phases formed relatively early in VHT s. This phase serves as a sink for $\mathrm{Na}, \mathrm{Al}$, and $\mathrm{Si}$ released during glass reaction, and phase formation appears to increase the rate of glass corrosion. It is reasonable to expect that zeolites will eventually appear in long-term PCT and increase the rate of glass reaction. Since the rate of release in $7 \mathrm{~d}$ PCT-Bs is very low, however, it is possible that the rate might remain relatively low after zeolites form. This pattern has been observed for the West Valley reference glass WV-6. It forms zeolite crystals fairly early in VHTs, but has not yet formed them in PCT- 
Bs of about two years in duration. In the VHTs, the rate of glass reaction is affected by the presence of zeolite, but the impact is much less than the effect that zeolite formation has on the rate of reaction of other reference glasses. We believe the relative effect of alteration phase formation on the glass corrosion rate depends on the glass composition, particularly on the $\mathrm{Al}: \mathrm{Na}$ :Si ratio. While more detailed analyses are required, the high $\mathrm{Al}$ content of the 630 series glass makes them amenable to accelerated corrosion.

It is possible that the presence of relatively high concentrations of fluorine in solution affects the chemical activities of Si or $\mathrm{Al}$, and thereby affects the nucleation of zeolites and the impact they have on glass corrosion. This explanation would be consistent with the observed behavior of Formula 127, which, despite a relatively high aluminum concentration, has not been observed to form zeolites in VHTs. The effect of high F concentrations on glass corrosion could presumably be addressed by using geochemical codes. If the above explanation proves correct, then the deliberate addition of fluorite $\left(\mathrm{CaF}_{2}\right)$ to the alumina and zirconia calcine glasses might suppress zeolite formation, or lessen the impact their formation has on the glass dissolution rate, and enhance the long-term durability of the resultant waste glass. 


\section{CONCLUSIONS}

Argonne National Laboratory has completed a testing program in support of a program at LITCO to develop waste forms for the vitrification of high-level waste calcines. The general results of this program are as follows.

- All glasses contain primary crystalline phases that affect, to varying degrees, the way the glass reacts with water. In the fluoride-bearing Formula 127 and the 630 series glasses, the primary crystalline phase is fluorite, $\mathrm{CaF}_{2}$, whereas in Formula 532, the primary crystalline phases are virgilite, $\mathrm{LiAlSi}_{3} \mathrm{O}_{8}$, and rutile, $\mathrm{TiO}_{2}$. The degree of crystallinity and the distribution of crystals in the glass matrix appear to vary considerably with composition and with processing conditions.

- In $7 \mathrm{~d}$ PCT-As, normalized mass losses of major glass-forming elements from the LITCO glasses are comparable to, or substantially less than, normalized mass losses from other domestic candidate waste glasses.

- The fluoride-free glass, Formula 532, forms zeolite alteration phases relatively early in its reaction with water, even in $2000 \mathrm{~m}^{-1}$ PCT-Bs. The zeolite serves as a sink for $\mathrm{Na}, \mathrm{Al}$, and Si and increases the rate of glass reaction. Even after $182 \mathrm{~d}$ at $\mathrm{S} / \mathrm{V}=2,000 \mathrm{~m}^{-1}$, however, the values of $\mathrm{NL}(\mathrm{B}), \mathrm{NL}(\mathrm{Li}), \mathrm{NL}(\mathrm{Na})$, and $\mathrm{NL}(\mathrm{Si})$ are still four times lower than those obtained in tests with SRLEA in just $7 \mathrm{~d}$ at the same $\mathrm{S} / \mathrm{V}$.

- The fluoride-bearing glasses form alteration phases only after prolonged exposure to water in tests with very high surface-area to volume ratios. The alteration phases formed during corrosion of Formula 127 glass have a relatively small impact on the rate of glass corrosion. No alteration phases formed in PCT-Bs of 630 series glasses, though zeolites formed during VHTs of the 630 series glasses indicate that zeolite alteration phases should be expected in PCT-Bs of longer duration.

- The corrosion rates and behaviors of the single alkali glasses and the mixed alkali glasses are similar, except for the behavior of $\mathrm{Na}$. The values of NL(Na) are much greater in tests with the single alkali glasses than with the mixed alkali glasses. This is due to the higher $\mathrm{Na} / \mathrm{Al}$ ratio and to there being more $\mathrm{Na}$ bonded to NBOs in the single alkali glass than in the mixed alkali glass. Most of the $\mathrm{Na}$ in the mixed alkali glasses occupy charge-balancing sites in the glass structures. In VHTs, both single- and mixed-alkali glasses form zeolite phases that increase the rate of glass reaction.

- The original 630 series glasses and those based on a revised surrogate calcine formulation show comparable normalized elemental release rates in PCT-Bs, and form the same major alteration phases in VHTs. 


\section{ACKNOWLEDGMENTS}

The authors thank Jeff Emery and Tom DiSanto for preparing sample materials for testing. They also thank Elaine Estand and Roberta Riel for preparing the manuscript.

This work was supported by the U.S. Department of Energy through Lockheed Idaho Technologies Company, under contract DE-AC07-94ID13223. 


\section{REFERENCES}

BAKEL-1995

A. J. Bakel, W. L. Ebert, and J. S. Luo, "Long-Term Performance of Glasses for Hanford LowLevel Waste," Ceram. Trans. Environmental and Waste Management Issues in the Ceramics Industry, Vol. 61, 515-522 (1995).

BATES-1995

J. K. Bates, et al., DOE DP Annual for FY 1995.

BOUCIER-1994

W. L. Bourcier, S. A. Carroll, and B. L. Phillips, "Constraints on the Affinity Term for Modeling Long-Term Glass Dissolution Rates," Mat. Res. Soc. Symp. Proc. $\underline{333}$, 507-512 (1994).

ELLISON-1994

A. J. G. Ellison, J. J. Mazer, and W. L. Ebert, Effect of Glass Composition on Waste Form Durability: A Critical Review, Argonne National Laboratory Report ANL-94/28 (1994).

\section{ELLSION-1995}

A. J. G. Ellison, S. F. Wolf, and J. K. Bates, Laboratory Testing of Glasses for Lockheed Idaho Technology Co. - Fiscal Year 1994 Report, Argonne National Laboratory Report ANL-95/12 (1995).

\section{EBERT-1991}

W. L. Ebert, J. K. Bates, and W. L. Bourcier, "The Hydration of Borosilicate Waste Glass in Liquid Water and Steam at $200^{\circ} \mathrm{C}$," Waste Management, 11, 205-221 (1991).

EBERT-1994

W. L. Ebert, The Effects of the Glass Surface Area/Solution Voilume Ratio on Glass Corrosion: A Critical Review, Argonne National Laboratory Report ANL-94/34 (1994).

FRENCH-1978

B. M. French, P. A. Jezek, and D. E. Appleman, "Virgilite: A New Lithium Aluminum Silicate Mineral from the Macusani Glass, Peru," Amer. Miner. 63, 461-465 (1978).

McGRAIL-1995

B. P. McGrail and D. K. Peeler, Evaluation of the Single-Pass Flow-Through Test to Support a LowActivity Waste Specification, Pacific Northwest Laboratory Report PNL-10746 (1995).

ROY-1984

B. N. Roy and A. Navrotsky, "Thermochemistry of Charge-Coupled Substitutions in Silicate Glasses: The Systems $\mathrm{M}_{\mathrm{ln}}^{\mathrm{n}+} \mathrm{AlO}_{2}-\mathrm{SiO}_{2}(\mathrm{M}=\mathrm{Li}, \mathrm{Na}, \mathrm{K}, \mathrm{Rb}, \mathrm{Cs}, \mathrm{Mg}, \mathrm{Ca}, \mathrm{Sr}, \mathrm{Ba}, \mathrm{Pb})$," J. Am. Ceram. Soc. 67, 606-610 (1984).

SMETS-1982

B. M. J. Smets and T. P. A. Lommen, "The Leaching of Sodium Aluminosilicate Glass Studied by Secondary Ion Mass Spectrometry," Phys. Chem. Glasses, 23(3), 83-87 (1982).

STAPLES-1983

B. Staples, H. Cole, and D. Pavlica, "Properties of Formula 127 Glass Prepared with Radioactive Zirconia Calcine,” Mater. Res. Soc. Symp. Proc. 15, 125-134 (1983). 
STRACHAN-1994

D. M. Strachan, W. L. Bourcier, and B. P. McGrail, "Towards a Consistent Model for Glass Dissolution," Radioactive Waste Management and Environmental Restoration 19, 129-145 (1994). 
Distribution for ANL-97/12

Internal:
J. K. Bates (25)
J. E. Harmon
D. M. Strachan
E. C. Buck
J. J. Laidler
S. F. Wolf
N. L. Dietz
J. S. Luo
TIS Files

W. L. Ebert

\section{External:}

DOE-OSTI (2)

ANL-E Library

ANL-W Library

Manager, Chicago Operations Office, DOE

A. Bindokas, DOE-CH

J. C. Haugen, DOE-CH

Chemical Technology Division Review Committee Members:

H. U. Anderson, University of Missouri-Rolla, Rolla, MO

E. R. Beaver, Monsanto Company, St. Louis, MO

D. L. Douglas, Consultant, Bloomington, MN

R. K. Genung, Oak Ridge National Laboratory, Oak Ridge, TN

J. G. Kay, Drexel University, Philadelphia, PA

R. A. Osteryoung, North Carolina State University, Raleigh, NC

G. R. St. Pierre, The Ohio State University, Columbus, $\mathrm{OH}$

T. Ahn, U. S. Nuclear Regulatory Commission, Washington, DC

D. H. Alexander, USDOE, Civilian Radioactive Waste Management, Washington, DC

S. Bates, Idaho Falls, ID

H. Benton, B\&W Fuel Company, Las Vegas, NV

A. Berusch, USDOE, Office of Civilian Radioactive Waste Management, Washington, DC

N. E. Bibler, Westinghouse Savannah River Company, Aiken, SC

J. M. Boak, USDOE, Yucca Mountain Site, Las Vegas, NV

K. Boomer, Lockheed Martin Hanford Company, Richland, WA

W. Bourcier, Lawrence Livermore National Laboratory, Livermore, CA

E. T. Bramlitt, Defense Nuclear Agency, Kirtland Air Force Base, Kirtland, NM

A. Brandstetter, Science Applications, International Corporation, Las Vegas, NV

N. R. Brown, USDOE, Richland Operations Office, Richland, WA

J. Bucher, Lawrence Berkeley Laboratory, Berkeley, CA

J. Canepa, Los Alamos National Laboratory, Los Alamos, NM

K. A. Chacey, USDOE, Office of Environmental Management, Germantown, MD

D. Chestnut, Lawrence Livermore National Laboratory, Livermore, CA

G. R. Choppin, Florida State University, Tallahassee, FL

S. Clark, University of Georgia, Savannah River Ecology Laboratory, Aiken, SC

P. Cloke, Science Applications International Corp., Las Vegas, NV

M. O. Cloninger, Mac Technical Services, Inc., Richland, WA

D. Codell, U. S. Nuclear Regulatory Commission, Washington, DC 
G. Colten-Bradley, U. S. Nuclear Regulatory Commission, Rockville, MD

S. Coplan, U. S. Nuclear Regulatory Commission, Washington, DC

J. Davidson, U. S. Environmental Protection Agency, Washington, DC

J. Docka, Roy F. Weston, Inc., Washington, DC

R. Dresser, Roy F. Weston, Inc., Washington, DC

R. S. Dyer, Yucca Mountain Project Office, Las Vegas, NV

A. J. G. Ellison, Corning Inc., Corning, NY

R. E. Erickson, USDOE, Office of Environmental Management, Germantown, MD

E. Essington, Los Alamos National Laboratory, Los Alamos, NM

R. C. Ewing, University of Michigan, Ann Arbor, MI

D. Farr, Los Alamos National Laboratory, Los Alamos, NM

R. Fish, B\&W Fuel Company, Las Vegas, NV

J. Gauthier, Sandia National Laboratories, Albuquerque, NM

F. Gelbard, Sandia National Laboratories, Albuquerque, NM

C. P. Gertz, USDOE, Yucca Mountain Project Office, Las Vegas, NV

S. E. Gomberg, USDOE, Office of Civilian Radioactive Waste Management, Washington, DC

W. Gray, Pacific Northwest National Laboratory, Richland, WA

P. W. Hart, USDOE, Office of Technology Development, Germantown, MD

J. Hennessey, USDOE, Office of Waste Management, Germantown, MD

J. Herzog, Lockheed Idaho Technology Company, Idaho Falls, ID

D. Hobart, LANL, TTSO Group Germantown, MD

J. Hunt, University of California, Berkeley, CA

D. Hutchins, Martin Marietta Systems, Inc., Oak Ridge, TN

C. Interrante, U.S. Nuclear Regulatory Commission, Washington, DC

C. Jantzen, Westinghouse Savannah River Company, Aiken, SC

L. J. Jardine, Lawrence Livermore National Laboratory, Livermore, CA

P. Kearl, Oak Ridge National Laboratory, Grand Junction, CO

J. Keith, Daniel B. Stephens \& Associates, Albuquerque, NM

J. Kerrisk, Los Alamos National Laboratory, Los Alamos, NM

W. S. Ketola, USDOE, West Valley Project Office, West Valley, NY

D. A. Knecht, Idaho National Engineering and Environmental Laboratory, Idaho Falls, ID

D. Kubosumi, Lockheed Idaho Technology Company, Idaho Falls, ID

W. L. Kuhn, Pacific Northwest National Laboratory, Richland, WA

W. Lee, Environmental Evaluation Group, Albuquerque, NM

W. W. Lee, University of California, Berkeley, CA

J. C. Lehr, USDOE, Office of Environmental Restoration, Germantown, MD

R. A. Lemons, Los Alamos National Laboratory, Los Alamos, NM

S. Levy, Los Alamos National Laboratory, Los Alamos, NM

D. Livingston, USDOE, Yucca Mountain Site, Las Vegas, NV

J. J. Lorenz, USDOE, Yucca Mountain Site, Las Vegas, NV

R. Luce, Nuclear Waste Technical Review Board, Arlington, VA

W. Lutze, University of New Mexico, Albuquerque, NM

H. Manaktala, Southwest Research Institute, San Antonio, TX

S. Martin, Lawrence Livermore National Laboratory, Livermore, CA

J. M. Matuszek, JMM Consulting, Del Mar, NY 
J. McCarthy, Oak Ridge National Laboratory, Oak Ridge, TN

L. McDowell-Boyer, Oak Ridge National Laboratory, Grand Junction, CO

T. W. McIntosh, USDOE, Office of Waste Management, Germantown, MD

J. Meldrum, University of Nevada, Las Vegas, NV

A. Mitchell, Los Alamos National Laboratory, Los Alamos, NM

R. Morissette, Science Applications International Corp., Las Vegas, NV

D. Morris, Los Alamos National Laboratory, Los Alamos, NM

P. K. Nair, Southwest Research Institute, San Antonio, TX

S. Nelson, Las Vegas, NV

B. Newman, Los Alamos National Laboratory, Los Alamos, NM

C. Novak, Sandia National Laboratories, Albuquerque, NM

E. Nuttall, University of New Mexico, Albuquerque, NM

W. O'Connell, Lawrence Livermore National Laboratory, Livermore, CA

T. O'Holleran, Lockheed Idaho Technology Company, Idaho Falls, ID

G. C. S. Ordaz, USDOE, Office of Technology Development, Germantown, MD

C. Palmer, Lawrence Livermore National Laboratory, Livermore, CA

R. Palmer, West Valley Nuclear Services, West Valley, NY

H. Papenguth, Sandia National Laboratories, Albuquerque, NMI

W. D. Pearson, Westinghouse Savannah River Company, Aiken, SC

T. H. Pigford, University of California, Berkeley, CA

M. J. Plodinec, Mississippi State University, Mississippi State, MS

W. Polzer, Los Alamos National Laboratory, Los Alamos, NM

W. G. Ramsey, Westinghouse Savannah River Company, Aiken, SC

P. Reimus, Los Alamos National Laboratory, Los Alamos, NM

B. Robinson, Los Alamos National Laboratory, Los Alamos, NM

P. Rogers, Los Alamos National Laboratory, Los Alamos, NM

R. Rundberg, Los Alamos National Laboratory, Los Alamos, NM

C. G. Russomanno, USDOE, Civilian Radioactive Waste Management, Washington, DC

J. Ryan, University of Colorado, Boulder, $\mathrm{CO}$

R. Schulze, Los Alamos National Laboratory, Los Alamos, NM[

W. C. Schutte, USDOE, Office of Technology Development, Germantown, MD

M. Siegel, Sandia National Laboratories, Albuquerque, NM

M. Silva, Environmental Evaluation Group, Albuquerque, NM

R. Silva, Lawrence Livermore National Laboratory, Livermore, CA

A. Simmons, USDOE, Las Vegas, NV

E. Springer, Los Alamos National Laboratory, Los Alamos, NM

J. Sproull, Westinghouse Savannah River Company, Aiken, SC

D. Stahl, Faramatome Cogema Fuels, Las Vegas, NV

B. Staples, Lockheed Idaho Technology Company, Idaho Falls, ID

W. Steinkampf, U.S. Geological Survey, Lakewood, CO

L. Stetzenbach, University of Nevada, Las Vegas, NV

R. B. Stout, Lawrence Livermore National Laboratory, Livermore, CA

M. Tomozawa, Rensselaer Polytechnic Institute, Troy, NY

V. Trice, USDOE, Office of Waste Management, Germantown, MD

D. Turner, Southwest Research Institute, San Antonio, TX 
B. Viani, Lawrence Livermore National Laboratory, Livermore, CA

K. Vinjamuri, Lockheed Idaho Technology Company, Idaho Falls, ID

J. Wan, New Mexico Tech, Socorro, NM

L. Wang, University of New Mexico, Albuquerque, NM

M. Whitbeck, Desert Research Institute, University of Nevada, Reno, NV

C. N. Wilson, Lockheed Martin Hanford Company, Richland, WA

J. Wilson, New Mexico Tech, Socorro, NM

M. Wilson, Sandia National Laboratories, Albuquerque, NM

J. H. Wolfram, Biotechnology-INTEL, Montana State University, Bozeman, MT

K. Wolfsberg, Los Alamos National Laboratory, Los Alamos, NM

A. Wollerman, Science Applications International Corp., Germantown, MD

A. Yang, U.S. Geological Survey, Denver, CO

M. P. Gardiner, Harwell Laboratory, Didcot, Oxon, UNITED KINGDOM

B. Grambow, Kernforschungszentrum Karlsruhe, GmbH, GERMANY

J. Kim, Kernforschungszentrum Karlsruhe, GERMANY

H. Nitsche, Forschungszentrum Rossendorf e.V., GERMANY

T. Payne, Australian Nuclear Science and Technology Organization, AUSTRALIA

P. Van Iseghem, Boeretang, BELGIUM

E. Vernaz, Centre d'EtudesNucleares de la Valle du Rhone, Marcoule, FRANCE

P. Vilks, Atomic Energy of Canada, Whiteshell Laboratories, Pinawa, Manitoba, CANADA

L. Werme, Svensk Karnbranslehantering AB, Stockholm, SWEDEN 